\title{
Abstracts of the International Symposium on Dementia in Parkinson's Disease
}

\author{
AGID Y \\ INSERM U 289 and Fédération de Neurologie, Hôpital de la \\ Salpêtrière, 47 Boulevard de l'Hôpital, 75651 Paris, France

\section{NEURONAL BASIS OF MENTAL IMPAIRMENT IN} \\ PARKINSONIAN SYNDROMES
}

\begin{abstract}
Mental changes including memory deficits, frontal lobe-like symptomatology and depression are commonly seen in parkinsonian syndromes such as Parkinson's disease, progressive supranuclear palsy, striatonigral degeneration. These deficits result from the dysfunction of neuronal networks in subcortical and cortical areas. (1) The severe degeneration of the nigrostriatal dopaminergic pathway is responsible for subtle cognitive changes, such as impaired simultaneous task performances, through the deafferentation of complex fronto-caudate feedback loops, interconnecting the striatum and the frontal lobe. (2) Partial lesions of long ascending dopaminergic, noradrenergic, serotoninergic and cholinergic neuronal systems may cause demodulation of cognitive programs. The loss of cholinergic neurons within the latero-dorsal tegmental nucleus and the substantia innominata may affect hippocampal and prefrontal structures, either directly or indirectly through the dorsomedian nucleus of the thalamus. (3) The severe lesions confined to the basal ganglia and upper brainstem, as seen in progressive supranuclear palsy for example, very likely interrupt the activity of the output systems of the basal ganglia towards the prefrontal cortex, thereby causing severe frontal lobe-like symptoms via deafferentation of the prefrontal cortex. (4) Besides this so-called 'subcortical' cognitive impairment, the cerebral cortex is involved (essentially Alzheimer's histopathological changes) in a number of parkinsonian patients, especially at end stage of the disease. These cortical lesions thus contribute to the severity of memory disorders and other cortical deficits. The lesions characteristic of the various parkinsonian syndromes can be superimposed on the distribution of symptoms (memory disorders, frontal lobe-like symptomatology, depression) which may overlap in individual patients.
\end{abstract}

\author{
AGUILAR M, QUINTANA S, GAROLERA M, SUÑE A, \\ SOLBES L AND CARRASCO M \\ Department of Neurology, Hospital Mutua de Terrassa, Spain
}

\section{LEISURE ACTIVITIES AND DAILY OBLIGATIONS OF PATIENTS WITH PARKINSON'S DISEASE}

Little information is available on the repercussions of Parkinson's disease (PD) on leisure activities. To examine this aspect of PD, we used a Leisure Activities (LA) and Daily Obligations (DO) Questionnaire (CATLOD). Materials and Methods: The questionnaire was administered to 115 PD patients ( 48 men, 67 women; age, $69.9 \pm 8.9$; evolution, $7.6 \pm 6.2$; Hoehn and Yahr: I 16\%, II 53\%, III 31\%, IV 15\%; education, $6.4 \pm 4.0$ years). Patients were asked about their activities now and before the onset of PD. Simultaneously it was administered to 71 family members (age: $63.4 \pm 14.4$ ) and 33 friends (age: $68.2 \pm 8.7$ ). Results: Patients reduced the number of activities (DO - LA) between the preclinical stage $(18.8 \pm 8.2)$ and the present $(12.4 \pm 6.7)(p<0.0001)$. Change increased as disease progressed (HY: I $21 \%$, II $22 \%$, III $37 \%$, IV $70 \%$ ). Women tended to continue DO longer than men (patients, $p<0.0001$; family members and friends, $p<0.05$ ). Family members tended to increase DO reported and reduce significantly LA $(p<0.05)$, and change increased with the progression of the disease (I 10\%, II 10.5\%, III 18\%, IV 35\%). Conclusion: PD brings about a decrease in LA and DO which is more marked in advanced stages of disease. In women, however, DO are continued longer. Family members also observe a decrease of LA but tend to report higher DO as disease progresses. Leisure activities, an aspect related to quality of life, deserves further study in PD.

AHARON-PERETZ J, ABBOT RJ, PLAYFER JR, FOSTER J, WELLS TJ, BROOKS D, SPOKES G, SAGAR H AND KORCZYN AD

Department of Neurology, Rambam Hospital, Haifa, Israel

ROPINIROLE: A PLACEBO CONTROLLED STUDY OF EFFICACY AS ADJUNCT THERAPY IN PARKINSONIAN PATIENTS NOT OPTIMALLY CONTROLLED ON L-DOPA

Ropinirole is a novel, selective, non-ergot dopamine agonist with antiparkinsonian activity. Preclinical data is predictive of lower dyskinetic potential; in an open label clinical trial of parkinsonian patients it was efficacious both as an adjunct to L-dopa and in early therapy. We have attempted to evaluate ropinirole as adjunct therapy in patients on L-dopa, exhibiting predictable 'on/off' fluctuations and end-of-dose akinesia. Efficacy was sought primarily in terms of reduction in total daily dose of L-dopa with concomitant improvement or maintenance of clinical symptoms (CGI). During the initial incremental dose titration period of ropinirole, L-dopa had to remain constant (6 weeks). Over a second 6 week period L-dopa could be reduced. Responder criteria required at least $20 \%$ reduction in L-dopa daily dose from baseline, without deterioration of clinical state. 68 patients with a mean age of 63 years were randomised (2:1) to ropinirole (46) or placebo (22). Baseline daily doses of $\mathrm{L}$-dopa were $675 \mathrm{mg}$ (ropinirole) and $520 \mathrm{mg}$ (placebo). Duration of illness was 5.6 years and 7.0 years, respectively. Overall $62.9 \%$ of patients on ropinirole and $29.4 \%$ in the placebo group $(p=0.010)$ responded to treatment. Side effects were minimal. We conclude ropinirole is an efficacious drug in treatment with complicated parkinsonism.

\section{AMINOFF MJ AND GOODIN DS \\ University of California, San Francisco, USA \\ ELECTROPHYSIOLOGICAL CHARACTERIZATION OF THE DEMENTIA IN PARKINSON'S DISEASE}

The cognitive changes of Parkinson's disease (PD) have been attributed to dementia or bradyphrenia, and have been distinguished by some from the changes in Alzheimer's disease (AD). Cerebral event-related potentials (ERPs) have been used to evaluate cognitive function, and depend on attention and the context in which stimuli are presented. They have been associated with memory, expectancy, and other cognitive functions. The peak latencies of certain ERPs, especially N2 and P3, are prolonged in dementia but not in nondementing disorders. Earlier components of the ERP (N1 and P2) have received less attention, but they too are delayed 
in certain dementing disorders. In AD there is a prolonged $\mathrm{N} 2$ and $\mathrm{P} 3$ response, but earlier components are normal in latency. In patients with PD and cognitive changes, we and others have also found delayed N2 and P3 responses, suggesting that the cognitive disturbances are due to dementia rather than bradyphrenia. However, the peak latency of these components in demented PD patients does not correlate well with the mini mental state (MMS) score. By contrast, we have found delays in N1 (but not P2) that do correlate with performance in the MMS examination. This finding, and recent studies suggesting that in the dementia of PD only the P3b component is delayed, distinguishes this disorder electrophysiologically from $\mathrm{AD}$.

\section{ARTEMIEV DV, GLOZMAN IM, DAMULIN IV AND YAKHNO NN \\ Clinic of Nervous Diseases, Neurogeriatric Research \\ Laboratory, Moscow Medical Academy, Rossolimo St. 11, 119021, Moscow, Russia \\ THE COGNITIVE IMPAIRMENTS IN PARKINSON'S DISEASE}

45 patients (mean age 59), 10 with Parkinson's disease (PD), were studied using Luria's tests. Also we used standardized clinical scales for neurological assessment, CT and MRI. 20 patients were less than 60 years old, and 25 were over 60 years old. The more severe neurologic disorders, especially instability and pseudobulbar signs, were seen in elderly cases with the akinetic-rigid form of PD. The pattern of neuropsychological disturbances in PD consists of non-verbal mnestic disorders, dynamic, digital and oral apraxia, acoustic and spatial agnosia, prosodic and naming defects, as well as categorical generalization troubles. The severity of apraxia and agnosia correlated with the enlargement of cerebral ventricles on $\mathrm{CT}$ and MRI. The difference between young and elderly PD patients was revealed not only in more severe neuropsychological defects, but also in the presence of some symptoms not typical and very rare in young PD patients, such as constructional apraxia, object agnosia, difficulties of naming and digital apraxia. The results support the assumptions that in PD there are some age-dependent neuropsychological features.

\section{BALL MJ}

Division of Neuropathology, Oregon Health Sciences University, Portland 97201, USA

\section{LEWY INCLUSION BODIES IN HIPPOCAMPAL PYRAMIDAL AND PONTINE RAPHÉ NERVE CELLS: LEWY BODY VARIANT OF ALZHEIMER'S DISEASE, OR A CYTOSKELETAL EPIPHENOMENON?}

In a series of over 700 cases of organic dementia referred to our laboratory from southern Ontario, Canada, the incidental presence in the autopsy CNS of Lewy bodies (LBs) outside substantia nigra was relatively rare (even after a history of some extrapyramidal features). In a more recent study of 300 brains from the Pacific Northwest USA, neocortical LBs are much more frequently observed. Following 11 years' Parkinsonism and 4 years' severe dementia, the brain of a 73 year old man showed modest Alzheimer lesions, dramatic neuronal depletion and gliosis of nigra and ceruleus, dystrophic 'spheroids' in nigra and innominata, and variable numbers of classical LBs in nigra, ceruleus, hypothalamus, nbM, dorsal motor of $\mathrm{X}$, cingulate cortex, but also in some pyramidal neurones of hippocampus and some cells of dorsal raphé nuclei of pons. To our knowledge these inclusions are extremely rare in hippocampus or pons. Do such Lewy inclusion bodies, confirmed by anti-ubiquitin immunostaining, represent a distinct 'LB variant', both clinical and pathological, of Alzheimer's disease (Förstl et al., Br.J. Psychiat., 1993), or merely a cytoskeletal epiphenomenon more frequent in neurodegenerated brain tissue in some geographic locâles than in others? If the latter hypothesis is correct, just as the dementia of idiopathic PD is unlikely to be due to Alzheimer lesions (Ball, Can.J.Neurol. Sci., 1984), so too the dementia of $\mathrm{AD}$ is unlikely to be due to concomitant Lewy bodies.

Supported in part by NIH grant \#P30 AG 08017.

\section{BALOYANNIS SJ, ARZOGLOU L, COSTA V AND PAPASOTIRIOU M}

First Department of Neurology, Aristotelian University, Thessaloniki, Greece

\section{THE NUCLEUS BASALIS IN AGING: MORPHOLOGY AND} CYTOARCHITECTURE - A GOLGI STUDY

The nucleus basalis was studied in autopsy material of 10 individuals who died accidentally, being neurologically unremarkable. The age of the brains ranged from 23 to 57 years. The excised specimens were impregnated with silver nitrate according to the rapid Golgi method. Thick sections of $130 \mu$ cut in a three-dimensional arrangement were studied in a light photomicroscope and detailed description was performed in camera lucida. Most of the neurons of the anterior part of the nucleus were large polyhedral cells with thick three-dimensional dendritic arborization and a long myelinated axon. In the posterior part of the nucleus the large majority of the nerve cells were large and small triangular or elongated neurons with several long dendrites and myelinated axons, from which protruded several collateral axonic profiles. A large number of spiny neurons were seen among the polyhedral and triangular cells of the nucleus basalis. The brains of advanced age individuals demonstrated a relative poverty of spiny neurons, whereas in the young brains the number of small spiny neurons exceeded the number of large polyhedral ones. The nucleus basalis in advanced age also demonstrated a marked diminution of dendritic arborization of the large triangular or polyhedral neurons, suggesting a decrease in the synaptic activity of the main neuronal components of the nucleus basalis in aging.

\section{BARCIKOWSKA M AND FRIEDMAN A}

Department of Neuropathology, Medical Research Centre, and Department of Neurology, School of Medicine, Warsaw, Poland

\section{CLINICOPATHOLOGICAL STUDY OF 10 CASES WITH DEMENTIA AND PARKINSONIAN SYNDROME}

The aim of this study was an assessment of the possibilities of immunohistochemical differential diagnosis of Parkinson's disease (PD) or Alzheimer's disease (AD) in patients who died with clinical symptoms of both dementia and parkinsonian syndrome. Ten cases with long history of parkinsonian symptoms and good response to L-dopa and coexistence of clinical signs of dementia-assessed by use of Reisberg's GDS (Global Dementia Scale) as stage 5-6-were examined. Representative specimens from frontal, temporal, hippocampal and parahippocampal regions and from substantia nigra (SN) and locus coeruleus (LC) were taken. Routine stainings (HE Klüver-Barrera) and silver impregnation (Yamamoto) were performed before immunohistochemical labeling. The following antibodies were used: 4G8 directed against beta-peptide, anti tau 1 and 3.39 anti ubiquitin to visualize cytoskeletal degeneration, neurofibrillary tangles (NFT) and Lewy bodies (LB). In all cases numerous senile plaques (SP) were observed within frontal cortex, hippocampus and a few in SN. In 9 cases they were also present in brainstem nuclei. Additionally NFT were noted in neocortex, hippocampus, SN and LC. In 8 cases changes were assessed as severe, in one as moderate. LB occurred 
in all cases within SN, in LC in 8 cases. In two cases LB were found (by 3.39 antibody staining) also focally within frontal and temporal cortex. In view of these findings the neuropathological diagnosis of $A D$ and $P D$ was made in 7 cases and in 3 cases we made the diagnosis of coexisting diffuse Lewy body disease. In no case was it possible to make a diagnosis of a single entity neither clinically nor neuropathologically. We propose that this is the result of an overlap of these disorders, which probably represent a kind of clinico-pathological continuum of neurodegenerative diseases.

BECHTEREVA NP, BEREZSHKOVA LV, ILLUCHINA VA, KOSTENNIKOV NA, MEDVEDEV SV AND RUDAS LAA Institute of the Human Brain of the Russian Academy of Sciences, St. Petersburg, Russia

\section{PET RESEARCH OF GLUCOSE UTILIZATION DISORDERS IN THE THALAMUS AND THE CAUDATE NUCLEUS OF PATIENTS WITH PARKINSONIAN DEMENTIA}

The level of FDG utilization was examined in the cerebral cortex and subcortical structures of 6 patients with Parkinson's disease. PET data were compared with results of clinical examination, psychological and neurophysiological research (EEG, REG) as well as magnetic resonance imaging. A reduction of glucose utilization in the thalamus and the caudate nucleus of patients with parkinsonian dementia was established for the first time. In patients with severe course of parkinsonism, pronounced dementia and extrapyramidal symptoms, the level of glucose utilization in these structures was $10 \%$ lower in comparison to that in cases with mild course of the disease without dementia. Obtained data reveal the significance of the level of glucose utilization in the thalamus and the caudate nucleus in the development of parkinsonian dementia.

BÉDARD MA, MASSON H, PERREAULT H AND QUEVILLON F Centre Hospitalier Côte-des-Neiges, Montréal, Canada

\section{SPECIFIC MEMORY DEFICITS RELATED TO LESIONS OF CHOLINERGIC SYSTEMS IN PARKINSON'S DISEASE}

Lesions of the central cholinergic systems have been well documented in Parkinson's disease (PD). Previous studies have shown that cholinergic blockade in PD does not produce the same cognitive deficits as those observed in SDAT, suggesting that different lesions of cholinergic systems may underlie these distinct neuropsychological features. Since acetylcholine is known to be implicated in memory processes, we wanted to further assess the specific role of cholinergic lesions in the characteristic frontal type memory deficit of PD. Methods: PD patients, aged 55 to 75, were selected for this study. None of them showed cognitive deficit as measured by a large neuropsychological tests battery. A subclinical dose $(0.25 \mathrm{mg}$, i.m.) of scopolamine, which does not produce detectable effect in normals, and a placebo were administered in a double blind cross over fashion. Memory tests included implicit and explicit recalls of verbal material, and the 'Self Ordered Pointing Task' (SOPT). Alternating forms of these tests were used for both phases of treatment. Results: Specific worsening of learning and free recall were observed during scopolamine treatment $(p<0.05)$. However, recall by repetition priming, semantic cues or items recognition remained unaffected by the anticholinergic drug. Proactive interference in the SOPT was also greater during the scopolamine treatment than during the placebo $(p<0.05)$. Conclusions: Our results confirm those of others, showing that a subclinical dose of scopolamine may induce a frontal syndrome in PD patients who were devoid of detectable cognitive deficit. This indicates that slight cholinergic blockade may decompensate only those cholinergic systems that are already affected in PD. Tegmental laterodorsal and pedunculopontine nuclei could be more specifically implicated, since both of them were found affected in PD and since their projections to mediodorsal thalamus and striatum could indirectly influence the frontal lobe activity.

BEHARI M, DIXIT SN AND AHUJA GK

Department of Neurology, All India Institute of Medical Sciences, New Delhi 110029, India

\section{ROLE OF SELEGILINE IN COGNITIVE FUNCTIONS IN PARKINSON'S DISEASE}

Selegiline hydrochloride is known to affect the course of Parkinson's disease by delaying the need to start levodopa, smoothening motor fluctuations and having a dopa sparing action. Whether these benefits in motor functions are associated with benefits in cognitive functions is not known. To answer this question we undertook a prospective placebo control study. 33 newly diagnosed patients with Parkinson's disease were allocated to selegiline or no-selegiline group, depending upon affordability. Patients were examined using UPDRS, modified WAIS, WMS and $\mathrm{P} 300$ before and 3 months after starting treatment. Patients receiving trihexyphenidyl and other cholinergic drugs were excluded from the study. The results will be analysed using Student's $t$ test and Fisher's test.

\section{BENNETT DA, BECKETT LA, MURRAY AM AND EVANS DA}

Rush Alzheimer's Disease Center, Chicago, USA

\section{PARKINSONISM AND RISK OF DEATH IN A COMMUNITY POPULATION}

Objective: To determine whether parkinsonism is associated with an increased risk of death among persons in a community population. Methods: 3622 persons $(80.8 \%$ ) of community-residing residents over the age of 65 had a structured interview performed in their homes. 467 persons ( $70.8 \%$ of survivors) identified by a stratified random sampling technique underwent a uniform neurologic examination including the presence or absence of 3 measures of gait disturbance, 4 of rigidity, 3 of bradykinesia, and 2 of tremor. Each domain was defined as positive if at least half of the signs within the domain were present; parkinsonism was defined as the presence of 2 or more domains. Complete data sets were available for 412 persons of whom 134 had parkinsonism and 278 did not. Proportional hazards models were used to compare the risk of death among persons with and without parkinsonism. Results: Over a mean follow-up of 4.9 years, $133(32 \%)$ subjects died (68 with parkinsonism and 65 without). After adjusting for the effects of age and sex, persons with parkinsonism had an overall relative risk of 2.00 ( $95 \%$ confidence interval, 1.40-2.86). The magnitude of the association between parkinsonism and mortality was approximately equal for both men and women and was evident in all age subgroups. Conclusions: Among older persons, parkinsonism is associated with an increased risk of death.

\section{BIBILEISHVILI ShI}

Institute of Clinical and Experimental Neurology, Tbilisi, Republic of Georgia

\section{RELATIVE CHARACTERISTICS OF DEMENTIA IN PATIENTS WITH ATROPHIC PROCESSES IN THE BRAIN}

It is known that progressive atrophic processes in the brain form the basis of both Parkinson's and Alzheimer's disease. In the course of these two diseases dementia phenomena and Parkinsonian signs may simultaneously coincide, though to a different degree. This often makes differential diagnostics of these diseases somewhat difficult, especially in the 


\section{Abstracts of the International Symposium on Dementia in Parkinson's Disease}

late stages of disease. We observed 15 Parkinson's disease patients and 12 patients with Alzheimer's disease. All the patients were subjected to CT and MRI checkups, and neuropsychological examination. As a result of the investigation it was shown that in case of Parkinson's disease intellectual impairments occur after Parkinsonian syndrome develops; they progress slowly and atrophic manifestations are mainly localized in the basal ganglia. But when L-dopa and cholinolytic drugs are administered we witness a parallel reduction both in the Parkinson's syndrome and in dementia. By contrast, in the case of Alzheimer's disease impairments mainly emerge at the very onset of the disease, but the Parkinsonian syndrome joins in the late stage of the disease. It progresses rather quickly, the atrophic processes are mainly localized in the cortical structures, and dementia is slightly reduced and then only under the influence of cholinergic and nootropic drugs. On the basis of all this we may conclude that dementia in these diseases is markedly different according to clinical manifestations and degree of progression, and is of a different pathogenesis.

\section{BIGGINS CA, MADELEY P, BOYD JL AND MINDHAM RHS Department of Psychiatry, University of Leeds, Leeds, UK}

\section{ESTIMATION OF PREMORBID INTELLIGENCE IN IDIOPATHIC PARKINSON'S DISEASE}

The purpose of the present study was to evaluate the validity of the NART as a measure of premorbid IQ in idiopathic Parkinson's disease (IPD). Eighty-nine IPD patients and 49 control subjects, matched for age and sex, were administered the NART and the Verbal scale of the WAIS. Among control subjects, but not among IPD patients, the relationship between performances on these two measures closely matched that found by the test author (Nelson, 1982). For both subject groups, the correlation between the measures was not strong enough to allow accurate prediction of Verbal IQ from NART performance in the individual case. For an individual predicted value of premorbid Verbal IQ, the $95 \%$ confidence intervals for that value were: for control subjects, 12 points either side of the predicted value; and for IPD patients, 16 points either side of the predicted value. Forty-nine IPD patients and 26 control subjects, previously tested with the NART, were followed up after a minimum period of 29 months and retested with the NART. In both groups a small but significant decrement in NART performance was observed at retest. Between testings with the NART, 11 IPD patients suffered cognitive decline as determined by change in MMSE score. Among this subgroup the decline in NART performances was not significant but a type-2 error was possible. These data suggest that, in the individual case, the NART does not predict premorbid Verbal IQ accurately, although it may be of value in matching groups of subjects for premorbid IQ. Among patients with IPD, caution should be used in using the standard equations to convert NART performance into premorbid IQ, as these did not appear to agree with the relationship between NART performance and measured Verbal IQ in our IPD group.

Nelson HE. National Adult Reading Test.Test Manual. Windsor: NFERNelson. 1982.

\section{BODIS-WOLLNER I, ANTAL A, ALEXANDER E, TAGLIATI M AND SAFARIK C}

Department of Neurology, SUNY HSC, Brooklyn, NY, USA

\section{NEUROPHYSIOLOGICAL ANALYSIS OF VISUO-COGNITIVE DEFECTS IN PARKINSON'S DISEASE AND RELATED DISORDERS}

In Parkinson's disease (PD) visuo-spatial defects are classically emphasised from a neuropsychological point of view only. Our approach for studying visual and visual cognitive dysfunction has been primarily geared to electrophysiological techniques which allow the recording of both 'primary' and 'cognitive' responses, since it is known that a significant number of patients with PD suffer from visual dysfunction. Our stimuli are sinusoidal gratings where the stimulus to be discriminated differs only in spatial frequency, contrast or orientation and is presented with either $10 \%$ or $20 \%$ probability in a so-called 'oddball' paradigm. The ERPs normative base was established in 44 volunteers. Primary and cognitive component (N70, P100, N140, P2, N2, P300) latencies and amplitudes were measured. $\mathrm{N} 2$ and $\mathrm{P} 300$ latencies were $309.8 \pm 31 \mathrm{~ms}$ and $436.6 \pm 20.97 \mathrm{~ms}$ in the orientation task, $322.6 \pm 27.3 \mathrm{~ms}(\mathrm{~N} 2)$ and $427.92 \pm 27.5 \mathrm{~ms}$ (P300) in the spatial frequency study. In PD patients P300 latency was significantly longer and its amplitude smaller than in the normal subjects. There was no correlation between the components of primary and cognitive ERPs in the mildly affected patient group. Standardized ERP recording may become a valuable tool for the quantification of visuo-cognitive deficits which may occur independently of primary visual dysfunction in PD and related disorders.

\section{BOLLER F AND MARCIE P \\ INSERM Unit 324, 2 ter, rue d'Alésia, 75014 Paris, France \\ COGNITIVE IMPAIRMENT IN PARKINSON'S DISEASE: ROLE OF PSYCHIATRIC FACTORS}

Cognitive impairments are a well recognized concomitant of Parkinson's disease (PD) (Cummings and Benson, 1984; Dubois, Boller, Pillon and Agid, 1991). Decreased attention and verbal fluency, anomia, visuospatial, memory and 'executive' disorders, as well as a frank dementia, are the most frequently observed. Depression is present in about half the cases (Shaw, Lees and Stern, 1980; Mayeux et al., 1981), whether demented or not (Lieberman et al., 1979). The purpose of this paper is to review the role of depression on the neuropsychological profiles of PD patients. Three groups of 11 subjects each (controls, non-depressed PD, depressed PD) were studied. The two PD subgroups were matched for degree of intellectual deterioration. Neuropsychological tests included tests of attention and short term memory in verbal and non-verbal modalities. The two groups of PD patients performed significantly worse than controls on all the neuropsychological tests, but there were no differences between the two patient groups. The lack of influence of depression on neuropsychological performance may have been due to inadequacy of the tests. More likely it was due to failure to include the most depressed patients due to a selection bias. These results are compatible with Starkstein's view (1989) that cognitive impairment is only found beyond a given threshold.

\section{BONUCCELLI U}

Institute of Clinical Neurology, University of Pisa, Italy

\section{$\alpha$-DIHYDROERGOCRIPTINE IN PARKINSON'S DISEASE AND IN ALZHEIMER'S DISEASE}

Ergot alkaloids are a group of natural and semisynthetic substances which may be effective in dementia and/or in diseases characterized by dopaminergic dysfunction. $\alpha$-Dihydroergocriptine (DHEC) is an ergot derivative whose therapeutic effectiveness in Parkinson's disease (PD) has been recently highlighted. Studies on receptorial binding have demonstrated that it has a D2-receptor agonist activity, both on striatum and hypophysis, so as to show in vivo an hypoprolactinemic activity. DHEC also shows a partial agonist activity on D1 receptors. As regards other cathecholaminergic systems, DHEC seems to have a very slight interaction with $\alpha$-adrenergic receptors and no serotonergic activity. The pharmacokinetic features of DHEC in humans are characterized by good absorption following oral administration, and long half-life (10-15 h). 
Clinical studies in PD have demonstrated that DHEC is effective and well tolerated both in de novo patients and in patients under levodopa therapy. Particularly in de novo patients the efficacy of DHEC has proved to be comparable to that of bromocriptine (BCR); combined with the levodopa, DHEC has also proved to be as effective as both lisuride and BCR in double-blind studies. We have recently investigated in a double-blind cross-over study the activity of DHEC on de novo PD patients. DHEC and $\mathrm{BCR}$ were randomly administered in a $4: 1$ ratio, each drug for three months with one week wash-out in between. Our data indicate that low dosage of DHEC can be a useful drug in the early treatment of PD, with an even greater tolerability than BCR. Recently, the ability of DHEC to activate antioxidant enzymatic systems, particularly reduced glutathione, has suggested that the drug may slow the evolution of neuronal degeneration. This possible neuroprotective effect of DHEC is currently being tested in Alzheimer's disease and in Parkinson's disease.

\section{CALNE DB}

Neurodegenerative Disorder Center, Division of Neurology, University Hospital, Vancouver, BC, Canada

\section{SIMILARITIES BETWEEN PARKINSON'S DISEASE AND ALZHEIMER'S DISEASE}

Accumulating evidence is leading to a need for a radical reappraisal of our traditional classification of the major neurodegenerative disorders. Features shared between Parkinson's disease (PD) and Alzheimer's disease $(\mathrm{AD})$ have led to difficulty in delineating where each ends. From a clinical viewpoint, dementia is common in advanced PD, and extrapyramidal deficits are often found in late AD. Lewy bodies are being reported with increasing frequency in $\mathrm{AD}$, and demented patients who initially presented with the symptoms and signs of PD are being found to have plaques and tangles in their brains. Some 5-10\% of patients with PD have a geneology suggesting dominant inheritance; the same is true for AD. First degree relatives of patients with $\mathrm{PD}$ have a significantly increased risk of developing $\mathrm{AD}$. $\mathrm{PD}$ and $\mathrm{AD}$ are both inversely related to smoking - an unusual negative correlation for chronic disorders. These considerations force one to reconsider the hitherto generally accepted nosology of the commonest of the neurodegenerative disorders; the simplest resolution of the conflicts can be reached by proposing that $\mathrm{PD}$ and $\mathrm{AD}$ are different expressions of similar pathogenic mechanisms deriving from the same etiologic origin.

\section{CAPARROS-LEFEBVRE D, PÉCHEUX N, PETIT V,} DUHAMEL A AND PETIT $\mathrm{H}$

Department of Neurology, CHU Lille, and Department of Information Science, CHU Lille, France

\section{WHICH FACTORS PREDICT COGNITIVE DECLINE IN FOLLOW-UP STUDY OF PARKINSON'S DISEASE?}

The aim of the study was (1) to assess the cognitive decline in nondemented, non-depressed patients with well-defined PD; and (2) to determine the predictive value of different motor symptoms for cognitive decline in patients characterized according to their type of symptoms at onset, their response to levodopa and their type of levodopa induced dyskinesias. Motor evaluation was performed between September 1987 and March 1992, at the neurological clinic of the Lille University Hospital, France. Motor evaluation included measure of motor disability with UPDRS, impairment in activities of daily living, levodopa test and long-term clinical follow-up. Neuropsychological evaluation was performed twice in each patient. The second evaluation was performed 3 years after the first one. Tests included: mMMS, fluency, Wechsler logical memory, Wisconsin card sorting test, and depression evaluation with MADRS. 53 patients with clinical criteria of idiopathic PD were studied. Disease duration average was 8.6 years, age at onset was 53 years, age at first evaluation was 61.7 years. Education was 9.6 years. The mean of L-dopa daily dose was $462 \mathrm{mg}$. Performance on tests 1 was significantly correlated with education, disease duration but not with age at onset. Performance on tests 2 was significantly reduced in the whole group. Performance reduction was significantly higher in the late-onset group, in patients with isolated dystonic dyskinesias, in patients with lower percentage of improvement under levodopa. The results confirmed that cognitive decline in idiopathic PD may depend on both the prevalence of non-dopaminergic lesions and the topography of dopaminergic denervation. Predictive factors for cognitive decline, especially in executive tasks, seem to be those reflecting non-dopaminergic lesions.

CEDARBAUM JM, WIEGAND S, ALTAR T AND LINDSAY RM Regeneron Pharmaceuticals Inc., Tarrytown, NY, USA

\section{NEUROTROPHIC FACTORS AS POTENTIAL TREATMENTS FOR NEURODEGENERATIVE DISEASE}

Neurotrophic factors are low-abundance proteins which function in nervous system development to promote neuronal survival and maturation. In the adult, these proteins appear to be important in maintaining the phenotypic and functional differentiation of neurons. In addition, they may participate in the nervous system's response to injury. Two main classes of neurotrophic factors are produced by the nervous system and its target tissues: the Neurotrophins Nerve Growth Factor (NGF), BrainDerived Neurotrophic Factor (BDNF), and Neurotrophins 3 and 4/5 (NT3 and NT4/5); and the neurotrophic cytokines, the only example of which is Ciliary Neurotrophic Factor, or CNTF. NGF has been shown to rescue injured basal forebrain cholinergic neurons. BDNF and NT-3 support survival of dopaminergic neurons. In culture, BDNF has been shown to protect cultured dopaminergic neurons from the neurotoxins 6-hydroxydopamine and MPP+, presumably by upregulating antioxidant enzyme activity. In vivo, BDNF administration leads to compensation for injury to the nigrostriatal dopamine system, rescues the cholinergic phenotype of axotomized cholinergic neurons, and reduces the rate of motor function loss in mice with Wobbler motor neuron disease. Because of its interactions with multiple neuronal systems, BDNF may have the potential to ameliorate multiple aspects of neurodegeneration.

\section{COHN DF}

Tel Aviv Medical Center, Tel Aviv, Israel

\section{FH LEWY, DESCRIBER OF THE HISTOLOGICAL 'BODIES' IN THE BRAIN OF PATIENTS WITH PARKINSON'S DISEASE}

On September 29, 1913, at the seventh meeting of the German Association of Neurologists, when FH Lewy was only 28 years old, he described the microscopic bodies which bear his name. Lewy was born on January 28,1885 , in Berlin, Germany. He was a brilliant clinician, scientist and teacher. In 1912, only two years after graduation from medical school, he became director of the laboratories of the Neuropsychiatric Clinics at the University of Breslau, at that time an International Brain Institute. In 1926 he became head of the Department of Neurology at the Charite Hospital of the University of Berlin, and in 1930 director of the Neurological Institute of Berlin. He had had an outstanding career up to 1933, when as a Jew he had to leave Germany. He was then invited by Frazer to join the University of Pennsylvania in Philadelphia, where he continued his successful research and clinical career. As a scientist with an interest in Parkinson's disease he was well aware of the difficulties in researching this disease, which he so competently expressed in 1940: 'When I had investigated my first two dozen cases of Parkinson, I was convinced that I knew where the cause of tremor and rigidity was located, 
when I had examined pathologically the seventh dozen of Parkinson brains I was completely confused because you seem to be able to prove just as well one theory as the contrary one.' (Proc. Ass. Res. Nerve Ment. Dis., 1940, 21, 487). He died on October 5, 1950, at the age of 65, in Pennsburg PA.

\section{COLLINSON C, DOHERTY SM, COOPER JA, TIDSWELL P AND SAGAR HJ \\ Department of Clinical Neurology, University of Sheffield, Sheffield, UK}

\section{EARLY PREDICTORS OF COGNITIVE DECLINE IN PARKINSON'S DISEASE}

Hypotheses for the pathological basis of cognitive impairment in Parkinson's disease (PD) include cortical changes in demented patients and subcortical neurochemical deficiencies in cases with restricted cognitive deficits of frontal lobe type. Dopamine deficiency in fronto-striatal circuits has been proposed as the major cause of these restricted deficits, but lesions in noradrenergic, cholinergic and serotonergic circuits may also contribute. The relationship between the early restricted deficits and later clinical dementia is not clearly established, although the prevalence of dementia increases with disease duration. The Sheffield Longitudinal Study of De Novo Parkinson's Disease evaluated the pattern of cognitive impairment at diagnosis and before treatment, observed the effects of modulation of dopaminergic and cholinergic circuits, and assessed early predictive factors of later cognitive decline. De novo patients showed impairments in several components of memory and executive capacity which correlated poorly with severity of motor disability and depression. Re-evaluation after randomisation to treatment with levodopa, bromocriptine or benzhexol showed that dopaminergic stimulation partially improved working memory capacity whilst anticholinergic therapy, even at small doses, produced memory registration deficits. A separate study using the alpha 2 agonist guanfacine shows that noradrenergic modulation in chronic patients has both facilitatory and inhibitory effects on aspects of cognitive function. 127 consectutive patients have now been evaluated serially for up to 36 months; 40 normal control subjects matched for age, IQ and years of education have been studied in parallel. In general, cognitive deficits increased across the serial assessments. Age at diagnosis correlated strongly with rate of decline in memory, particularly in patients treated with benzhexol. Rate of motor decline was not strongly associated with rate of cognitive decline. These studies show that dopaminergic, noradrenergic and cholinergic systems affect specific aspects of cognition, and progressive cognitive decline in $\mathrm{PD}$ is largely due to age-related, non-dopaminergic neurodegeneration.

\section{CREWS FT, ANDALORO V, POTTER M AND CHANDLER J Center for Neurobiology of Aging, College of Medicine, University of Florida, Gainesville, FL 32610, USA \\ MUSCARINIC-CHOLINERGIC SIGNALS ARE DECREASED DURING SENESCENCE: ROLE IN DEMENTIA}

Intracellular calcium $\left(\left[\mathrm{Ca}^{2+}\right]_{i}\right)$ levels are of fundamental importance in neuronal growth as well as neuronal degeneration and death. Neuronal $\left[\mathrm{Ca}^{2+}\right]_{i}$ is regulated in part by phosphoinositide-specific phospholipase $\mathrm{C}$ mediated phosphoinositide hydrolysis. Multiple phospholipase Cs have been found to be activated through three interactive mechanisms: receptor-guanine nucleotide protein activation, growth factor tyrosine kinase receptor activation, and calcium activation. Muscarinic-cholinergic receptors are uniquely coupled to phospholipase $C$. Studies in aging brain indicate that muscarinic coupling to Ins $(1,3,4,5) \mathrm{P} 4$ formation is de- creased in senescent rats. Membrane studies suggest that this is due to a decrease in receptor coupling to phospholipase $C$ in senescence and may be secondary to guanine nucleotide protein-phospholipase $\mathrm{C}$ sensitivity to oxidation. In neuroblastoma cells muscarinic receptors activate two phases of calcium flux, a large rapid transient peak compatible with neurotransmission and a smaller but prolonged plateau that may be involved in differentiation in neuroblastoma cells. These studies suggest that muscarinic receptors may play both neurotransmitter and trophic roles in brain. Further studies in Alzheimer's brain suggest a loss of muscarinic coupling associated with neurodegeneration. Amyloid $\beta$ protein accumulates in Alzheimer's disease and disrupts muscariniccholinergic coupling to PLC. Taken together, these studies support the hypothesis that disruption of phospholipase $\mathrm{C}$ activation could underlie neuronal degeneration during aging and in other age-associated neurodegenerative diseases.

\section{CRYSTAL HA AND DICKSON DW}

Albert Einstein College of Medicine, 1300 Morris Park Avenue, Bronx, NY, USA

\section{NEUROLOGICAL FINDINGS IN SUBJECTS WITH PATHOLOGICALLY PROVEN DIFFUSE LEWY BODY DISEASE OR WITH ALZHEIMER'S DISEASE}

Objective: To determine which findings on neurological exam help distinguish subjects with pathologically proven diffuse Lewy body disease (DLBD) from those with Alzheimer's disease (AD). Method: We searched our database of prospectively studied demented subjects to identify those who met operational pathological criteria for DLBD, AD, and AD+DLBD. Criteria for DLBD were widespread neocortical Lewy bodies as demonstrated by inmunocytochemistry with an anti-ubiquitin antibody. Subjects in these studies had had yearly neurological and neuropsychological examinations. Results: Five subjects had DLBD alone, $9 \mathrm{AD}+\mathrm{DLBD}$, and $36 \mathrm{AD}$ alone. Four of 5 subjects with DLBD were men; $73 \%$ of subjects with $\mathrm{AD}$ or $\mathrm{AD}+\mathrm{DLBD}$ were women. The 3 groups were comparable in age at death and final score on the Blessed information and memory test. The subjects with either DLBD or DLBD+AD had worse gait scores than subjects with $\mathrm{AD}(F=3.5, p=0.04)$. Both postural and resting tremors were more common in the group with DLBD than in the DLBD+AD or AD groups $(F=12.1, p=0.0001 ; F=16.4, p=0.0000)$. Frontal release signs did not differ among the three groups. Conclusion: In this small sample, resting and postural tremor were more characteristic of DLBD than of DLBD+AD or of AD. Gait failure was more common in subjects with DLBD or DLBD+AD than in subjects with $A D$.

\section{DAMULIN IV, ARTEMIEV DV, TERNOVOY SK,} BELICHENKO OI AND YAKHNO NN

Clinic of Nervous Diseases, Neurogeriatric Research Lab., Moscow Medical Academy, Rossolimo St. 11, 119021, Moscow, Russia

\section{MAGNETIC RESONANCE TOMOGRAPHY IN PARKINSON'S DISEASE}

The aim of this study was to assess cognitive impairment and magnetic resonance tomography (MRT) data in patients with Parkinson's disease (PD). Complex investigation, including neurological, neuropsychological, MRT studies, was performed in 20 PD patients. Assessment of neurological status was performed using clinical and disability scales of Austrian PD society, Webster's clinical scale and Northwestern University disability scale. Neuropsychological investigation was based on Luria's battery with quantitative assessment of revealed symptoms. Dementia was diagnosed in $25 \%$ of patients. MRT studies were performed using 
'Magnetom-SP 63' (Siemens) tomograph with $1.5 T$ magnetic field strength. Cerebral atrophy was the typical MRT finding in PD. There was severe internal cerebral atrophy in 4 cases, and severe external in 5 . There was a correlation between the degree of internal type of cerebral atrophy, age of patients and dementia. Small multiple periventricular and subcortical white matter lesions were revealed in 10 cases, mostly in patients older than 65 years with severe cerebral atrophy and dementia. Such white matter changes in some patients has a relationship with arterial hypertension. Diffuse periventricular white matter T2-hyperintensity (leukoaraiosis) showed no correlation with clinical features of PD.

DELL'ANTONE P, BRAGADIN M AND ZATTA PF

Dip. Scienze Biomediche, Università di Padova; Dip. Scienze

Ambientali, Università di Venezia; and Centro CNR Metalloproteine,

Via Trieste 75, 35131 Padova, Italy

\section{THE ACCUMULATION OF TACRINE IN ACIDIC COMPARTMENTS OF THE CELLS}

Among the pharmacological strategies suggested by the biochemical changes found in the cholinergic system of Alzheimer's disease (AD) patients, the most promising results have been obtained using anticholinesterasic compounds such as physostigmine (PS) and 9-amino1,2,3,4-tetrahydroacridine (THA). In this study we have focused our interest on the localization of these drugs into the cells. THA is a weak base and its unprotonated neutral form is membrane permeant, through which the drug is expected to accumulate by protonation inside acidic organelles, similarly to other amines with comparable $p \mathrm{~K}$. To investigate this possibility, rat liver lysosomes and rat thymocytes were used as an in vitro model. We found that THA but not PS accumulated into lysosomes and acidic compartments of cells. As a consequence of its high lysosomotropic property it could affect the exocytic process by means of a physical mechanism such as inducing osmotic swelling of secretory vesicles, as we observed by scan electron microscopy. Inside acidic vesicles THA at low concentrations is unable to produce a consistent $\mathrm{pH}$ enhancement; most likely the drug stimulates the rate of ATP hydrolysis in order to maintain the internal acidic $\mathrm{pH}$.

DÉMONET J-F, CELSIS P, AGNIEL A, CARDEBAT D, RASCOL O AND MARC-VERGNES J-P

INSERM U 230, Hôpital Purpan, F-31059 Toulouse Cedex, France

\section{ABNORMALITIES IN BRAIN ACTIVATION DURING MEMORIZING TASK IN EARLY PARKINSON'S DISEASE PATIENTS}

This work aimed at assessment of slight verbal memory deficits in patients with early Parkinson's disease. Task-induced changes in rCBF during memory activation were compared in 18 patients with early PD and 20 normal volunteers. We used SPECT and ${ }^{133}$ Xenon in 21 regions of interest during rest, passive listening to a word list, and memorizing of another word list, followed by free recall and recognition tests performed immediately after scanning. The number of freely recalled words was not significantly lower in PD patients than in controls but patients presented more false alarms than normals on the recognition test. In normal subjects, 5 left-sided regions (anterior middle frontal, posterior inferior frontal, superior middle temporal, thalamic and lenticular) showed a significant increase at memorizing compared to passive listening. This pattern of activation suggests the existence of a verbal rehearsal strategy during memorizing in normals. In PD patients, increases in these regions did not reach significance, whereas significant activations were noted in superior prefrontal regions. Such alterations to the pattern of activation in PD patients, in spite of memory performance similar to that of controls, is viewed as a consequence of an early dysfunction of the articulatory loop system along with possible compensatory mechanisms in other parts of the frontal lobe.

\section{DE VOS RAI, JANSEN ENH, À NIJEHOLT JL, WESSELING P} AND BRAAK H

Regional Laboratory of Pathology, Enschede, The Netherlands, Department of Neurology, M.S.T., Enschede, The Netherlands; Department of Pathology, University Hospital, Nijmegen, The Netherlands; and Zentrum der Morphology, University of Frankfurt, Germany

\section{A SINGLE CASE OF JUVENILE NEUROAXONAL DYSTROPHY ('HALLERVORDEN-SPATZ SYNDROME') COMBINED WITH DIFFUSE LEWY BODY DISEASE}

The clinical features were typical: slowly progressive paresis of the limbs, starting in the feet at the age of 10 years, with dysarthria, spasticity and mental deterioration. No sensory abnormalities could be established and tendon reflexes were normal. Total duration of disease: 24 years. Gross morphological examination revealed brown discolouration of the pallidum and paler appearance of the substantia nigra. Cortical atrophy was present. Light and ultrastructural microscopy disclosed widespread neuroaxonal dystrophy (NAD) with numerous spheroids in cortical, subcortical, brainstem and medullary levels. In the pallidum an accumulation of iron pigment among degenerative neurons was seen. The substantia nigra showed loss of large pigmented neurons with focal gliosis. Lewy bodies (LBs) were seen not only in the remaining melanin pigmented neurons of the brainstem; they were also present in considerable numbers in the cerebral cortex (neo- and allocortex). Such a case of a widespread neuroaxonal dystrophic process, suggestive of HallervordenSpatz syndrome in combination with a specific morphology of diffuse Lewy body disease, is quite unusual and is an expression of the clinical and pathological heterogeneity of Hallervorden-Spatz disease and Lewy body disease.

\section{ROCCO A, MOLINARI SP, KOLLMEIER B AND}

YAHR MD

Mount Sinai Medical Center and School of Medicine, New York, NY, USA

\section{DEMENTIA IN PARKINSON'S DISEASE: A RETROSPECTIVE LONGITUDINAL STUDY IN L-DOPA-TREATED PATIENTS}

In order to evaluate the overall incidence and progression of dementia in Parkinsonian patients treated with L-dopa, we reviewed the charts of 304 deceased patients who had been treated with L-dopa and followed in our Parkinson's disease center. $33.7 \%$ of these patients (117) developed varying degrees of dementia during the course of their illness. Imaging studies of the brain were obtained in most of these patients to rule out structural abnormalities. In 54 patients, post-mortem studies were conducted and the diagnosis of Parkinson's disease was confirmed in 48 $(89.1 \%)$. The remaining 6 patients $(10.9 \%)$ had symptomatic parkinsonism due to various degenerative disorders. The overall evaluation of the patients with dementia showed that the mean age of onset was 70.2 years, with an average interval of 9.5 years from the onset of their first symptoms and an average interval of 6.0 years from the onset of the treatment with $\mathrm{L}$-dopa. The intellectual deficit was progressive in nature and the life expectancy from the onset of the dementia was 3.7 years. These data indicate that dementia presently occurs in a significant 
number of Parkinsonians. Its relation to increased longevity, the use of dopaminergic agents, and/or intrinsic features of the Parkinsonian process, are all factors which play a role.

\section{ELIAN M}

London, England

\section{SEX AND PARKINSON'S DISEASE}

Little attention has been paid to the sexual needs and behaviour of people suffering from a chronic illness and their partners. Parkinson sufferers seem to be more neglected than sufferers from other chronic diseases, possibly because of it affecting the older age group. Consecutive Parkinson sufferers attending a neurology clinic were interviewed with their partners. The interviewer was not previously known to the couple. After completing a questionnaire on another topic they were warned that they would be asked very personal questions and that they had the right to refuse answering them. None refused. Many commented that this was the first time they had talked about sex and they enjoyed doing so. Insomnia and restlessness was a common problem leading to separation of bedrooms. Several couples had stopped having sexual intercourse. Several others were continuing to have intercourse, although the frequency had diminished considerably. One woman complained about an embarrassingly increased sex drive. In general the change in frequency did not coincide with the onset of the disease nor with the time of diagnosis. Sexual thoughts were frequent; kissing, cuddling, holding hands were spontaneously reported. The couples had been married for between 23 and 43 years. They had not previously discussed their sexual problems with the general practitioner, and accepted the change in their sexual conduct.

\section{ESTEBAN-SANTILLAN CE, PETERSEN RC, WARING SC, O'BRIEN PC AND KURLAND LT \\ University of Guam, Mangilao, Guam; and Mayo Clinic and}

Foundation, Rochester, MN, USA

\section{THE CHARACTERISTICS OF DEMENTIA IN THE CHAMORRO POPULATION OF GUAM}

Objective: To determine the distinguishing features of dementia in Chamorros on Guam in cases with parkinsonism-dementia complex (PDC) and those with dementia only. Background: The Cognitive Abilities Screening Instrument (CASI), developed for cross-cultural studies of dementia and modified for this population, and a detailed mental status examination (MSE) were used to characterize the dementia, which has not been described previously. Design/Methods: The CASI and MSE were administered to 75 consecutive cases of PDC $(n=62)$ and dementia $(n=13)$. PDC cases were grouped as follows: Group $1(n=16)$ presenting with dementia and parkinsonism at the same time, Group $2(n=30)$ with dementia first, and Group $3(n=16)$ with parkinsonism initially. The diagnosis of dementia was based on DSM-III-R criteria while severity was based on the CDR scale. Results: The total duration of CASI and overall performance on MSE testing were similar among the cases. Regression analysis comparing PDC (all groups) to dementia only controlling for dementia severity yielded no significant association with CASI total score but a significant difference between 2 of 9 domain subscores, attention $(p=0.0128)$ and language $(p=0.0262)$. Similar analysis comparing each PDC subgroup showed Group 1 differed significantly from Group 2 ( $p=0.0291$ ) for CASI total score, with only short-term memory being significantly different between Groups 1 and $2(p=0.0077)$. All other comparisons between groups were not significant. Conclusion: Cases with PDC differed from dementia only on the basis of attention and language scores, with Group 1 differing from Group 2 within PDC subgroups on the basis of CASI total score and short-term memory score.
FINALI G, PICCIRILLI M, BENEDETTI A AND RIZZUTO S

Department of Neurology, University of Perugia, Italy

\section{LEFT HEMISPATIAL INATTENTION IN RIGHT BRAIN-DAMAGED NON-DEMENTED PARKINSON PATIENTS}

Evidence for defective visuo-spatial processing in Parkinson's disease (PD) is still conflicting. Impaired performances may be due to generalized cognitive deterioration whereas in non-demented PD patients it may be due to testing procedure, employing tasks requiring substantial motor components and time limits, or frontal executive abilities. These observations argue against a widespread visuo-spatial impairment in $\mathrm{PD}$. The neglect syndrome is a selective visuo-spatial dysfunction which usually accompanies lesions in the right hemisphere. We examined the influence of extrapyramidal lateralization on visuo-spatial activities. Two groups of right-sided (PDRS) and left-sided (PDLS) non-demented right-handed hemi-parkinsonians were evaluated. The symmetrical clinical parameters of the CURS were used to determine the prevalent side affected. Only the patients with an index of lateralization $=3$ were included. The visuospatial functions were examined using a task of copying crosses as an indicator of generalized visuo-spatial ability, and a line bisection task as a marker of hemispatial inattention. Healthy matched controls performed the same test battery. Non-demented PDLS patients showed a significant trend towards a left neglect without concurrent generalized visuo-spatial deficit. Therefore, the results seem to confirm the existence of focal neuropsychological abnormalities in selected groups of PD patients.

\section{FRAILE V, MASSON H AND COHEN H \\ Laboratory of Cognitive Neuroscience, Université du Québec, Montréal, Canada \\ DEFICITS IN TEMPORAL ASPECTS OF PARKINSONIAN SPEECH}

Cohen et al. (1993) found, in a series of studies, that PD patients had difficulties in tasks involving complex modulation of intonative vowels and production of intonative sentences under visual conditions. Control of voicing and pauses was also found to be impaired in fast rate diadochokinetic tasks (repeated syllables), but not in conversational rate: These last results showed that motoric aspects of speech timing were impaired in PD, and that speech motor control is less effective in more complex contexts, as is the case for limb movements. In this study, we investigated speech temporal organization in PD by evaluating a specific aspect of speech timing, i.e. number and relative duration of pauses. Measures were extracted from sentences produced in three linguistic modes (interrogative, imperative, declarative). Eight mild PD, 13 moderate PD and 11 control subjects read aloud sentences presented auditorily and visually. ANOVAs conducted on measures extracted from digitized speech samples revealed fewer pauses and relatively shorter duration of pauses for PD subjects. These results suggest a striatal involvement in the control of highly automatized actions, as in speech production; they also indicate that deficits in temporal organization of sequences may be a characteristic feature of PD.

\section{FRIEDMAN A}

Department of Neurology, Medical Academy, Warszawa, Poland

THE EFFECT OF AGING ON SIMPLE REACTION TIME, VISUAL MEMORY AND VISUOSPATIAL ORIENTATION IN PARKINSON'S DISEASE AND CONTROL

Age-related changes in simple reaction time (RT), visual memory (VM), and visuospatial orientation (VSO) were evaluated in 46 patients with 
idiopathic Parkinson's disease (PD), whose age ranged from 41 to 86 , and 41 controls (age range 46-88). In three consecutive tests, RT to a simple stimulus, RT where the stimulus was a sequence of 3 geometric figures displayed randomly with non-significant figures, and RT requiring visuospatial orientation were related to age. Simple RT was positively related to age $(r=+0.62, p=0.0001)$ in the control but not in the PD group. $\mathrm{RT}$ to the stimulus requiring VM and VSO were also positively related to the age of the subject in the control group $(r=+0.56, p=0.02$, and $r=+0.49, p=0.002$, respectively), but not in the PD patients. In the PD group RT was in general longer in all three tests. The number of errors committed by the subject in the VSO test was positively related to age in the PD group $(r=+0.34, p=0.02)$, but not in the controls.

\section{GARCIA-MAS A, LLINAS SERVERA J, ROSSIÑOL FAR A AND} ROCA BENNASAR

Department of Psychology, University of the Balearic Islands (UIB), Cra. Valldemossa km 7.5,07071 Palma, Spain

\section{CLINICAL, COGNITIVE AND ELECTROPHYSIOLOGICAL CHARACTERISTICS OF PARKINSON'S DISEASE DEMENTIA}

The aim of this study is to present clinical, cognitive and electrophysiological features related to Parkinson's disease (PD) dementia. We studied 35 subjects affected with idiopathic not secondary PD, without cortical signs of deterioration. In former publications the authors have described differences observed between this population and age matched normals and also PD patients showing cortical deterioration. These subjects were classified into several groups according to clinical form, level of the disease, and finally lateralization at the time of PD debut. From the cognitive point of view, the patients were examined by means of a neuropsychological battery, comprising some specific subtests from the Weschler Scale, and a group of items from the Barcelona Scale. Lastly, the groups were also studied by means of several indexes of the quantified electroencephalography (EEGq) technique, such as the alpha/theta index, antero/posterior deplacement index and the topographical distribution of the alpha rhythm. The results showed a distribution between groups related to the clinical forms. However, we found altered values in some EEGq indexes with respect to the clinical groups. Also, data from the cognitive study suggest a clearly frontal affectation in some PD subgroups.

\section{GAROLERA M AND AGUILAR M}

Department of Neurology, Hospital Mutua de Terrassa, Spain

\section{DEPRESSION IN PATIENTS WITH PARKINSON'S DISEASE, AS MEASURED ON THE GERIATRIC DEPRESSION SCALE}

Objective: To evaluate the nature of depression in patients with Parkinson's disease (PD) by applying the Geriatric Depression Scale (GDS) and analyzing its relationship to age, sex, degree of cognitive and motor disability. Patients and methods: 87 PD (age, $69 \pm 10.0 ; 43.7 \%$ men, $56.3 \%$ women; early onset $(<65) 49.4 \%$, late onset $(>65) 50.6 \%$; Hoehn and Yahr: I $16.1 \%$, II $46.0 \%$, III $28.7 \%$, IV-V 9.2\%). Measurement instruments: GDS cutoff point for depression $\geq 11$. Severity: moderate $(\geq 11$ to $<14)$, severe $(\geq 14)$. Unified Parkinson's Disease Rating Scale (UPDRS). Shawb and England's Activities of Daily Living Scale (ADLS). Mini Mental State, Spanish version (MMS). Results: GDS (10.5 \pm 7.4$)$ with $46 \%$ PD depressed (16.1\% moderate depression and $29.9 \%$ severe depression). Significant differences in GDS with $\operatorname{sex}(p<0.001)$ (women, $12.8 \pm 7.3$; men, $7.5 \pm 6.4)$, evolution $(p<0.024)$, onset age $(p<0.048)$ (late onset, $12.1 \pm 7.2$; early onset, $8.9 \pm 7.3$ ). Positive correlation for GDS with UPDRS (daily activities and the items 'akinsesia' and 'posture' $(p<0.01)$. Moderate and severe depression showed no significant differences related to demographic variables or cognitive loss. Factorial analysis of GDS items yielded 9 factors (I $26.3 \%$, II 6.6\%, III 5.3\%, IV $4.9 \%$, V $4.6 \%$, VI $4.4 \%$, VII $4.0 \%$, VIII $3.7 \%$, IX $3.5 \%$ ). Conclusions: We found a link between depression and sex, stage of disease, onset age, loss of autonomy, motor abnormalities and mental loss. The profile of depression in PD involves maintenance of a positive attitude towards life, subjective feelings of depression, anxiety, social withdrawal and mental dullness.

GAROLERA M AND AGUILAR M

Department of Neurology, Hospital Mutua de Terrassa, Spain

USEFULNESS OF THE MINI MENTAL STATE

(SPANISH VERSION) IN ASSESSMENT OF COGNITIVE DETERIORATION OF PATIENTS WITH PARKINSON'S DISEASE

Objective: To assess the application of the Mini Mental State (MMS), Spanish version, as a screening device for measuring cognitive deterioration in patients with Parkinsons disease (PD). Patients and methods: 87 patients ( $43.7 \%$ men, $56.3 \%$ women); age, $69.1 \pm 10.0$; age at onset, $62.4 \pm 11.8$; evolution, $6.6 \pm 5.5$ years; Hoehn and Yahr: I 16.1\%, II $46.0 \%$, III $28.7 \%$, IV-V $9.2 \%$; educational level, $6.4 \pm 4.4$ years, $26.4 \%$ illiterate). Measurement instruments: MMS (35 items). Cutoff points for deterioration: $<27$ points for patients $<65$ years of age, $<23$ points for those $>65$. Results: MMS $(27.71 \pm 4.90)$ yielded $17.2 \%$ of PD patients showing signs of deterioration. Significant differences in MMS results were found for sex $(p<0.001)$ (women, 28.2 \pm 4.9 ; men, 31.6 \pm 4.1 ). Negative correlation of MMS was found with age $(p<0.001)$ and age at onset $(p<0.01)$. Positive correlation was found with educational level $(p<0.001)$. Significant differences were found between illiterate and educated patients for MMS items involving digits, calculation, similarities, reading, writing, drawing $(p<0.005)$. Significant differences were also found between deteriorated and not deteriorated patients $(\mathrm{p}<0.005)$ on the same items. Factor analysis yielded three factors: (I $43.31 \%$, II $17.8 \%$, III $8.3 \%$ ). Conclusions: The MMS is not sensitive enough to detect cognitive deterioration (low prevalence recorded) in PD. Low educational levels may give false positives. Cutoff points need to be revised taking into account educational level and age. Factorial analysis indicates that change in the items 'evocative memory' and 'orientation in time' may be markers of cognitive loss in PD.

\section{GASPARINI M, ALESSANDRI A, BONIFATI V, VANACORE N} AND MECO G

Dept. Neurological Sciences, 'La Sapienza' University, Roma, Italy

\section{VARIETIES OF PERSEVERATION IN PARKINSON'S DISEASE}

The term perseveration is generally used to describe any recurrence of experience or activity without the appropriate stimulus. Perseveration on tests requiring memory and cognitive flexibility has been associated with dysfunctions in the regulation/inhibition activity of frontal lobes; it has also been observed in patients with subcortical disorders. In addition to continuous perseveration (the compulsive repetition of a movement) the taxonomy proposed by Sandson and Albert (1984) includes recurrent perseveration and stuck-in-set perseveration. In elderly, untreated patients with Parkinson's disease, stuck-in-set perseveration has been described by Lees and Smith (1983) on the Wisconsin Card Sorting Test (WCST). In the present study we have examined the performances on neuro- 
psychological tests of 32 newly diagnosed patients with idiopathic Parkinson's disease (14 females and 18 males; age 67.16 \pm 5.50; education 7.19 \pm 3.50 ; duration of illness $6.53 \pm 4.37$ ). All patients have been treated with L-dopa therapy and were evaluated in the 'off-phase'. ANOVA revealed no significant differences between patients on the I/II and III/IV stages of the Hoehn and Yahr scale. Significant correlations were found between increase of recurrent perseverations and decrease of mnemonic retrieval on the Rey Complex Figure $(r=-0.830 ; P<0.05)$ and between increase of stuck-in-set perseverations and number of categories achieved on the WCST $(r=-0.830 ; P<0.005)$. Our data seem to suggest the interference of perseverations on the storage of mnemonical input and on executive functions; they also suggest a similar impairment at different stages of Parkinson's disease, without correlations with severity and duration of the illness.

\section{GEHLERT DR AND TOLLEFSON GD}

CNS Pharmacology, Lilly Research Laboratories, A Division of Eli

Lilly Company, Lilly Corporate Center, Indianapolis, IN 46285, USA

\section{NONPEPTIDE ANTAGONISTS OF NEUROPEPTIDE RECEPTORS: POTENTIAL THERAPEUTICS FOR NEUROPSYCHIATRIC DISEASE}

Neuropeptides are found throughout the central and peripheral nervous systems. The colocalization of many neuropeptides with one or more biogenic amines has led to the speculation that neuropeptics play a modulatory role in monoaminergic neurotransmission. Neuropeptides and classical biogenic amine transmitters are structurally unrelated and exhibit different synthesis, release, receptors, actions and metabolism. Much like the biogenic amines, neuropeptides exert cellular actions through membrane bound receptors coupled to second messenger systems. Until recently, clinical and basic research in this area was slowed by the absence of specific antagonists for neuropeptide receptors. In addition, peptide analogs have limited utility due to rapid metabolism and poor blood-brain barrier penetration. During the past few years, several nonpeptide antagonists for peptide receptors have been discovered and are showing promise in preclinical studies for the treatment of a variety of CNS disorders. These include antagonists for cholecystokinin, neurokinins, neurotensis, corticotrophic releasing factor, vasopressin and oxytocin receptors. In preclinical studies, these agents show promise for the treatment of a variety of psychiatric and neurologial disorders such as psychoses, panic, anxiety, pain, cognition and depression. A number of other peptides are promising targets for future drug development, including galanin (cognition, appetite disorder), neuropeptide $\mathrm{Y}$ (anxiety, appeitite disorders) and bradykinin (pain). The clinical availability of these agents should open an exciting new frontier for the treatment of psychiatric diseases.

GELADZE M, MALASHKHIA V AND DANELIA G Institute of Clinical Immunology and Allergology, Tskhaltubo, Republic of Georgia

\section{DEFECTIVE AUTOLOGOUS MIXED LYMPHOCYTE REACTION IN CASES OF DEMENTIA IN PARKINSON'S DISEASE}

We studied 16 patients with dementia in Parkinson's disease (PD) and 14 persons without marked symptoms of nervous system lesion (control group). Their age ranged from 40 to 60 years. Clinical and neuropsychologic observation of patients was carried out by means of standard neuropsychologic tests. Autologous mixed lymphocyte reactions (AMLR) were investigated according to DA Hafler's method. We mixed bloodnot-T-lymphocytes (previously treated with mitomycin-C) with bloodT-lymphocytes during the AMLR. In PD cases the AMLR responses were reduced ( $3027 \pm 558, P<0.02)$, in comparison with those of control group $(6985 \pm 1760)$. The results of the investigation allowed us to suggest that autorecognising T-lymphocytes (responders) play an important role in development of autoimmune reactions in PD. Immunomodulators can be recommended in pathogenetic treatment of dementia in Parkinson's disease.

GELADZE M, MALASHKHIA V, ORKODASHVILI G, IAKOBI SH AND SEPHIASHVILI R Abasheli St., No. 6, 380079 Tbilisi, Republic of Georgia

\section{DECREASED AUTOLOGOUS MIXED LYMPHOCYTE REACTION IN DEMENTIA IN PARKINSON'S DISEASE}

The autologous mixed lymphocyte reaction (AMLR) was studied in 18 patients with dementia in Parkinson's disease (DPD) and 16 patients with vascular dementia (VD)/control group. The AMLR response was correlated with T-cell subsets. AMLR values were expressed as delta count per min (cpm). In DPD patients (3615 $\pm 1670 \mathrm{cpm}, p<0.01)$ there was significant difference. A more pronounced difference was also seen when patients with DPD associated with blood $T_{h} / T_{s}$ ratios greater than 3.0 were compared with $T_{h} / T_{s}$ ratios of less than 1.0; these last had an increased AMLR as compared to patients with either a high $\mathrm{T}_{\mathrm{h}} / \mathrm{T}_{\mathrm{s}}$ ratio $(p<0.001)$ or control ratio $(p<0.05)$. Thus, DPD patients have a decreased AMLR which correlates with high $\mathrm{T}_{\mathrm{h}} / \mathrm{T}_{\mathrm{s}}$ ratios. The results obtained show that autoimmune disturbances play a certain role in pathogenesis of dementia in Parkinson's disease.

\section{GLOSSER G, WOLFE N AND ALBERT ML}

Graduate Hospital, Philadelphia, PA; University of California, Davis, CA; and Boston University, Boston, MA, USA

\section{CROSS-CULTURAL STUDIES OF DEMENTIA SYNDROMES ASSOCIATED WITH CORTICAL AND SUBCORTICAL PATHOLOGY}

Most dementia screening instruments are not suited for cross-cultural assessments where there may be a cultural mis-match between the examiner, the examinee and the examination materials. Existing tests yield high false negative rates of detection among highly educated and mildly cognitively impaired subjects; and they yield high false positive rates among the very elderly and subjects with limited education or a different linguistic background. Because most existing measures were developed to evaluate the more prevalent types of dementia resulting from cortical pathology, they are not optimal for detecting dementias in patients with primarily subcortical types of pathology. The CrossCultural Cognitive Examination (CCCE) is a brief dementia screening test that was developed for cross-cultural neuroepidemiological research to identify patients with dementing disorders who have primarily subcortical pathology. It has been validated in a population at risk for developing ALS-PD-Dementia Complex in Guam $(N=115)$, in Japanese subjects at risk for Alzheimer's Disease (AD) and Multi-Infarct Dementia $(N=185)$, and in Parkinson's Disease (PD) patients with and without clinically diagnosed dementia and $\mathrm{AD}$ patients in the US Mainland $(N=117)$. Results will be presented to show that the CCCE is highly sensitive and specific for detecting dementias in various populations; it 
matches or exceeds the sensitivity and specificity of already accepted dementia screening instruments; it is not biased by gender, linguistic preference, education or cultural background; and it differentiates between dementia symptom profiles associated with cortical (AD) and those associated with subcortical pathology (PD).

GREEN J, SIROCKMAN BE, ZAKERS GO, MAIER CL AND WATTS RL

Emory University School of Medicine, Atlanta, GA, USA

\section{MILDLY-AFFECTED, UNMEDICATED PARKINSON'S DISEASE PATIENTS SHOW EVENT-RELATED POTENTIAL CHANGES AND BRADYKINESIA BUT NOT NEUROPSYCHOLOGICAL DEFICITS}

The purpose was to test the hypothesis that aging contributes to neuropsychological deficits and event-related potential (ERP) changes in mildly-affected, unmedicated Parkinson's disease $(\mathrm{PD})$ patients. We also examined whether there were relationships between these variables and motor measures. Ten younger PD patients (age $<50$ years), ten older PD patients (age $>60$ years), and controls were assessed. Patient groups were matched for disease severity and had discontinued medications five days before evaluation. Both younger and older patients showed increased amplitude of the P3 component of the auditory oddball ERP, possibly reflecting that patients had to expend greater mental effort in performing the task. Movement time was prolonged to a similar degree in both patient age groups, but reaction time was not prolonged in these early PD patients. As P3 amplitude increased, there were also increases in scores on the Unified Parkinson's Disease Rating Scale, supporting a relationship between ERPs and motor impairment. In contrast to studies of medicated patients, the unmedicated patients did not show neuropsychological deficits in either age group. We conclude that mildly-affected PD patients when tested off medication exhibit significant ERP changes and bradykinesia, but not pronounced neuropsychological deficits. ERPs may provide measures of subtle electrophysiological dysfunction that have potential for tracking disease severity and progression.

GREEN J, VITEK JL, BARON M, COHEN-COLE SA, BAKEY RAE AND DELONG MR

Emory University School of Medicine, Atlanta, GA, USA

\section{NEUROPSYCHOLOGICAL SEQUELAE OF PALLIDOTOMY FOR TREATMENT OF PARKINSON'S DISEASE}

There is resurgent interest in treatment of intractable Parkinson's disease (PD) via lesions of the internal globus pallidus (GPi). While demonstrating significant improvement in Parkinsonian motor signs, previous studies have not performed extensive neuropsychological evaluation, particularly of frontal lobe function and memory, to document possible cognitive sequelae. In the present study, we assessed advanced, medically intractable PD patients within one month before, and within ten months following, stereotactic, microelectrode-guided, unilateral lesioning of the caudal (sensorimotor) region of GPi. High-resolution MRI reconstructions were used to determine lesion site. Frontal lobe function, attention, memory, visuospatial ability and verbal ability were evaluated. Following pallidotomy, all patients showed improvement of motor signs. Five out of seven patients completed to date did not show change greater than one standard deviation on over $75 \%$ of measures. Where there was evidence of decline, it was more frequent on measures sensitive to frontal lobe function. Both of the patients with neuropsychological decline on $50 \%$ or more of measures had experienced frontal hematomas postsurgically. Modified Schwab and England Activities of Daily Living
Scale average scores improved from $53 \%$ presurgery to $81 \%$ postsurgery. Consistent with the notion of functionally segregated basal gangliathalomocortical circuits, the preliminary results suggest that pallidotomy aimed at creating caudal GPi lesions is not associated with neuropsychological change for most of the measures assessed.

\section{GUIROY DC, GARRUTO RM, YANAGIHARA R, BAYREUTHER K AND GAJDUSEK DC Laboratory of CNS Studies, NIH, Bethesda, MD, USA; and Zentrum Molekular Biologie, University of Heidelberg, Germany \\ NEUROFIBRILLARY TANGLES OF GUAMANIAN PARKINSONISM-DEMENTIA AND AMYOTROPHIC LATERAL SCLEROSIS CONTAIN A 4 TO 4.5 KILODALTON PROTEIN WHICH IS IMMUNOREACTIVE TO ANTI-AMYLOID BETA/A4-PROTEIN ANTIBODIES}

Neurofibrillary tangles (NFT), a neurodegenerative feature of Alzheimer's disease (AD), Down syndrome and normal aging, is a constant, widespread neuropathological finding in Guamanian parkinsonismdementia (PD) and amyotrophic lateral sclerosis (ALS). NFT in brain tissue sections of patients with Guamanian PD and ALS were immunoreactive to antibodies directed against a 43-amino acid synthetic peptide homologous to amyloid beta/A4-protein (anti-SP43) associated with AD. NFT extracted from brain tissues of Guamanian patients with PD and ALS were congophilic and birefringent. By negative-stain electron microscopy, NFT preparations contained bundles and/or isolated single, straight, unpaired or paired filaments measuring $5-20 \mathrm{~nm}$ in diameter. Formic acid digestion of NFT preparations, followed by SDS-polyacrylamide gel electrophoresis and size exclusion HPLC, showed a protein with an apparent molecular mass of 4 to $4.5 \mathrm{KDa}$, which by Western analysis was immunoreactive to anti-SP43. Immunoabsorption of purified NFT or SP43 with anti-SP43 abolished immunostaining. Our data indicate that amyloid beta/A4-protein is present in NFT in brain tissues of patients with Guamanian PD and ALS, suggesting a common mechanism of amyloidogenesis with NFT formation in Alzheimer disease and normal brain aging.

HANOGLU L, ÖZER F, KIZKIN S, ALTUNHALKA A, ATAKLI D, ORAL T AND KARSIDAG S

Bakirköy State Hospital for Psychiatric and Neurological Diseases, Neurology Department, Istanbul, Turkey

\section{OBSESSIVE-COMPULSIVE FEATURES IN PARKINSON'S DISEASE}

Introduction: Men and women with idiopathic Parkinson's disease (PD) were compared with normal controls in relation to their obsessivecompulsive features; the results were reported. Methods: Thirteen male and 8 female patients with idiopathic $\mathrm{PD}(n=21)$, aged 28 to 78 years, and normal healthy subjects $(n=20)$ as controls, adjusted to age and sex, participated in this study. A scale to evaluate obsessive-compulsive features (Moudsty Scale) was applied to both groups. Total scores and the scores obtained from subscales (controlling, cleaning, slowness and scepticism) were statistically analysed using the Mann-Whitney U Test. Results: The average of total scores of the patients was significantly higher than that of the normal controls $(p<0.01)$. Accordingly, mean scores for controlling and scepticism were found to be significantly higher in patients ( $p<0.04$ and $p<0.01$, respectively), while the differences for mean scores in subscales of cleaning and slowness did not reach statistical significance ( $p>0.13$ and $p>0.08$, respectively). Conclusions: In the patients with $\mathrm{PD}$, obsessive and compulsive features were found to 


\section{Abstracts of the International Symposium on Dementia in Parkinson's Disease}

be more prominent compared with the healthy controls. This can be considered in clinical accordance with the recent suggestions that there is a serotoninergic dysfunction in PD.

\section{HARDIE RJ AND KARTSOUNIS L \\ National Hospital for Neurology and Neurosurgery, Queen Square, London WC1 3BG, UK}

\section{THE PATTERN OF COGNITIVE IMPAIRMENTS IN NEUROACANTHOCYTOSIS}

Neuroacanthocytosis (NA) is a rare, often inherited, neurodegenerative condition in which acanthocytosis in peripheral blood is associated with progressive movement disorder and mental illness. In order to identify patterns of cognitive impairments, a retrospective analysis was conducted of detailed neuropsychological assessments made in 8 of a published series of 15 surviving patients with NA (Hardie et al., 1991, Brain, 114 13-49). Evidence of both general intellectual deterioration and focal cognitive deficits was sought using standard psychometric tests. Clinical psychiatric features affected all except one case least cognitively impaired, including emotional stability (3 cases), anxiety, depression, marked personality change, obsessional-compulsive disorder, immature personality with 'developmental dyslexia' (each in 2 cases). Six cases showed unequivocal evidence of generalized intellectual impairment based on discrepancies between measured and estimated premorbid IQ, and 5 cases significant memory impairment. The most consistent finding was evidence of deterioration in the 'executive' skills of all 8 cases, suggesting frontal lobe dysfunction, whereas visuo-perceptual and language skills were, respectively, relatively or completely preserved. Radiological evidence of focal caudate or generalized cerebral atrophy did not correlate with any neuropsychological abnormalities. The pattern of psychiatric disturbance and neuropsychological profile most closely resembles that seen in Huntington's Disease (HD). In contrast to HD however, neuropathological examination in NA suggests sparing of the cerebral cortex, raising interesting questions about the role of the basal ganglia in cognition.

\section{HERISHANU YO, PODGAIETSKI M AND GRANOVSKI R}

Department of Neurology, Soroka Medical Center, Faculty of Health Sciences, Ben-Gurion University, Beer-Sheva, Israel

\section{OLFACTORY FUNCTION IN A COHORT OF PREPARKINSONIAN SUBJECTS}

20 asymptomatic residents (aged $70.6 \pm 7.8$ ) living in two kibbutzim where we had previously found a cluster of Parkinson's disease (PD) were examined in 1989 and any extrapyramidal signs detected were scored by Webster's scale. Since then, they have been reexamined annually for four years, in order to assess if there is a progressive disorder and to provide data on candidates for a trial of prevention. Since olfactory dysfunction in PD is common and appears to occur early in the disease process, the University of Pennsylvania Smell Identification Test (UPSIT) was administered to these subjects, to $13 \mathrm{PD}$ patients (aged 66.69 \pm 7.63 ) and to 12 controls (aged 63.75 \pm 6.3 ). Results: In 10 subjects a marked progression in extrapyramidal signs was observed, tremor appeared in addition to the rigidity and bradykinesia previously seen in these people. In 5 subjects an asymmetry of extrapyramidal signs was also observed. UPSIT score in PD patients was $17.84 \pm 5.09$ and in this cohort of presymptomatic subjects was $21.30 \pm 5.19\left(t=1.83, \mathrm{df}=30, p=7.57^{-2}\right.$, NS). The score was lower in the latter compared with that found in the control group, $25.08 \pm 5.19\left(t=1.93, \mathrm{df}=30, p=6.20^{-2}, \mathrm{NS}\right)$. The score in the control group differed significantly from that found in the PD group. Conclusions: Olfactory dysfunction is present in presymptomatic stages of PD although not of a similar intensity as in advanced PD cases.
HOCHERMAN S AND AHARON-PERETZ J

Freiman Hospital, Haifa, Israel

\section{PARKINSON'S DISEASE PATIENTS MANIFEST IMPAIRED VISUO-MOTOR COORDINATION WHILE BEING TREATED WITH DEPRENYL}

Objective: To evaluate the symptomatic effect of deprenyl on the visuomotor coordination in Parkinson's disease (PD). Rationale: Deprenyl is an inhibitor of type B monoamine oxidase. In PD, it is believed to manifest a symptomatic effect (ameliorating Parkinsonian symptoms), and a neuroprotective effect (prolongation of life span in advanced PD patients and delaying L-dopa therapy in de novo patients). However, deprenyl therapy may also be associated with adverse effects, dyskinesia and confusion being common examples. Methods: Eight (Stage 1-2) PD patients, therapeutically controlled on anticholinergics (6), L-dopa (2), and deprenyl (8), participated in the study. Visuo-motor performance was tested in a tracing (hand movement along a given path at free speed) task and in a tracking (hand movement along a given path at a required speed) task on days $0,14,28$ and 42. Results: A significant improvement in the directional control of hand movement was revealed in the difficult tasks (tracing and tracking along a sine wave) upon withdrawal of deprenyl. Hand movement speed increased too upon deprenyl withdrawal. Conclusions: Deprenyl therapy seems to have a detrimental effect on visuomotor control in PD patients.

\section{HOFMAN S}

Tel Aviv, Israel

\section{THE FUNCTION OF MUSIC IN PARKINSONIAN PATIENTS}

Parkinson's Disease (PD) has afflicted mankind from time immemorial. According to the Bible and Talmud (II Chron. 5, 13, and Bab. Talmud, Hulin 24, a-b) the trembling of hands, feet and voice in priests and Levites justified arresting their function, including musical function, in the temple. Since James Parkinson published his description of the 'Shaking Palsy', many studies have been carried out and published on different aspects of PD. A number of studies have been published on music function and amusia, but publications on music function in PD have been extremely sparse. The present study investigated the music functionperception and expression - of seven musicians, 11 of them PD patients. These musicians were one violinist, one trombonist, one singer, one composer, one conductor, one music teacher and one musicologist. Seven controls of the same domain but non-Parkinsonian were compared. A large scale of music elements including rhythm, meter, pace, pitch, timbre, volume, harmony, form, memory-musical and extra musical-as well as cognition and dementia were studied. It is suggested that music activity may slow down the motor and cognitive deterioration of PD musicians.

HOLINKA B, LIESS J, BÖCKENHOLT S, CALABRESE P, GREULICH W AND GEHLEN W

Neurologische Universitätsklinik, Knappschaftskrankenhaus, Bochum-Langendreer, Bochum, Germany

\section{COGNITIVE DYSFUNCTIONS IN PARKINSON'S DISEASE}

In recent literature there is a consensus that Parkinson's disease can be accompanied by cognitive impairments. Especially dysfunctions of memory, visual-spatial skills and functions of the frontal lobes have been reported. However, the relations among these specific dysfunctions and between them and clinical symptoms of Parkinson's disease remain subject to further investigation. We examined patients with Parkinson's disease, Alzheimer's disease and damage of the frontal lobes concerning their cognitive performance. A battery of neuropsychological tests 
comprising the Mini Mental State Examination, MWT-B (Mehrfachwortschatztest, Form B), Word Fluency, Tower of Hanoi, CCS (Diagnostikum für Cerebralschädigung), Rey Auditory Verbal Learning Test, Digit span and Corsi block-tapping was used. The patients were rated according to the Columbia University Rating Scale. A neurological examination was carried out. In patients with Parkinson's disease we found disturbances of working memory and frontal lobe functions similar to those of frontal lobe damaged patients. In contrast patients with Alzheimer's disease particularly showed impairments of verbal performance. Further evidence for a specific profile of cognitive disturbances in Parkinson's disease could be demonstrated. Different degenerative diseases can be distinguished by means of neuropsychological assessment.

\section{HOROWSKI R, BALZER T, RIZAND P AND RUNGE I}

Research Laboratories of Schering AG, 13342 Berlin, Germany

\section{ERGOT-DERIVED DOPAMINOMIMETICS: TOOLS FOR STUDYING PERCEPTUAL DISTURBANCES?}

Dopaminomimetics with ergot-like structure, and especially $8-\alpha-$ aminoergolines, have outstanding affinities to different subtypes of the cationic amine receptors (DA, 5-HT, $\alpha$ and $\beta$ ) as part of the G-protein coupled receptor superfamily. Minor structural changes result in different activity (e.g. lisuride $\Rightarrow$ terguride $\Rightarrow$ bromerguride $=D_{2}$ agonist $\Rightarrow$ partial agonist $\Rightarrow$ antagonist) and make these compounds (which also can be labelled and detected in different ways) good tools for studying receptors. Interaction with new receptor subtypes in the 5-HT field and especially the $D_{3}, D_{4}$ and $D_{5}$ receptor subtypes may bring new light to some old questions: e.g. why d-LSD causes acute visual hallucinations in everybody, whilst dopaminergic ergots do so only in Shy-Drager patients but need prolonged exposure (a kind of 'sensitation') and other risk factors to result in so-called dopaminergic psychosis in Parkinson's disease. Age, concomitant diseases and sub-clinical deficiencies may contribute as well as drug factors (e.g. dosage and way of application), but also effects on sleep (and especially REM), as disturbances in sleep pattern and dreaming are often premonitory signs. So-called dopaminergic psychosis could become an interesting tool for better understanding of neuropsychiatric disturbances, even if, as in other complex human behaviour, the pre-existing personality is still the most important factor.

\section{INGSTER-MOATI I, ALBUISSON E, LE COZ P, PIERRON C AND GRALL Y \\ Lariboisier Hospital, 2 rue A. Pare, 75010 Paris, France \\ COLORED BACKGROUNDS AND SPATIAL CONTRAST SENSITIVITY IN PARKINSON'S DISEASE}

There are two common methods to test spatial contrast sensitivity (SCS) function-photographically reproduced gratings patterns and microprocessor controlled video display using the Von Bekesy tracking procedure-but they do not give the same defect in the SCS of Parkinson's disease. Eleven parkinsonian patients and 12 sex- and age-matched controls were studied. The test consisted of presentation, on a high resolution monitor screen, of vertical stationary gratings with a sinusoidal luminance profile decreasing along the horizontal axis, with 4 backgrounds (white, red, green, blue) randomly displayed. By acting a joystick, the subject positioned a cursor at the contrast threshold. Six spatial frequencies (SF) were tested from 0.8 to 19 cycles/degree (cpd); the data were stored in a microcomputer. Using a Friedman rank test, regardless of the color of the background the rank from best to worst frequency is always, within the control group: $3.2,1.6,6.4,0.8,10$ and $19 \mathrm{cpd}$. Within the parkinsonian group there are two permutations: between 3.2 and 1.6 and between 6.4 and $0.8 \mathrm{cpd}$. The two frequencies
10 and $19 \mathrm{cpd}$ are unchanged. This study showed that the defect of the SCS is located in the intermediate spatial frequencies and does not change with the color of the background.

INZELBERG R, PLOTNIK M, SCHECHTMAN E, SHAHAR I, FLASH T AND KORCZYN AD

Tel-Aviv University, Ramat Aviv and Weizmann Institute of Science, Rehovot, Israel

\section{MENTAL AND MOTOR SWITCHING ABILITIES IN PARKINSON'S DISEASE}

Parkinson's disease (PD) patients are known to be impaired in both mental and motor switching. Non-demented parkinsonian patients and age-matched controls were examined using the Modified Wisconsin Card Sorting Test and a motor switching task based on reaching towards visual targets the location of which could unexpectedly change within the reaction time. In both mental and motor tasks, patients performed worse than controls. However, there was no inter-correlation between them. Abnormalities in mental and in motor switching, although occurring simultaneously in PD, originate from different abnormal mechanisms stemming from pathologies in different cortico-basal ganglia-cortical circuits. Differences in planning when given tasks based on internal versus external cues should be taken into account in the interpretation of the results.

\section{INZELBERG R, MILDWORF B, REIDER I, VISNIEVSKAYA S} AND KORCZYN AD

Tel-Aviv University and Tel-Aviv Medical Centre, Tel-Aviv, Israel

\section{TEMPORAL LOBE MEASUREMENTS IN PARKINSON'S DISEASE}

Objective: To analyze the extent of temporal lobe (TL) atrophy in the dementia of Parkinson's disease (PD+D). Background: Alzheimer's disease (SDAT) and PD+D show clinical and neurochemical similarities. Neuroradiological changes in TL have been reported in SDAT, but not previously studied in Parkinson's disease (PD). Method: $\mathrm{PD}+\mathrm{D}$ patients and non-demented Parkinsonian (PD-D) patients matched for age, sex and disease duration underwent Mini Mental State Examination (MMSE), a battery of memory evaluation tests, and CT examinations using $5 \mathrm{~mm}$ cuts, oriented $20^{\circ}$ to the plane of the orbitomeatal line. Spearman correlation and $t$-test were used. Results: Groups were not different for age (PD+D, $71 \pm 12$ years; PD-D, $75 \pm 9$ years) and disease duration ( $7 \pm 4$ and $6 \pm 3$, respectively). The interuncal distance was significantly greater in $\mathrm{PD}+\mathrm{D}(p<0.05)$. The temporal horn width was larger in $\mathrm{PD}+\mathrm{D}$ $(p<0.05)$. Conclusion: Temporal lobe changes occur more frequently in $\mathrm{PD}+\mathrm{D}$ than in $\mathrm{PD}-\mathrm{D}$, being a better hallmark than verticular changes. TL changes seen in CT scans can be visualized only in special cuts and are associated with the existence of dementia in PD. Special imaging protocols should be used in the evaluation of brain atrophy in PD.

JANSEN ENH, DE VOSS RAI, STAM FC, RAVID R, SWAAB DF AND BRAAK $\mathrm{H}$

Department of Neurology, M.S.T. and Regional Laboratory of Pathology, Enschede, The Netherlands; The Netherlands Institute for Brain Research, Amsterdam and Zentrum der Morphologie, Amsterdam; and University of Frankfurt, Germany

\section{CLINICOPATHOLOGICAL FINDINGS IN 22 CASES OF 'LEWY BODY DISEASE'}

Postmortem neuropathological findings in 22 consecutive cases of Parkinson's disease (PD) are reported. The incidence of cortical Lewy 
bodies (CLBs) and/or Alzheimer type pathology (ATP) in specific areas of the brainstem, neo- and allocortex is correlated with clinical findings of depression, changes in cognitive status and neurobehavioural abnormalities. Lewy bodies of variable density and localisation were found in the neocortices of all subjects. ATP was found in 14 subjects but a diagnosis of Alzheimer's disease (AD) on the basis of the Khachaturian and CERAD criteria could be made in only 5 . It was possible to stage the $\mathrm{AD}$ changes according to the Braak and Braak criteria in no more than 17 subjects. The 3 subjects in the isocortical stage all had clinical dementia, but the latter was present in only 4 of the 6 subjects in limbic stages III and IV. Two subjects in whom clinical dementia was associated with CLBs had no trace of ATP. Although the number of patients in our study was small, we were unable to confirm the existence of a specific clinicopathological entity in patients with PD and CLBs.

\section{JANSEN ENH}

Movement Disorder Unit, Hospital Medisch Spectrum Twente,

P.O. Box 50.000, 7500 KA Enschede, The Netherlands

\section{CLOZAPINE IN THE TREATMENT OF TREMOR IN PARKINSON'S DISEASE}

Despite optimal anti-Parkinson medication many patients with PD have a troublesome tremor. Clozapine is an atypical neuroleptic drug, with a very low propensity to provoke extrapyramidal side effects. In this open label study 23 patients with PD participated in an investigation on the efficacy and tolerability of low dose clozapine on resting-tremor. The tremor scores and other items of motor examination were established with the UPDRS. Patients were seen every two weeks; blood counts were done every week, because of agranulocytosis as the major adverse event of clozapine. Previous anti-Parkinson medication was kept unchanged during this study. Clozapine induced a beneficial response on resting tremor in $73 \%$ of patients; this anti-tremor efficacy of clozapine was statistically significant. Mean dosage of clozapine was $18.2 \mathrm{mg} / \mathrm{d}$. Major adverse events were leucopenia (1 case), transient hypnosedation ( 8 cases) and hypersalivation ( 6 cases). The putative pharmacological mechanisms for the antitremor efficacy of clozapine are discussed.

JELLINGER KA, BANCHER C, BRAAK H AND FISCHER PL Boltzmann Institute of Clinical Neurobiology, Lainz Hospital, Vienna, Austria; and Center of Morphology, Goethe University, Frankfurt, Germany

\section{NEUROPATHOLOGY OF DEMENTIA IN PARKINSON'S DISEASE}

Causes of dementia in Parkinson's disease (PD) are multiple and controversial. ${ }^{1,2}$ Cognitive impairment has been associated with (a) damage to subcorticocortical neuronal systems with cell loss in medial substantia nigra (mesocorticolimbic dopamine deficiency) and degeneration of noradrenergic (locus ceruleus), serotonergic (dorsal raphe nucleus), cholinergic (nucleus basalis of Meynert), and peptidergic systems; (b) cortical and limbic Alzheimer pathology ${ }^{1-3}$ (c) cortical Lewy bodies (LB); ${ }^{4}$ (d) combined lesions. Recent morphometric studies indicate that damage to subcortical nuclei appears not sufficient by itself to produce dementia, although degeneration of the ascending innominato-cortical system and the resulting cholinergic deficit may contribute to cognitive impairment and subcorticofrontal behaviour changes in PD. ${ }^{5}$ By contrast, cortical changes, either AD and/or LB pathology, or both, lead to dementia when of sufficient intensity. In $P D$ brain, $A D$ pathology reveals a similar pattern as in aging brain and AD. Neurofibrillary changes, in contrast to amyloid deposits, show a hierarchical spreading pattern from the allocortex to isocortical (prefrontal) areas with early involvement of the entorhinal region, a major relay station between hippocampus and isocortex. Comparative clinicopathologic studies in prospective cohorts of aged and PD patients showed linear correlations between psychostatus and morphologic $\mathrm{AD}$ staging. ${ }^{6}$ The pattern of neuronal degeneration associated with neuritic AD changes may be associated with cortical $\mathrm{LB}$ pathology, both lesions being implicated as morphological substrates of dementia. The specific contribution of cartical and subcortical lesions to dementia in PD and their etiology await further elucidation.

1. Duyckaerts C et al. Adv. Neurol. 1993, 60, 447-455.

2. Jellinger K et al. In: Wolters C, Scheltens P (eds), Mental Dysfunctions in Parkinson's Disease, Vrije Universitet, Amsterdam.

3. Braak H, Braak E. Neurosci. Res. 1992, 15, 6-31.

4. Kosaka K. Adv. Neurol. 1993, 60, 456-463.

5. Reid WG. Dementia 1992, 3, 114-120.

6. Bancher C et al. Neurosci. Lett. 1993, 162, 179-182.

JENDROSKA K, POEWE W AND DANIEL SE

Neurology, UKRV, Berlin, Germany; and Parkinson's Disease Society Brain Bank, London, $U K$

\section{$\beta$-AMYLOID PROTEIN AND ITS RELATIONSHIP WITH DEMENTIA IN PARKINSON'S DISEASE}

Dementia in Parkinson's disease (PD) is a frequent complication in late stages of the illness. The aetiology is heterogeneous, but Alzheimer-type changes are found in many cases. To investigate the relationship of $\beta$ amyloid protein ( $\beta$-A4) with dementia in PD we carried out whole hemispheral immunostains for $\beta$-A4 in 50 well documented cases of histologically proven PD; 23 cases were clinically demented. In cases with $\beta$-A4 distribution throughout the entire cerebral cortex dementia was always present. However, a pathological diagnosis of Alzheimer's disease according to current histological criteria was not justified in many of these cases. In the majority of demented patients without significant $\beta$-A4 immunoreactivity, there was an association with cortical Lewy bodies, but other causes of dementia such as vascular pathology and normal pressure hydrocephalus were also identified. We conclude that dementia in PD may be attributable to $\beta$-A4 deposition in addition to the pathology of PD. On pathological grounds 'Parkinson's disease dementia' as a specific entity does not exist.

\section{KIEBURTZ K, McDERMOTT M, GROWDON J AND THE PARKINSON STUDY GROUP \\ University of Rochester, Rochester NY; and Massachusetts General Hospital, Boston, MA, USA}

\section{COGNITION IN PD: THE DATATOP STUDY}

Specific aims: To determine demographic and clinical correlates of cognitive performance in PD patients, and to determine effects of deprenyl and tocopherol on annualized rates of cognitive change. Subjects: 800 Stage 1 and Stage 2 patients with idiopathic PD enrolled in the DATATOP study; none was demented or depressed. Methods: Subjects were randomly assigned to receive L-deprenyl $5 \mathrm{mg}, \alpha$-tocopherol 1000 IU, L-deprenyl $+\alpha$-tocopherol, or matching placebo bid in a $2 \times 2$ factorial design. We administered tests that assessed memory, visuospatial, and frontal lobe functions at baseline and every 6 months thereafter for a mean of $14 \pm 6$ months. Results: There were four major findings. (1) Younger and more highly educated patients had better test scores than older subjects and those with less education. (2) Women performed significantly better than men on the Symbol Digit and Selective Reminding Tests, despite their having fewer years of education. (3) There were no significant associations between baseline cognitive performance and features of PD, including duration of illness or presenting PD features such as initial side affected, bradykinesia, tremor, rigidity and postural instabil- 
ity. (4) Treatment with L-deprenyl or $\alpha$-tocopherol, alone or in combination, did not affect cognition: test scores in the four treatment groups were similar at baseline and did not change significantly during the period of observation. During this same time, the UPDRS motor score worsened by 7 points/year in the group of 800 , and by 8.9 points/year in the placebo group. Conclusions: Cognitive function is remarkably stable in nondemented patients with idiopathic PD. These data support the view that motor and cognitive functions are not closely linked in this patient group.

\author{
KOLLER WC, GLATT SL, HUBBLE J, TROSTER A, PAOLO A \\ AND HASSANEIN R \\ University of Kansas, Kansas City, KS, USA
}

\section{RISK FACTORS FOR DEMENTIA IN PARKINSON'S DISEASE: EFFECT OF EDUCATION}

A number of studies have suggested that educational attainment influences the risk of developing dementia related to Alzheimer's disease. In order to study whether there is a similar effect of education in other dementing disorders, we compared 52 patients with Parkinson's disease (PD) without cognitive deficits to 43 patients with PD and dementia (PDD). Patients were judged to meet DSM-III-R criteria for dementia with Mattis Dementia Rating Scale (DRS) scores below 124 and subtest scores more than two standard deviations below the mean in at least two of the five subtests. Patients were considered to be cognitively intact (PDC) with total DRS score above 136 , no single subtest score more than two standard deviations below the mean. The PDD group was older (mean age 73.2 years) than the PDC group (mean age 64.9 years, $p<0.01$ ) and had late onset of motor symptoms (PDD mean 66.2 years, PDC 58.9, $p<0.01$ ). There was no difference in disease duration (PDD 7.9 years, PDC 6.0 years). Motor impairment as measured by the motor subscale of the UPDRS was more severe in PDD (28.3) than PDC $(20.7, p<0.01)$. Educational attainment was less in patients with dementia (PDD 12.7 years, PDC 15.7 years, $p<0.01$ ). A stepwise multivariate logistic regression yielded independent effects for education (less than a high school graduate) (odds ratio 21 , confidence interval 2.38-185), severity of motor deficit (UPDRS total motor score greater than 20) (OR 6.34, CI 2.17-18.5) and PD onset at greater than 60 years of age (OR 4.12, CI $1.36-12.5)$. We conclude that educational attainment is an important factor in the development of dementia in PD. This supports the observation that educational protection may be generalizable to non- $\mathrm{AD}$ dementia.

\section{KORCZYN AD}

\section{Sackler Faculty of Medicine, Tel-Aviv University, Ramat-Aviv, Israel CREUTZFELDT-JAKOB DISEASE: A DEMENTING
DISORDER WITH EXTRAPYRAMIDAL FEATURES}

Creutzfeldt-Jakob disease (CJD) is the most prevalent of human spongiform encephalopathies. It shares clinical, epidemiological and pathological features with both Alzheimer's disease (AD) and Parkinson's disease (PD). Recent progress in the elucidation of the molecular pathology and biochemistry of CJD may be relevant to progress in the understanding of $\mathrm{AD}$ as well as PD. Both CJD and $\mathrm{AD}$ were defined at the beginning of this century based on unique pathological features. At the same time, Lewy described the pathognomonic bodies bearing his name. The clinical features of CJD, as well as those of $\mathrm{AD}$, are quite heterogeneous. All three diseases occur primarily sporadically, but a clear genetic group exists in each. In CJD as well as in AD, these subgroups were related to specific mutations in 'brain-specific' proteins. Pathological similarities between $\mathrm{AD}$ and $\mathrm{CJD}$ include neuronal loss with occassional white matter lesions. Spongiform changes and amyloid deposition occur in both but in different frequencies. The proteins accumulated in the amyloid plaques in the two diseases differ in their chemical identity. Mutations in the genes encoding these proteins were identified in several familial cases of AD and CJD. The exact relationships between the existence of the mutations and the abnormal procession presumed to affect the respective proteins is unclear, as is the relationship between these factors and neurodegeneration. Most cases of AD, CJD and PD are sporadic rather than familial, and presumably are not related to any genetic mutation. Even in those carrying the specific mutations, pathological and clinical changes occur only after several decades. This is probably due to a second event. A similar event may be responsible for sporadic cases, and the existence of the mutation may merely make the process more likely to occur. The identification of this event may lead to a therapeutic intervention against the progression of these diseases.

\section{LANG AE \\ The Toronto Hospital, Toronto, Canada \\ COGNITIVE AND PSYCHIATRIC FLUCTUATIONS IN PARKINSON'S DISEASE}

Cognitive disturbances and psychiatric complications of dopaminergic therapy are well recognized features of Parkinson's disease. Less common and less well appreciated are the fluctuations in cognitive and psychiatric status that patients may experience in response to varying levels of dopaminergic stimulation throughout the day. Neuropsychological testing has demonstrated variable changes in cognitive function when patients are studied boih in the 'on' and the 'off' states. In some studies cognitive disturbances have increased when the patients were 'off'; however, in others improvement has been seen. Mood changes may accompany motor fluctuations, sometimes with pronounced depression occurring in the 'off' periods and occasionally manic episodes accompanying 'on' periods. Rarely, an unmasking of latent sexually deviant behaviour may accompany this latter disturbance. A number of other psychiatric abnormalities may also accompany motor fluctuations, including hallucinations, anxiety, screaming and panic. At times, these non-motor components of the fluctuations are a greater source of disability than are the changes in parkinsonism. These disturbances are probably much more common than is currently appreciated. Further study is required to determine the frequency and spectrum of these disorders, as well as any additional features that correlate with their presence and possibly predict their occurrence, and finally their response to therapeutic interventions.

\section{LIEBERMAN A}

Barrow Neurological Institute, St. Joseph's Hospital and Medical Center, Phoenix, AZ, USA

\section{WHAT IS THE OPTIMUM APPROACH ONCE SERIOUS DISABILITY THREATENS THE PATIENT WITH PARKINSON'S DISEASE?}

Advanced Parkinson's disease is characterized by a decreased response to levodopa, complex response fluctuations, dyskinesia and dystonias, postural instability, and a variety of mental changes. The major therapeutic consideration is optimizing levodopa levels. Several different modalities are used including liquid Sinemet, Sinemet infusion pumps, and COMT inhibitors (tolcapone). For patients in whom dyskinesias are a problem and who are no longer responding to parlodel, some options include substituting a new agonist: cabergoline, ropinirole or pramipexole. Surgery is another option, including thalamotomy for unresponsive tremor and pallidotomy for severe dyskinesias and dystonias and postural instability. Best results are obtained with stereotactic procedures, but gamma knife pallidotomy is useful for elderly patients. Fetal transplants 
are done in younger individuals (below age 60) with severe response fluctuations. Gene therapy will soon be an option. MRI and deoxyglucose PET scanning are useful in excluding atypical PD patients. Clozapine is useful in treating patients with mental changes related to levodopa.

\section{LIEBERMAN P AND FRIEDMAN JH \\ Cognitive and Linguistic Sciences and Parkinson's Disease and Movement Dis. Unit, Brown University, Providence, RI, USA \\ SPEECH MOTOR AND COGNITIVE DEFICITS OF PARKINSON'S DISEASE}

The production of human speech entails precise motor coordination. For example, stop consonants distinctions such as [b] versus [p] necessitate regulating the time interval between the 'burst' produced when a speaker's lips open. The onset of periodic phonation produced by having Parkinson's disease (PD) reveals deficits in the regulation of this fine motor timing similar in nature to those noted for Broca's aphasia. PD subjects having these speech motor timing deficits also tend to have cognitive deficits. ANOVAs indicate that Voice Onset Time (VOT) overlap subjects had significantly higher syntax error rates and longer response times on the Rhode Island Test of Language Structure (RITLS) than VOT non-overlap subjects: $F(1,70)=12.38, p<0.0008 ; F(1,70)=7.70$, $p<0.007$, respectively. The correlation between number of VOTtiming errors and number of syntax errors was significant: $r=0.6473$, $p<0.01$. VOT overlap subjects also had significantly higher error rates in cognitive tasks involving abstraction and ability to maintain a mental set. The pattern of deficits may derive from degradation of basal ganglia pathways to prefrontal cortex. The procedures used to determine these deficits can potentially serve as quantitative metrics of the disease process and to evaluate the effectiveness of different treatment regimens.

\section{LITVAN I AND GRAFMAN J}

Neuroepidemiology Branch and Cognitive Neuroscience Section, NINDS, National Institutes of Health, Bethesda, MD, USA

\section{PROGRESSIVE SUPRANUCLEAR PALSY: A STRUGGLE TO THINK}

Cognitive disturbances were reported in the original description of progressive supranuclear palsy (PSP). However, impaired cognition is not always considered as a criterion to diagnose PSP. In our research, long-term memory is affected in PSP but less so than in Alzheimer's disease. Similar to what is found in other basal ganglia disorders, procedural learning is impaired while short-term memory and perceptual priming are preserved. Executive dysfunction and slowed central information processing appear early in the course of PSP. These last two processes are characteristic of PSP and distinguish it from other dementias. Evidence from functional neuroimaging studies indicates that PSP patients have frontal hypometabolism, suggesting that frontal deafferentation secondary to basal ganglia lesions is the cause of their dementia.

LITVAN I, BLESA R, NICHELLI P, MOURADIAN MM, CLARK K, GRAFMAN J AND CHASE TN $N E B, E T B, C N S, N I N D S, N I H$, Bethesda, USA

\section{WHAT CAN SCOPOLAMINE TELL US ABOUT THE INTEGRITY OF THE CHOLINERGIC SYSTEM IN PROGRESSIVE SUPRANUCLEAR PALSY?}

Severe cholinergic loss occurs in the forebrain, basal ganglia and brainstem of patients with progressive supranuclear palsy (PSP). However, inconsistent effects on PSP cognitive impairment without motor changes have been found following cholinergic stimulation using oral physostigmine. In order to further investigate whether the disease-related cholinergic loss in the brain of PSP patients produces an abnormal sensitivity to anticholinergics, a group of PSP patients underwent cholinergic blockade with intravenously injected scopolamine in conjunction with neurobehavioral testing. Scopolamine at low $(0.15 \mathrm{mg} /$ body surface area), medium $(0.20)$ and high $(0.25)$ doses was administered to 7 PSP patients and 7 healthy matched controls. Low and medium doses of scopolamine impaired the memory performance of both groups, but worsened the gait of only PSP patients. High dose scopolamine $(0.44$ $\mathrm{mg}$ ), which could not be tolerated by patients, resulted in gait deterioration among control subjects. Loss of cholinergic neurons appears to contribute to the pathogenesis of certain cognitive and motor deficits found in PSP. Therefore, anticholinergics should be used with caution in this disorder.

LOPEZ DEL VAL J AND LOPEZ DEL VAL A

Servicio de Neurologia, Hosp. Clinico Universitario, Zaragoza, Spain

\section{COGNITIVE FUNCTIONS IN PARKINSON'S DISEASE:} EVALUATION OF PROGRESS THROUGHOUT ONE YEAR

A study was made of 45 patients with a diagnosis of PD. During one year, three clinical controls (Hoehn-Yahr scale, NWDS) and two studies of higher mental functions were performed, including: WAIS (for the evaluation of intellectual, verbal and manipulative coefficient, together with subtests for comprehension, vocabulary, incomplete figures and cubes); a left-right orientation test (Benton); a temporal orientation test (Benton); a serial digit learning test; a vascular dementia scale (Hachinski) and the drawing-a-bike test (Lezak). All the data obtained were collected for analysis on a procedure form, using STATVIEW-512 statistical sofware. During the analysis a search was made for correlations between age at the onset of the illness, time of its evolution, medication given to the patient, previous education and abnormalities in higher functions of the patients studied. The results indicated that the most altered higher mental functions were those which involve attention and manipulation, and to a lesser degree, memory. In the first control, $11 \%$ presented mild dementia, $51.1 \%$ presented partial deficits and $28.8 \%$ were normal. In the second control, dementia was found in $11.1 \%$ of the patients, $8.8 \%$ presented mild dementia, $46.6 \%$ partial deficits and $33.3 \%$ were normal.

\section{McGEER PL, TOOYAMA I AND KLEGERIS A}

Kinsmen Laboratory of Neurological Science and the Neurological Disorders Centre, University of British Colombia, Vancouver, BC, Canada; and Institute of Molecular Neurobiology, Shiga University of Medical Science, Otsu, Seta, Japan

\section{GROWTH FACTORS AND IMMUNE PRODUCTS AS POTENTIAL CAUSES OF NEURONAL DEATH IN PARKINSON DISEASE}

The cause of death of dopaminergic neurons of the substantia nigra $(\mathrm{SN})$ in Parkinson disease (PD) is still a mystery. A slow dropout of these neurons occurs throughout normal life, but is accelerated in PD. Considerable emphasis is currently being placed on the ability of neuronal growth factors to sustain viability in vitro and to rescue neurons from various lesions in vivo. Basic fibroblast growth factor (bFGF) is one of the most powerful of these in its actions upon dopaminergic neurons. We found a dramatic depletion of bFGF in surviving SN neurons in $\mathrm{PD}(8.2 \%$ of $\mathrm{PD}$ vs. $94 \%$ of control melanin positive neurons). These data suggest that bFGF depletion may play a causal role in the neuronal death of PD, 
and that bFGF stimulation therapy might be beneficial. Immune system changes occur in the SN in PD, particularly activation of microglial cells. Reactive microglia are often seen surrounding the surface of dopaminergic neurons. The respiratory burst in activated microglia powerfully produce toxic oxygen free radicals (OFR), which may inflict damage on SN neurons. We have also shown that activated microglia express MAOB, but not MAOA. MAOB inhibitors, such as deprenyl, may provide some protection by limiting OFR production.

\section{McKEITH IG, FAIRBAIRN AF, PERRY RH, BRIEL R AND HARRISON R \\ University Department of Old Age Psychiatry, Brighton Clinic; and MRC Neurochemical Pathology Unit, Newcastle General Hospital, Newcastle upon Tyne NE4 6BE, UK}

\section{CLINICAL FEATURES OF LEWY BODY DEMENTIA}

Several recent autopsy surveys of elderly patients dying with dementia suggest that $15-20 \%$ have neuropathological features distinguishable from Alzheimer's disease and characterised by subcortical and cortical Lewy body formation. Analysis of case notes of 21 such patients with autopsy confirmed Lewy body dementia showed a clinical syndrome of fluctuating cognitive impairment, visual and auditory hallucinations, delusions, depressed mood, repeated falls, transient disturbances of consciousness and mild spontaneous extrapyramidal features. Clinical operational criteria for the lifetime diagnosis of Lewy body dementia derived from this study were examined for inter-rater reliability and predictive validity in a second independent sample $(n=20)$ of autopsy confirmed Lewy body cases. Adverse reactions were seen in $81 \%$ of neuroleptic treated Lewy body patients. In $54 \%$ of such cases the reactions were severe with acute extrapyramidal symptoms and features reminiscent of neuroleptic malignant syndrome. Patients with severe neuroleptic sensitivity had a shorter mean survival time from presentation, 9.6 months (2.6-16.5) compared with the rest of the group, 25.8 months (11.5-40.0), and survival analysis showed them to have a significantly increased hazard ratio of $2.70,\left(\chi^{2}=2.68\right)$.

\section{McKEITH IG, FAIRBAIRN AF, PERRY RH AND THOMPSON P University Department of Old Age Psychiatry, Brighton Clinic; and MRC Neurochemical Pathology Unit, Newcastle General Hospital, Newcastle upon Tyne NE4 6BE, UK \\ THE CLINICAL DIAGNOSIS AND MISDIAGNOSIS OF SENILE DEMENTIA OF LEWY BODY TYPE (SDLT) - DO THE DIAGNOSTIC SYSTEMS FOR DEMENTIA NEED TO BE REVISED?}

Several recent autopsy studies have suggested that senile dementia of Lewy body type (SDLT) associated with subcortical and cortical Lewy body (LB) formation may account for $15-20 \%$ of all cases of dementia in the elderly, making it the second most common cause after dementia of Alzheimer type (DAT). The clinical classification systems currently in use have been designed to identify DAT and multi-infarct dementia (MID) predominantly and have no specific category for SDLT patients. We have recently identified fluctuating confusion in the presence of either (a) visual/auditory hallucinations, or (b) mild spontaneous Parkinsonism/sensitivity to neuroleptics, or (c) transient disturbances of consciousness/falls, as characteristics distinguishing SDLT patients. ${ }^{1}$ A range of clinical diagnostic criteria for DAT, MID and SDLT have been applied to the detailed case notes of 20 autopsy confirmed SDLT cases, these being randomised with DAT and MID cases, and rated blind to pathological diagnosis. Although up to $85 \%$ of SDLT cases could be correctly identified using the Newcastle criteria for SDLT, the majority also erroneously met criteria for MID (35\% with Hachinski scores $\geq 7$ ) or DAT ( $15 \%$ by NINCDS 'probable AD', $35 \%$ by DSM-III-R DAT, and $50 \%$ by NINCDS 'possible AD'). The implications of these findings for the clinical diagnosis of dementia subtypes is discussed with particular reference to existing concepts about the clinical heterogeneity of DAT.

1. McKeith IG, Percy RH, Fairburn AF, Jabeen S and Percy EK. Operational criteria for senile dementia of Lewy body type (SDLT). Psychol. Med. 1992, 22, 911-922.

\section{McSHANE R, McDONALD B, READING M, ESIRI M} AND HOPE RA

Dept. Neuropathology, Radcliffe Infirmary, Oxford OX2 6HE, UK

\section{PSYCHOSIS AND LEWY BODIES IN ALZHEIMER'S DISEASE}

Method: The behaviour of a series of patients with dementia was prospectively assessed by a questionnaire administered to their main carer every 4 months over a period of up to 5 years until death. Forty-one cases satisfied CERAD criteria for definite or probable Alzheimer's disease. Four cortical areas were assessed semi-quantitatively for $\mathrm{AD}$ pathology and the number of cortical Lewy bodies (LBs) was counted. These assessments were all made blind to symptom status and, importantly, blind to pathology in the substantia nigra (SN) and to each pathology in each of the other areas. The $\mathrm{SN}$ of 21 of the $41 \mathrm{AD}$ cases were also examined (the remaining 20 were not available). Results: $8 / 41$ had cortical LBs. 5/21 had LBs in the SN, of whom 4 had LBs in at least 2 of the 4 cortical H\&E sections. Patients with cortical LBs were significantly more likely to have ever been paranoid $(p=0.04)$ and there was a trend towards having had hallucinations $(p=0.051)$. Paranoia was associated with LBs in the cingulate gyrus but not in other areas. Patients with cortical LBs were likely to be more persistently hallucinated and paranoid than those without. They also had more severe hallucinations, but not more severe paranoia, than those without cortical LBs. Analysis of covariance revealed that symptom severity and persistence was dependent on the presence of cortical LBs but not on the presence of LBs in the SN nor on the severity of dementia at death. A simple measure of the intensity of cortical LB involvement was significantly correlated with both the severity and persistence of hallucinations and paranoia. Conclusion: This study provides prospective evidence of an association between the presence of cortical Lewy bodies and the phenomena of hallucinations and paranoia in demented patients with $\mathrm{AD}$.

\section{MAJOOR-KRAKAUER D, OTTMAN R AND ROWLAND LP}

GH Sergievsky Center and Epidemiology Division, School of Public Health, Columbia University, New York, NY 10032, USA; Department of Clinical Genetics and Department of Epidemiology and Biostatistics, Erasmus University, Rotterdam, The Netherlands; Epidemiology of Brain Disorders Research Department, New York State Psychiatric Institute, New York, NY 10032, USA; Department of Neurology, Columbia University, New York, NY 10032, USA

\section{FAMILIAL AGGREGATION OF AMYOTROPHIC LATERAL SCLEROSIS, DEMENTIA AND PARKINSON'S DISEASE: EVIDENCE OF A SHARED GENETIC SUSCEPTIBILITY}

An association of classical amyotrophic lateral sclerosis (ALS) with dementia, parkinsonism or both has been long suspected, raising the hypothesis of a shared genetic susceptibility to the three disorders. We compared 151 newly diagnosed ALS patients with 140 controls, in terms 
of cumulative incidence of ALS, Parkinson's disease (PD) and dementia in parents, siblings, and grandparents. We used Cox proportional hazards analysis to compute rate ratios (RRs) for ALS, dementia and PD in relatives of cases versus relatives of controls. The risk for dementia was significantly higher in relatives of ALS patients $(\mathrm{RR}=1.9,95 \% \mathrm{CI}$ 1.1-3.1). In relatives of ALS patients the cumulative incidence for dementia to age 90 was $15.4 \%$ (S.E. $2.9 \%$ ) and $7.5 \%$ (S.E. $2.1 \%$ ) in relatives of controls. Risk of PD was increased 5.6-fold in relatives of familial ALS patients, and 1.7-fold in relatives of sporadic ALS patients, but neither of these differences was statistically significant, possibly due to insufficient statistical power with the available sample size. These findings indicate that ALS and dementia, and perhaps also PD, co-occur within families more often than expected by chance, suggesting there may be a shared genetic susceptibility to these three disorders. Genetic heterogeneity of ALS and dementia has been proven. The familial cooccurrence of ALS, dementia and PD may represent a distinct genetic subtype. It would be interesting to investigate whether, in some families with ALS, dementia and/or PD, all three disorders may be linked to the same genetic defect, and if so to determine the factors responsible for variability in expression.

\section{MALASHKHIA YUA, GELADZE M AND KUKAVA M}

Institute of Clinical Immunology and Allergology, Tbilisi, Republic of Georgia

\section{TRANSMITTER DEFICITS IN DEMENTIA OF PARKINSON'S DISEASE}

The aim of the work was to study the participation of lymphocytes synthesized lymphokines in the functions of human memory. To ascertain the possibility of synthesis by CSF and blood lymphocytes of $\beta$-endorphin and acetylcholine-like substrate (ALS), CSF and blood lymphocytes were cultivated for 5 days and their concentration determined in supernatant fluid (SNF) by the radioimmune analysis method. Sixteen patients with Parkinson's disease (PD) and 15 patients of the same age (50-70 years) without marked symptoms of nervous system lesion were studied. Results were as indicated in the table below.

\begin{tabular}{lccccc}
\hline & \multicolumn{2}{c}{$\begin{array}{c}\text { B-Endorphin-SNF } \\
(\mathrm{pg} / \mathrm{ml})\end{array}$} & & \multicolumn{2}{c}{$\begin{array}{c}\text { ALS-SNF } \\
(\mathrm{N} \mathrm{mol} / \mathrm{l})\end{array}$} \\
\cline { 2 - 3 } & Blood & CSF & & Blood & CSF \\
\hline PD & $1.1 \pm 0.4$ & $2.2 \pm 0.3$ & & $95.2 \pm 32$ & $83 \pm 35$ \\
Control group & $4.0 \pm 0.1$ & $12.1 \pm 1.2$ & & $280 \pm 75$ & $96 \pm 42$ \\
\hline
\end{tabular}

Besides lymphocytes, the source of $\beta$-endorphin and ALS in CSF may be provided by neuroglial cells, etc. The investigations carried out allow us to assume that blood and CSF lymphocytes synthesize mediators of immunopeptides, nature-memory immunomodulator $\beta$-endorphin and memory lymphotransmitter ALS analogous to mediators and immunomodulators synthesized in brain neurons. Obviously, mediators and ALS synthesized in lymphocytes provide the information transfer from immune system cells to those of the nervous system.

MARDER K, COTE L, TANG M, STERN Y, MAESTRE G, TYCKO B AND MAYEUX R

Columbia University College of Physicians and Surgeons, New York, USA

THE RISK AND PREDICTIVE FACTORS ASSOCIATED WITH DEMENTIA IN PARKINSON'S DISEASE
Parkinson's disease is the third most common cause of dementia in the elderly. Between 1 April 1988 and 31 December 1991, 175 patients meeting criteria for idiopathic PD without evidence of dementia were identified in the community of Washington Heights-Inwood in New York City. Twenty seven patients became demented over the next two years. Antecedent risk factors for incident dementia in this cohort were an extrapyramidal sign score of $>25(\mathrm{RR} 3.56,95 \% \mathrm{CI}=1.4-8.9)$ and a Hamilton Depression Rating Scale (HAM) $>10$ (RR 3.55, 95\% CI = 1.6-7.9). A principal components factor analysis of the baseline extrapyramidal signs yielded three factors representing tremor, rigidity and a composite factor representing gait, postural stability, bradykinesia and rapid alternating movements. Only the composite factor was associated with the development of dementia (RR 3.9, 95\% CI $=1.5-9.9$ ). When nondemented PD patients were compared to nondemented community residents free of neurological disease, the RR for the development of dementia was $1.7(95 \% \mathrm{CI}=1.1-2.7)$, after adjusting for age, education and gender. Dementia in PD may be unique, and not represent $\mathrm{AD}$. In a separate analysis, we determined the Apo-E genotypes for 79 patients with PD, 22 of whom were demented, and 44 age matched controls. We hypothesized that if the dementia was similar to $\mathrm{AD}$, there would be a higher allelic frequency of ApoE4 in demented PD patients compared to nondemented patients and controls. ApoE4 allelic frequencies were not significantly different in the three groups, suggesting that the biological basis for dementia in PD may differ from that of $\mathrm{AD}$.

MARKAROV G, MARKAROVA I AND SHULMAN Z

Hospital 83, Lipetskaya 13-47, Moscow 115598, Russia; and RAMBAM-International Institute of Medicine, Jerusalem, Israel

QUASI-STATIONARY ELECTROMAGNETIC FIELD OF WEAK INTENSITY, BALNEOTHERAPY AND DRUGS IN DEMENTIA PARKINSON PATIENTS

It is possible that remote control of brain bioelectrical activity, haemodynamic and behavioral reactions occurs by selective frequencies of weak electromagnetic field (EMF). This is confirmed indirectly by findings of the dependence of efflux of calcium ions from brain tissue upon frequencies of EMF, as well as in our earlier works the 'window' effects of some EMF frequencies on brain activity in hypertonic, asthenic patients. Also, balneotherapy (BT) is known to have a positive effect on the neurohaemodynamic in humans. The aim of our study was to confirm the possibility of control of brain activity by EMF, and check the treatment effectiveness of EMF and BT in dementia parkinson patients (DPP). All the patients (97) suffering from dizziness, tremor, headache were examined by a double blind method, divided into one main and four control groups, and received the following therapy $(D=$ drugs): Main group (37 DP), EMF+BT+D; Group 1 (15 DPP), EMF-placebo+BT+D; Group 2 (15 DPP), BT+D; Group 3 (15 DPP), D; Group 4 (15 DPP), EMF+D. The EMF-30-57 Hz was generated by an Infita device. BT was achieved by sea bath. Drugs were identical in all DPP. The research showed best results in the Main group and Group 4, more pronounced in the Main group, where EMF, BT, D were used. We noted in the groups where EMF was used a reduction of headache, dizziness, memory improvement, decrease of tremor, optimization of the alpha-, beta-, tetraamplitude indices of EEG, and improvement of neurohaemodynamic. Arresting of headache was dependent upon the EMF frequency. It is clear from this study that EMF therapy improves intracortex communications, optimizes brain activity and neurohaemodynamic and in combination with sea bath gives a good result in DPP. The research allows discussion of the role of 'window-like' effects of EMF frequency in the treatment of Parkinson's disease patients. 
MARTIGNONI E, SINFORIANI E, PACCHETTI E, MARTELLI A, GODI L, MAURI M AND NAPPI G

Parkinson's Disease Centre, Neuropsychological Unit and Neuroradiological Service, IRCCS, C. Mondino, University of Pavia, Italy

\section{COGNITIVE DYSFUNCTIONS IN PATIENTS WITH MULTI-SYSTEMIC ATROPHY}

In contrast to the abundant literature on cognitive dysfunctions in Parkinson's disease, little research has been performed in patients with multi-systemic atrophy (MSA). In this study 12 patients with MSA aged between 52 and 72 years (median: 62) were administered a neuropsychological protocol exploring memory, language, visuo-spatial and logic functions and frontal abilities; the data were then compared with findings of nuclear magnetic resonance (NMR) imaging. In 4 out of 12 patients the cognitive performance was within the normal range. Three subjects showed a widespread impairment of discrete degree: neither overt dementia, however, nor involvement of the so-called cortical functions, like aphasia, agnosia, apraxia, were detectable in any case. Five patients performed worse than the normal control group on memory measures and on tests exploring frontal functions (Verbal Fluency, Weigl's test, Stroop test). No relation was observed between clinical variables, disease duration in particular, and neuropsychological parameters. NMR findings showed, besides the pictures typical for MSA, a diffuse cortical atrophy in 6/12 patients. Four out of these subjects presented cognitive impairment, but we did not find any relation between the neuropsychological profile (diffuse versus frontal dysfunction) and neuroimaging.

\section{MAYER RJ, FERGUSSON J, LANDON M, LENNOX G AND LOWE J \\ Departments of Biochemistry, Neurology and Pathology, University of Nottingham Medical School, Queen's Medical Centre, Nottingham, UK}

\section{CORTICAL LEWY BODIES: ROLE IN DEMENTIA AND PARKINSON'S DISEASE}

A significant number of patients initially presenting with parkinsonian symptoms subsequently become demented; the converse applies for some patients. Ubiquitin immunocytochemistry reveals that cortical intraneuronal Lewy bodies are not rare cellular inclusions but are widespread in the cortex. The number of cortical Lewy bodies correlates with the clinically determined extent of dementia. Diffuse Lewy body disease accounts neuropathologically for $15-30 \%$ of cases coming to autopsy with dementing illness. Lewy body disease is therefore the second most common cause of dementia after Alzheimer's disease. Lewy body disease can now be clinically distinguished from Alzheimer's disease and routinely diagnosed. A further characteristic of Lewy body disease is the presence of ubiquitin-protein conjugates in abnormal neurites of the CA2-3 regions of the hippocampus. Cortical Lewy bodies contain phosphorylated neurofilaments and some molecularly uncharacterised forms of ubiquitin-protein conjugates. Additionally, Lewy bodies may contain a ubiquitin carboxyl-terminal hydrolase, proteosomes, and $\alpha \mathrm{B}-$ crystallin. The reason for the formation of Lewy bodies and their mechanism of biogenesis is not known. Comparison with events in model systems and in other neurodegenerative diseases indicates that the extensive reorganisation of neurofilaments may be to generate an intracellular 'cocoon' in order to isolate and degrade damaged proteins or organelles. Lewy body formation may be part of a neuronal cytoprotective system designed to eliminate unwanted or toxic proteins from the cell. Failure of this system may result in the activation of programmed neuronal death to give the extensive cellular loss associated with neurodegeneration and dementia in parkinsonian patients.
MILDWORF B, OSCAR-BERMAN M, KAPLAN E, ALBERT MA, TREVES TA AND KORCZYN AD

Boston University, Boston, MA, USA; and Tel Aviv Medical Center, Tel Aviv, Israel

\section{PERCEPTION AND MEMORY FOR VISUAL AND AUDITORY COMPONENTS OF EMOTIONAL MATERIALS IN ALZHEIMER'S DISEASE AND PARKINSON'S DISEASE}

Objective: To compare Alzheimer's disease (AD) patients and Parkinson's disease (PD) patients in perception of emotional expressions in two sensory modalities. Background: Patients with AD and PD often exhibit changes in emotional status and personality. However, their ability to comprehend emotional materials, as well as the brain regions involved in emotional functions, are incompletely defined. Design: Tasks measuring perception in two modalities-vision (using photographs of facial expressions) and audition (using spoken sentences differing in emotional intonations and semantic content)--were administered to $11 \mathrm{AD}$ patients, 22 PD patients and 11 normal controls. The subjects were required to identify and rank the intensity of the emotion expressed in the photographs and sentences. Results: The $\mathrm{AD}$ patients rated facial emotions more intensely than nondemented PD patients and controls. PD patients with dementia rated them as having less intensity than the nondemented PD patients and controls. Results of neuropsychological evaluation suggested that emotional abnormalities were related to severity of dementia, memory impairment, frontal dysfunction and age. Conclusion: $\mathrm{AD}$ and equally demented $\mathrm{PD}$ patients differ in impairments of emotional comprehension in two sensory modalities. Damage to cortical and subcortical systems is implicated in both diseases.

MIZUNO Y, IKEBE S, HATTORI S, HATTORI Y, MOCHIZUKI H, NISHI K, YOSHINO H, KONDO T AND IMAI H

Department of Neurology, Juntendo University School of Medicine, Tokyo, Japan

\section{OXIDATIVE STRESS AND MITOCHONDRIAL RESPIRATORY DEFECT IN PARKINSON'S DISEASE}

Although the primary cause of nigral cell death in Parkinson's disease (PD) is still unknown, oxidative stress and mitochondrial respiratory failure appear to play an important role. Oxidative stress: Evidence to indicate oxidative stress in PD includes decrease in reduced glutathione, increase in superoxide dismutase activities, elevation in lipid peroxidation, and accumulation of iron in the substantia nigra. Ferrous iron catalyzes the Fenton reaction to produce hydroxyl radicals which may damage nigral cells in a number of ways including lipid peroxidation, damage to DNAs, inhibition of sulfhydryl enzymes, and protein cross linking. We tested toxicity of iron using mesencephalic culture, which showed decrease in TH-positive cells and increase in lipid peroxidation when incubated with iron-ADP and dopamine-melanin. Mitochondrial respiratory defect: We and other groups have found decrease in mitochondrial complex I in PD; however, complex I deficiency does not appear to be the primary defect, as many nigral neurons still retained ample immunoreactivity for complex I in our study. Regarding mtDNA, we found an increase in deleted $\mathrm{mtDNA}$ in $\mathrm{PD}$, and we could demonstrate this deleted mtDNA to be localized in some of the nigral neurons by in situ hybridization, but many neurons also contained normal mtDNA. Therefore, we raised a question whether or not mitochondrial respiratory failure really plays a role in $\mathrm{PD}$, and we decided to study another important mitochondrial enzyme, that is, $\alpha$-ketoglutarate dehydrogenase $(\mathrm{KGDH})$ complex, the rate-limiting enzyme of the TCA-cycle. Nine patients and 6 control subjects were studied by immunohistochemistry for the KGDH complex; immunostaining was markedly reduced in the lateral part of the substantia nigra in PD. A rough correlation was present 
between the severity of degeneration and the loss of immunoreactivity. As complex I is already diminished in PD, electron transfer may be shifted towards the complex II to complex III pathway; but for effective electron transfer via this pathway, supply of succinate is mandatory; in the presence of loss of KGDH complex, supply of succinate may be deficient, and thus dual loss of complex I and the KGDH complex may deleteriously affect the electron transport. Mitochondrial respiratory failure appears to play an important role in PD.

\section{MOHR E, BROUWERS P, PURDON SE, GAGNON M AND CHASE TN \\ Institute of Mental Health Research, Ottawa, Ontario, Canada; and National Institutes of Health, NCI, NINDS, Bethesda, MD, USA \\ DIAGNOSIS OF PARKINSONIAN DEMENTIA}

The diagnosis of dementia in Parkinson's disease (PD) continues to be based on clinical criteria. While general guidelines (DSM-III-R) are available, their utility in the distinction of the mild cognitive deficits ubiquitous in PD and PD dementia may be limited. Further, current evidence suggests that there may be distinct dementia subtypes present in this illness. To ascertain possible characteristic patterns of dementia, age-scaled neurobehavioral test results were used to derive a discriminant function, based on test performance of 19 Alzheimer's patients (DSMIII-R and NINCDS-ADRDA criteria), 19 patients with Huntington's disease (positive family history, evidence of striatal atrophy on CT scan and abnormal neurological exam) and 29 neurologically normal controls. Both patient groups were matched for overall level of intellectual functioning on the basis of their Full Scale IQ (AD $90 \pm 2.3$, HD $90 \pm 2.6$ ). Variables discriminating between $\mathrm{AD}$ and $\mathrm{HD}$ patients consisted of complex psychomotor tasks, attention and memory. The discriminant function was then applied to $45 \mathrm{PD}$ patients, who were otherwise unselected. All testing in this group was done while patients were 'off'. Approximately $1 / 3$ of all PD patients were classified as demented. Of these demented patients, almost $2 / 3$ evidenced a subcortical (HD-like) pattern of dementia, while $1 / 3$ demonstrated a cortical, AD-like configuration of deficits. The reliability of this discriminant formula was then tested with an independent, new sample of $\operatorname{AD}(N=10)$ and $\operatorname{HD}(N=20)$ patients with results closely resembling those of the original sample. Results were essentially identical. Neuropsychological measures may thus be useful in discerning dementia subtypes and, in the absence of biological markers, may provide an avenue for more valid diagnostic classification of patients with secondary or coincidental dementia.

\section{MRCHEV SJ}

Ul. 'Yordan Yovkov' 21A, 8600 Jambol, Bulgaria

\section{NEURON MODELS (DISCRETE, ANALOGUE, FUZZY) FOR HUMAN MEMORY MODELLING}

Study of neuron memory and learning is attacked at four levels: (1) a system structure-functional level (the mnemo-functions described by psychology are projected on already known morpho-functional brain structures of memory); (2) neuron-neuroglia networks (ensembles, populations, microsystems, realizing partial memory and learning functions); (3) a neuron and neuro-gliaes as a system (a neuron-neuroglia complex as a multiheterosynapse network, realizing the tracing); (4) a sub-cell level (neuro-chemical processes in the cell). Three models of the system 'neuron-neurogliaes' are suggested: discrete (numerical), continuous (analogue) and polyfunctional (fuzzy). Memory mechanisms are described in terms of these: short-term memory, the trace abates and disappears as time passes; long-term memory, the trace does not disap- pear as time passes. For the three models determined, stochastic and fuzzy networks are described, realizing the global functions remembering $(\mathrm{R})$, storing (S) and reproducing (RP) in short-term ( $R$, creating of neurodynamics; $S$, stability; $R P$, reproduced neuro-dynamics) and longterm $(R$, creating of a structure organization; $S$, strengthening and preserving of the structure; RP, activating of the structure) human memories.

\section{MRCHEV SJ}

Ul. 'Yordan Yovkov' 21A, 8600 Jambol, Bulgaria

\section{STOCHASTIC MODEL OF MULTICHANNEL TRANSPORT MNEMO-NEURON SYSTEM}

A random process $\xi(t)$ is investigated, which describes oscillations of the potential quantities of the neuron with infinite (finite number of synapses $=1000$ to 10,000 ) capacity, as a potential of transport means (synaptic contacts) is brought to the neuron. The transport means are loaded on $C \geq 1$ number of parallel devices (service channels) with final speed $j$, and from that potential we continually draw constant speed $U>0$ (if the neuron is 'non-blank'). The flow of transport means (axons and dendrites) is supposed to be simple with parameter $\lambda$, and the potential brought from the transport means is an independent random value which is distributed by the exponent law with the average $g$. The length of the transport queue is not limited. For such a transport neuron system investigation a specific type of random process is introduced. It is a semi-Markov process which is equal to the number loaded with a potential transport means at the moment $t$. Suppose $\left\{t_{n}\right\}, n \geq 1$ is a sequence of the moments of the states variations of the process $V(t)$, then $\xi\left(t_{n}+0\right)$ forms a homogeneous chain of Markov. We designate: $\Phi_{k n}(X)=P\left\{\xi\left(t_{n}+0\right) \geq X, \mathrm{~V}\left(t_{n}+0\right)=K\right\}, F_{k}(X, t)$ $=P\{\xi(t) \geq X, V(t)=K\}, K=0, C ; X \geq 0$. The condition of the ergodicity of the chain $\xi\left(t_{n}+0\right)$ is the inequality $V>\lambda \cdot g$. It is shown that the stationary functions of distribution $\Phi_{k}(X)=\lim _{n \rightarrow \infty} \Phi_{k n}(X)$ satisfy a certain system of linear integral equations of the type of turning the semiaxis. With the help of the two-facet conversion of Laplas-Stilltes this system of equations comes down to the vector short task of Riman for the semi plane which is solved by the method of factorization of the matrix coefficient in finite conditions.

\section{MUENTER MD, HOWARD FM, OKAZAKI H,}

MARAGANORE DM, CASELLI RJ, FORNO LS, KISH SJ, HORNYKIEWICZ O, CALNE DB AND SNOW BJ

Mayo Clinic, Rochester, MN and Scottsdale, AZ, USA; VA Medical Center, Palo Alto, CA, USA; Clarke Institute of Psychiatry, Toronto, Ontario, Canada; and University of $B C$, Vancouver, Canada

\section{HEREDITARY PARKINSONISM-DEMENTIA}

We analyzed in a family with dominantly inherited parkinsonismdementia clinical, pathological and biochemical correlates. Thirteen members in four generations were affected. The clinical picture of parkinsonism was followed by memory loss, progressing to severe dementia. Autopsies were obtained in four afflicted siblings. The neuropathological picture shared features with advanced Parkinson's disease of Lewy body type and Lewy body dementia with widespread, including cortical, Lewy bodies. There was also vaculoation of the temporal cortex and an unusual pattern of nerve cell loss and gliosis in the hippocampus, nerve cell loss in the nucleus basalis of Meynert and bizarre Lewy bodies especially in the hypothalamus. No senile plaques, neurofibrillary tangles or amyloid deposits were present. The biochemical findings in one brain showed profound reduction of dopamine and HVA levels in the 
striatum and of choline acetyl transferase in the frontal and temporal cortex and the hippocampus. PET scans in three cases showed marked reduction of fluorodopa uptake in the striatum. The dementia may be due to nerve cell loss in the anterior and medial temporal lobe, and/or the nucleus basalis of Meynert; the cholinergic deficit is more likely to contribute to the dementia than the dopaminergic deficit.

ÖZER F, DOGU O, HANOGLU L, KARSIDAG S, ATAY T, EZELSOY B AND ARPACI B

Bakirköy State Hospital for Psychiatric and Neurological Diseases, Neurology Department, Istanbul, Turkey

\section{THE RELATIONSHIP BETWEEN DEPRESSIVE SYMPTOMS AND FRONTAL LOBE RELATED TASKS IN PARKINSON DISEASE}

Introduction: It has been proposed in recent reports that there may be a relationship between frontal lobe dysfunction and depressive symptoms in Parkinson disease (PD). In this study, we investigated if there was such an association between frontal lobe related tasks and depressive symptoms in 54 patients with idiopathic PD (IPD). Methods: The participants $(n=54)$ were male $(n=37)$ and female $(n=17)$ patients with IPD, aged 32 to 83 years. Primary symptoms of IPD were evaluated with Webster Scale. Short Test of Mental Status (STMS) was used to appraise general mental status of the patients. Depressive symptoms were assessed with Hamilton Rating Scale for Depression (HRDS) and the patients were assigned in two groups according to their HRDS scores (Group I, HRDS score less than 7; and Group II, 7 or more). Alternant Hand Movements Test (AHMT) and Alternant Sequence Test (AST) of Luria, and Verbal Fluency Tests (Categorical and Alternant) (VFTc, VFTa) were used to evaluate frontal lobe related tasks in participants. Based on the results of these tests, the patients were allocated in two categories: those deemed to have frontal lobe dysfunction and those not. To analyse the results statistically, Student $t$ and $\chi^{2}$ tests were used. Results: The differences for mean ages, mean scores of STMS and WS were not statistically significant between Group I (low HRDS score) and Group II (high HRDS). These groups were also compared according to the results obtained from the tests for frontal lobe related tasks: for AHMT and VFTc. The differences were not significant ( $p>0.23$ and $p>0.11$, respectively); however, when compared according to the results of AST and VFTa, frontal lobe related tasks were found disordered in patients assigned in Group II and the differences for these tests were statistically significant ( $p<0.04$ and $p<0.006$, respectively). In addition, when mean HRDS scores of two categories including patients with or without frontal lobe dysfunction were compared, it was found that mean HRDS scores of the patients with frontal lobe dysfunction were significantly higher $(p<0.01)$. Conclusions: In the patients with IPD, we found that the severity of depressive symptoms and the degree of breakdown of the functions of frontal lobe were correlated.

ÖZER F, HANOGLU L, ALTUNHALKA A, DOGU O, ATAY T, KIZKIN S AND ORAL T

Bakirköy State Hospital for Psychiatric and Neurological Diseases, Neurology Department, Istanbul, Turkey

\section{PSYCHOTIC SYMPTOMS APPEARING WITH THE USE OF ANTIPARKINSONIAN DRUGS}

Introduction: It is known that antiparkinsonian drugs may occasionally cause psychotic symptoms. In previous reports on this issue, it has been proposed that some factors such as old age, presence of mental deterioration and long duration of the disease may cause a tendency for psychotic symptoms to appear. Method: 43 patients with Idiopathic Parkinson's Disease (PD) participated in this study. We applied the Short Test of Mental Status (STMS) and Webster Score (WS). In addition, psychotic symptoms and relationships between these symptoms and the drugs given, and premorbid features of the patients were evaluated. The patients were assigned in two groups: those who experienced pyschotic symptoms (Group I, $n=13$ ) and those who did not (Group II, $n=30$ ). These groups were compared according to mean age, mean duration of the disease and mean scores for STMS and WS, using Student- $t$ test. Results: The incidence of pyschotic symptoms was $30.2 \%$ in our population. The differences for mean age, WS and STMS did not reach statistical significance between the two groups. Mean duration of the disease was significantly higher in Group I $(p<0.05)$. The types of psychotic symptoms appearing in our patients were delirium (in 5 patients), hallucinations (in 8 patients), delusion (in 4 patients) and illusion (in 2 patients). Considering the appearance of a psychotic symptom on the addition of a new antiparkinsonian drug or on increasing dose of the drugs, and the disappearance of this symptom when the drug was discontinued or the dose decreased, it was suggested that the psychotic symptoms were caused by L-dopa in 5 cases, bromocriptine in 4 cases, lisuride in 1 case, biperidene in 1 case and L-dopa + bromocriptine in 1 case. Conclusions: Psychotic symptoms were quite frequent in our patient population. It may be reasonable to prefer an agent which seems less potent at causing psychotic symptoms, like lisuride, in patients who are considered to have a tendency for such symptoms.

PANISSET M, SIMARD M, PAPAGNO C, BOLLER F, CESARO P AND DEGOS J-D

Mc Gill Centre for Studies in Aging, Montreal, Canada; INSERM, U324, Paris; 1 st Neurological Clinic, Milan, Italy; and Hôpital H. Mondor, Créteil, France

\section{CENTRAL EXECUTIVE SYSTEM DEFICITS IN PARKINSON'S DISEASE}

The nature of specific cognitive deficits often encountered in Parkinson's disease (PD) patients is far from being clear. Impairments in the ability to generate strategies or in attention resources have been hypothesized. This paper examines whether a deficit in the central executive system of the Working Memory Model could be responsible for the cognitive deficits of PD. Nine moderately handicapped non-demented PD patients and 13 control subjects were tested with the Mini-Mental State Examination, digit and visuo-spatial spans, the Benton Visual Recognition Test (BVRT), the California Verbal Learning Test (CVLT) and a dual task. Patients and controls were matched for age, education level and MMSE scores. Patients had significantly inferior performances in the CVLT on learning $(p=0.04)$, short and long term free recall ( $p=0.04$ and 0.03$)$. They also had differences that almost reached significance on cued recall, on digit span, on BVRT and on the dual task. Patients' performances on the dual task were correlated with BVRT, Corsi and Learning scores of the CVLT. Our results indicate that non-demented PD patients may have impaired attentional processes which could be responsible in part for some of the neuropsychological deficits.

PEARCE JMS

Hull, UK

\section{THE DIAGNOSTIC CRITERIA FOR DEMENTIA IN PARKINSON'S DISEASE}

Criteria for both dementia and Parkinson's disease (PD) are ill-defined. This position paper discusses problems and applications in diagnosis in 
therapeutic trials. Clinical: (1) Cognitive decline impairing social and work functions \pm inability to care for oneself; (2) impairment of memory and abstract thinking; (3) absence of delirium or clouded consciousness. Severity: Assessment of behaviour and cognition $\rightarrow$ ADL. Histology: SPs and NFTs in neocortex and hippocampus without ischaemic lesions (e.g. Mod > 8/field $\times 200(\mathrm{Ag})$ ). Radiology: CT or MRI volume, densities, linear measurements. Neuropsychology: Mnestic, language, visuospatial function. Blessed, Mini Mental State, DSM, NINCDS-ADRDA criteria; and other scales. Which slice(s) of the cake do we select? How do we interpret drug and behavioural trials of varied criteria and exclusions?

PEPPE A, STANZIONE P, FORMISANO R, BIANCHI P, SANTILLI V AND BERNARDI G

IRCCS Clinica S. Lucia, Roma, Italy

\section{PERG MODIFICATIONS IN POST-TRAUMATIC PATIENTS WITH EXTRAPYRAMIDAL SIGNS AND PARKINSON'S DISEASE PATIENTS}

It is a common clinical experience that extrapyramidal signs in patients after severe brain injury may occur. Retinal electrophysiological studies have shown altered pattern electroretinogram (PERG) in patients affected by idiopathic Parkinson's disease (PD). This finding has been tentatively explained by histochemical data reporting a certain decrease of dopaminergic innervation in PD retina. If PERG alteration and retinal histochemical modifications in PD are strictly related, these findings should not be present in patients affected by post-traumatic extrapyramidal syndrome. The aim of this study was to compare the steady-state PERG responses at two different contrast levels and four spatial frequencies in a control young group, a post-traumatic patients group and a PD patients group. We selected a group of 8 patients with previous severe brain injury. Clear extrapyramidal signs such as hypomimia, bradykinesia, rigidity were present, as well as a good response to levodopa therapy. We selected a group of 6 rigid-akinetic $P D$ patients, $H \& Y 2$, good responders to levodopa therapy. Both groups were recorded after a withdrawal of at least 15 days. The data were compared with two age-matched control groups, by means of a three-way ANOVA. The PD patients group and post traumatic group showed a general decrease of PERG amplitude which was statistically significant only in PD patients. In conclusion, these data support the hypothesis that PERG alteration is related to a dopaminergic retinal deficit.

PÉREZ-VICENTE JA, SAURA-TORRES MJ, PÉREZ-PAGÁN C, BAUTISTA J AND INIESTA J

Div. Neurology, Santa María del Rosell Hospital, Cartagena, Spain

\section{ABNORMALITIES OF LONG-LATENCY SOMATOSENSORY EVOKED POTENTIALS IN PARKINSON'S DISEASE}

Introduction: Altered sensorimotor integration could explain some of the motor difficulties in Parkinson's disease (PD) and abnormalities of shortlatency somatosensory evoked potentials (SEP) have been reported in parkinsonian patients. We studied the long-latency P45 and N60 components of SEP in PD patients with and without dementia. Methods: Fourteen non-demented PD patients, 5 patients with PD and mild dementia (PDD) and 6 age-matched controls were studied with neuropsychological tests and SEP. Cervical, parietal, central and frontal SEP to median nerve stimulation at the wrist were recorded with an earlobe reference. Neuropsychological tests included the Mini-Mental State, a modified version of the Wechsler Memory Scale, the Wisconsin Card Sorting Test and a word fluency test. Statistical analysis was performed by means of a two-tailed Student's test. Results: Significant differences were found in all the neuropsychological tests in the PDD patients with respect to controls and non-demented PD patients. The central conduction time of prerolandic P45 (N13-P45 interval) was significantly reduced $(p=0.04)$ in the PDD patients with respect to controls. No differences were found in the N60 latencies. Conclusions: A depressed frontal N30 wave has been reported in PD and we have found this reduction to be more evident in our PDD patients. The reduced latency of prerolandic P45 in our study coud be related to a decrease of N30 amplitude and may be indicative of altered transcortical loops or an abnormal cortical motor modulation of somatosensory input in PD patients with severe frontal lobe dysfunction.

\section{PERL DP AND OLANOW CW}

Mount Sinai School of Medicine, New York, NY, USA; and University of South Florida, Tampa, FL, USA

\section{OVERLAP SYNDROMES - THE GUAM EXPERIENCE}

An increasing body of clinical and neuropathologic data have suggested substantial overlap between Alzheimer's disease (AD), Parkinson's disease (PD) and ALS. This has led some to suggest that these seemingly separate and distinct diseases may actually represent different manifestations of a singular pathogenetic process. The endemic neurodegenerative disorders encountered among the Chamorro natives of Guam offer a rich model of what is likely a single condition with clinical and pathologic manifestations spanning the full range of AD, PD and ALS. Although originally described as separate entities, namely ALS and parkinsonism dementia complex (PDC), careful clinico-neuropathologic evaluation of cases from Guam reveals numerous examples of PDC with amyotrophy and ALS with evidence of extensive nigral pathology. Furthermore, cases with a somewhat older age of onset have shown a tendency to present with dementia in the absence of amyotrophy or extrapyramidal signs. Some of these cases will eventually develop parkinsonian features but many will demonstrate isolated progressive dementia throughout their course. We have chosen to refer to these latter cases as 'Marianas dementia' (MD), pending further clinical, neuropsychological and pathologic characterization. So far, neuropathologic examination of autopsied MD cases has shown widespread severe neurofibrillary tangle formation with extensive involvement of the hippocampus and neocortex, accompanied by prominent nigral degeneration, and MD appears morphologically indistinguishable from PDC. It is assumed that although the patients encountered on Guam demonstrate a wide range of clinical and neuropathologic patterns of CNS involvement, the phenomenon must represent a spectrum of responses to a single aetiopathogenetic process. Guam remains an important argument suggesting common pathophysiologic mechanisms for the analogous neurodegenerative disorders encountered elsewhere in the world.

\section{PERLOV SM, KAREPOV VG AND KORCZYN AD \\ Tel Aviv University Medical School, Israel}

\section{PRIMITIVE REFLEXES IN DEMENTIA, PARKINSON'S DISEASE AND THEIR COMBINATION}

Primitive reflexes (PR) are manifested among patients with cognitive and extrapyramidal disorders, but the relationship is unclear. We have investigated the frequency of PR and abnormal face-hand test (FHT) among patients with cognitive decline and/or Parkinson's disease (PD). Elderly patients with primary degenerative dementia (PDD, $n=55$ ), Parkinson's disease without dementia (PD-D, $n=69$ ), PD with dementia (PD+D, $n=18$ ), and age associated memory impairment (AAMI, $n=23$ ), 
were compared with an age matched control group of 40 subjects without neurological disorders and among themselves. Results: Abnormal FHT: PD+D 94\%, PDD 71\%, PD-D 48\%, AAMI 26\%, controls 2.5\%. PMR: PD+D 78\%, PDD 38\%, PD-D 41\%, AAMI 26\%, controls 35\%. Snout: PD+D 83\%, PDD 44\%, PD-ID 36\%, AAMI 17\%, controls 13\%. Persistent glabellar tap: PD+D 89\%, PDD 55\%, PD-D 48\%, AAMI 52\%, controls $20 \%$. These results confirm that PR are common among patients with cognitive and extrapyramidal disorders, and particularly when the two conditions co-exist.

\section{PERRY G}

Division of Neuropathology, Institute of Pathology, Case Western Reserve University, 2085 Adelbert Road, Cleveland, $O H$, USA

\section{IS A LEWY BODY ALWAYS A LEWY BODY?}

Lewy bodies (LB) are eosinophilic intraneuronal inclusions associated with degenerating neurons in the subcortical nuclei of Parkinson disease. Ultrastructurally, LB comprise peripheral unbranched $7-20 \mathrm{~nm}$ straight filaments enveloping a dense 'core' of intersecting filaments. The term LB is also applied to 'coreless' eosinophilic filamentous inclusions in diffuse Lewy body disease (DLBD). However, there is considerable controversy regarding whether parkinsonian-LB and DLBD-LB are distinct or a single pathological entity. To answer this question, we undertook epitopic and biochemical studies. Parkinsonian-LB contain neurofilaments, extracellular matrix proteoglycans and ubiquitin; however, diffuse-LB additionally contain a broader array of elements, including $\tau$ and tropomyosin, while they lack extracellular matrix elements. These compositional differences occur even with LB located in the same subcortical neuronal populations. Further, following neuronal death parkinsonian-LB persist in the extracellular space while DLBD-LB are removed. This is consistent with our finding that Parkinsonian-LB filaments are insoluble in denaturants while DLBD-LB are soluble. These findings provide evidence that DLBD-LB are distinct pathological lesions and should not be considered part of the spectrum of Parkinson disease.

Supported by NIH grants AG07552 and AG09287.

\section{PIGGOTT MA, PERRY EK, MCKEITH IG, MARSHALL E AND PERRY RH \\ MRC Neurochemical Pathology Unit, Newcastle General Hospital, Westgate Road, Newcastle upon Tyne NE4 6BE, UK \\ STRIATAL DOPAMINERGIC MARKERS IN LEWY BODY DEMENTIA IN RELATION TO NEUROLEPTIC DRUG REACTION}

Lewy body dementia (LBD), associated with cortical and subcortical Lewy bodies and variable Alzheimer-type pathology, is characterised clinically by fluctuating cognitive function, psychotic features and mild extrapyramidal symptoms, the latter often severely exacerbated by neuroleptic medication. This neuroleptic sensitivity, which can resemble the neuroleptic malignant syndrome, was investigated in basal ganglia obtained from $9 \mathrm{LBD}$ cases with severe neuroleptic reaction, $7 \mathrm{LBD}$ cases with no exposure to neuroleptic drugs, 5 LBD cases with mild or no reaction to neuroleptics, 8 Parkinson's disease (PD) cases, and 11 controls. Substantia nigra (SN) neuron densities were significantly reduced by $40 \%$ and $60 \%$ in LBD with severe neuroleptic reaction and PD respectively, but were not significantly reduced in other LBD cases. Striatal concentrations of dopamine and its metabolites were reduced in LBD, particularly in caudate as opposed to putamen, the loss being most extensive in the severely neuroleptic sensitive group, approaching the reductions apparent in PD. Dopamine uptake sites measured by ${ }^{3} \mathrm{H}$ mazindol autoradiography showed a $60-80 \%$ reduction in $\mathrm{PD}$ compared to controls, but in LBD there were no significant reductions, except in those cases with severe neuroleptic reaction where binding was significantly reduced by $40 \%$ in dorsal caudate. Dopamine $\mathrm{D}_{2}$ receptor binding, measured by ${ }^{3} \mathrm{H}$ raclopride autoradiography, tended to be reduced in LBD without exposure to neuroleptics, but was significantly elevated in PD and in LBD with no or mild neuroleptic reaction compared to controls. In the LBD cases with severe neuroleptic reaction $\mathrm{D}_{2}$ binding in putamen and nucleus accumbens was significantly less than the nonreactive group, indicating that a failure to upregulate $\mathrm{D}_{2}$ receptor activity as a result of presynaptic dopaminergic degeneration or post synaptic receptor blockade could account for the sensitivity of this subgroup to neuroleptic medication.

PILLON B, DEWEER B, MALAPANI C, ROGELET P, AGID Y AND DUBOIS B

INSERM U-289, Paris, France

\section{EXPLICIT MEMORY DISORDERS IN DEMENTED PARKINSONIAN PATIENTS}

Do memory disorders observed in demented patients with Parkinson's disease (PD) result from subcortical lesions or from coexisting Alzheimer's disease? To answer this question, the performance of 15 consecutive demented PD patients was compared to that of patients with Alzheimer's disease (AD; $n=15$ ), progressive supranuclear palsy (PSP; $n=15$ ) and Huntington's disease (HD; $n=15$ ), matched for severity of dementia, using various situations of verbal learning acquisition (free or controlled encoding) and retrieval (immediate and delayed free and cued recall, and recognition). Although deficit in free recall was similar in the four groups of patients, a dramatic improvement by the association of controlled encoding and cued recall was observed in demented patients with PD, PSP and HD, but not in AD. These results: indicate a similar pattern of explicit memory dysfunction in patients with predominantly subcortical lesions, characterized by an inefficient planning of memory processes; suggest that the memory deficits of demented PD patients result from subcortical lesions, the nature of which remains under debate.

\section{PLOTNIK M, SCHECTMAN E, INZELBERG R, FLASH T AND KORCZYN AD \\ Weizmann Institute of Science, Rehovot and Tel Aviv University Medical School, Israel}

\section{SWITCHING ABILITIES IN PARKINSON'S DISEASE}

In neurologically healthy young adults arm trajectories are modified in response to target displacement, with minimal delay (psychological refractory period). Parkinson's disease (PD) patients have difficulties in performing simultaneous or sequential tasks. In order to examine the ability of PD patients to modify arm trajectories in response to unexpected visual target displacement, we have examined PD patients and agematched controls. They were instructed to move their hand to visual targets which were unexpectedly displaced within the reaction time (RT), after different time intervals (ISI) between presentation and displacement. Both control subjects and patients responded to target modification with a longer reaction time (RT2) than to an unmodified target (RT1). The RT2/RT1 ratio was significantly higher in PD patients $(p<0.05)$. Healthy elderly and PD patients are unable to prepare responses to two stimuli in parallel, in contrast to the behavior previously observed in young adults. This deficiency is more pronounced in PD patients. 
PRIMAVERA A, NOVELLO R, FONTI A, PARTINICO D AND STARA $S$

Department of Neurology, Genova, Italy

\section{QUANTITATIVE ELECTROENCEPHALOGRAPHY IN} PARKINSON'S DISEASE WITH AND WITHOUT DEMENTIA

Computerized EEG spectral analysis and topographic mapping were studied in demented and non-demented patients with Parkinson's disease (PD), in normal subjects, and in patients affected by dementia of Alzheimer type (DAT). EEGs were derived from 19 channels in waking condition with the eyes closed. All 18 patients with PD met the following criteria: unequivocal diagnosis of idiopathic $\mathrm{PD}$, no previous treatment with neuroleptics. All patients were stabilized on antiparkinsonian medication at the time of the study. PD patients with symptomatic causes of metabolic and vascular dementia were excluded by clinical, laboratory and CT data. On the basis of clinical and neuropsychological assessment, the PD patients were divided in two groups: demented ( 6 cases, mean age 70.4 ) and non-demented (12 cases, mean age 62.1). The most conspicuous findings were: diffuse prevalences of slow EEG activity in PD patients in comparison with normal controls; PD patients with dementia showed a greater increase in delta activity; an 'asymptotic profile' without a dominant peak in the $6.5-12 \mathrm{~Hz}$ band and the highest power in the 1-6.5 Hz band, which is considered pathognomonic of DAT (Giannitrapani, 1992), was found only in one demented PD patient. Moreover we noted the presence of a dominant peak in the $1-6.5 \mathrm{~Hz}$ band in frontal derivations in demented PD patients. In non-demented PD patients we detected the presence of a dominant peak in the $7-12 \mathrm{~Hz}$ band in the same derivations. These data seem to indicate that PD patients with dementia show a different neurophysiological profile from that of DAT patients, with a greater prevalence of slow frequencies in frontal derivations.

PRUCHNIK D, KORYTOWSKA A AND WENDER M Department of Neurology and Department of Otolaryngology, University of Medical Sciences, Poznan, Poland

\section{DISTURBANCES OF OLFACTORY AND TASTE FUNCTIONS IN PARKINSON'S DISEASE}

Parkinson's disease is determined by the lesion of dopaminergic neurones of the central nervous system leading to domination of extrapyramidal symptoms. However there are many indications that neurotransmitters associated with other functions of the nervous system also demonstrate some abnormalities in Parkinson's disease. To enlarge the knowledge of the problem we have performed studies of olfactory and taste functions in patients with Parkinson's disease. Olfactory tests evaluating detection and recognition thresholds were performed using the method of Elsberg as modified by Pruszewicz. Threshold of taste detection was established by the electrogustometric method of Pruszewicz. and threshold of taste recognition by the method of Börnstein. Our present investigations have confirmed that in patients with Parkinson's disease the threshold of odor detection and recognition is significantly increased. The taste reception is lowered too, but the difference from the normal values is only a minor one. Our results testify that in Parkinson's disease the dysfunction of the nervous system is more diffuse than has previously been suggested.

\section{PRZUNTEK H AND BÜTTNER T}

Department of Neurology, Ruhr-University, Bochum, Germany

\section{DISTORTED COLOUR PERCEPTION IN PARKINSON'S DISEASE}

Dysfunction of the visual system in Parkinson's disease (PD) was elucidated by abnormal VEP recordings and distorted achromatic con- trast sensitivity. We studied functions of chromatic vision in PD by determining colour discrimination (60 patients) and colour contour perception (36 patients) in Parkinsonian patients and in age-matched controls. The colour discrimination was determined by the use of the Farnsworth-Munsell 100 Hue test. The mean total error score (TES) was 89.4 in Parkinsonian patients as compared to 16.8 in controls $(p<0.00001)$. TES is correlated with the duration $(p<0.05)$ and severity of $\mathrm{PD}(p<$ 0.00001 ) but not with depression. Colour contour perception was measured using a computer-aided method for determining colour fusion time (CFT) of various colours. Parkinsonian patients generally have a shortened fusion time as compared with controls, especially for the dark-green $(p<0.001)$, light-blue $(p<0.001)$ and dark-red $(p<0.05)$ stimuli. Conclusion: Functions of colour vision in PD are significantly worsened as compared to controls. The dependence of colour misperceptions on further clinical and pharmacological variables must be evaluated in ongoing studies.

\section{RABEY JM, TREVES TA, ORLOV E, KATZ T AND KORCZYN AD \\ Tel-Aviv Medical Center, Tel-Aviv, Israel}

\section{LOW DOSE CLOZAPINE IN THE TREATMENT OF LEVODOPA-INDUCED MENTAL DISTURBANCES IN PARKINSON'S DISEASE}

Delusions and psychotic behavior are common side-effects observed in Parkinson's disease (PD) patients chronically treated with dopaminergic drugs. Clozapine, a dibenzapine derivative, is a neuroleptic drug apparently devoid of extrapyramidal side-effects, although aggravation of Parkinsonism by high doses of clozapine has been reported (Peppard $e t$ al., 1989). We have evaluated the effects of low doses of clozapine on mental and motor functions in levodopa (LD) treated PD patients requiring antipsychotic medication. Twenty-seven $\mathrm{PD}$ patients showing psychotic behavior were included: mean age 73 years; mean disease duration 9 years, stage of PD (Hoehn and Yahr scale) II, III and IV, 1, 16 and 10 patients, respectively. Mean daily dose (mg): LD $605+$ carbidopa 60.5 (27 patients), bromocriptine 7.5 (5 patients). Twenty patients received clozapine (mean dose $51 \mathrm{mg}$, range $12.5-75 \mathrm{mg} / \mathrm{day}$ ) for 1-11 months (mean 5 months) and 5 patients for more than 1 year (mean 15 months). None of the patients showed motor deterioration. In 10 patients psychotic signs disappeared after a few weeks of clozapine and did not reappear after clozapine was stopped. Fifteen patients are still under clozapine, but are free of psychiatric symptoms. None developed neutropenia. Two patients stopped clozapine after 48 hours because of somnolence. In conclusion, clozapine at low doses (up to $75 \mathrm{mg} /$ day) seems to be useful in the treatment of psychosis in PD.

RABEY JM, NEUFELD MY, TREVES TA, GRAFF E AND KORCZYN AD

Departments of Neurology and Chemical Pathology, Tel-Aviv Medical Center, Sackler School of Medicine, Tel-Aviv University, Tel-Aviv, Israel

\section{BIOLOGICAL MARKERS AND NEUROPHARMACOLOGICAL TESTS IN DEMENTIA}

Derangement of the cholinergic system has been postulated as a key factor in the mental decline of Alzheimer's (AD), Parkinson's (PD) and multi-infarct (MID) dementia. Muscarinic cholinergic receptors, measured with ${ }^{3} \mathrm{H}$ quinuclidinyl benzilate (QNB), were characterized in blood lymphocytes from normal controls. Lymphocytes derived from 27 patients with 'probable' $\mathrm{AD}$ and 20 patients with $\mathrm{PD}$ showed a marked 
reduction in binding capacity (Bmax) compared with age-matched controls. In 24 patients with PD without dementia, QNB was similar to controls. The $\mathrm{Kd}$ was similar among the different groups. These findings suggest that lymphocytes may prove useful as peripheral markers for the cholinergic muscarinic system. Scopolamine (SCO, $0.5 \mathrm{mg}$ IV) and saline (placebo) were administered randomly, on separate days, to 11 patients with AD, $8 \mathrm{MID}, 7 \mathrm{PD}$ and 9 controls. Analysis (ANOVA and ANCOVA) of mental performance (Wechsler and Short Mental Test) showed that SCO administration decreased mental performance more in controls than in demented patients and did not differentiate between dementia subgroups.

\section{RABIN BM}

Department of Psychology, University of Maryland, Baltimore County, Baltimore, MD 21228, USA; and Behavioral Sciences Department, AFRRI, Bethesda, MD 20850, USA

\section{BEHAVIOURAL SENSITIVITY OF CENTRAL DOPAMINE SYSTEMS TO FREE RADICAL DAMAGE}

Possible relationships between ionizing radiation, free radicals and the dopaminergic system have been explored using the conditioned taste aversion (CTA) procedure. A CTA is produced when a toxic stimulus is paired with a novel tasting food. The role of nitric oxide and oxygen free radicals in radiation-induced CTA learning was studied by pretreating rats with $N$-nitroarginine or $n$-tert-butyl-a-phenyl nitrone (PBN). Neither compound was effective in preventing radiation-induced CTA learning. Haloperidol disrupted amphetamine-induced CTA learning, but did not affect the acquisition of a radiation-induced CTA. Preexposing rats to PBN did not prevent the acquisition of a radiation-induced CAT, suggesting that different mechanisms mediate the CTA responses to ionizing radiation and to $\mathrm{PBN}$.

RADIL T, ROTH J, RUZICKA E, TICHY J AND WYSOCKI CJ Clinic of Neurology, Charles University, Institute of Physiology, Czech Academy of Sciences, Prague, Czech Republic; and Monell Chemical Senses Center, Philadelphia, USA

\section{OLFACTORY DYSFUNCTION: A PATHOGNOMONIC SYMPTOM OF PARKINSON'S DISEASE?}

To verify the concept of olfactory dysfunction as an early marker of Parkinson's disease (PD), we studied olfactory functions in 16 patients with idiopathic PD and in 18 healthy controls. Amylacetate (banana smell) in 12 sequential dilutions (in 50\% steps) was used as odorant in four conditions: (A) binary ascendent forced choice (odorant vs. pure solvent in random order); (B) ascendent and (C) descending limit thresholds; (D) time course of deadaptation after olfactory adaptation. The testing showed anosmia in one patient; six more patients and one control subject were found to be hyposmic. Average olfactory thresholds were slightly higher in the patients compared with healthy controls. The decrease of olfaction was unrelated to the age of the patients, duration of the disease, degree of motor impairment, dose and duration of $\mathrm{L}$-dopa treatment. A facilitatory effect of ascendent stimulus ordering (lower B than $C$ threshold), representing a modulatory or adaptive phenomenon related to stimulus expectancy, was observed in the patients as well as in healthy controls. No difference in the time course of deadaptation was found between the two groups. In conclusion, our study revealed olfactory disturbances in fewer than half of the PD patients. The dysfunction was mostly limited to slight hyposmia, and no impairment of modulatoryadaptive olfactory phenomena was disclosed. Thus, olfactory impairment does not appear to be a pathognomonic symptom of PD and, if present, represents rather non-specific sensory changes.

\section{RAPOPORT A, STEIN D, SCHWARTZ M, LEVINE J, ELIZUR A} AND SAROVA I

Abarbanel Mental Health Center, Bat-Yam; E Wolfson Medical

Center, Holon and Sackler Medical School, Tel Aviv University, Israel

L-DEPRENYL TREATMENT IN ACUTE

\section{NEUROLEPTIC-INDUCED PARKINSONISM}

The aim of this study was to evaluate the efficacy of L-deprenyl, a selective MAO-B inhibitor, in the treatment of neuroleptic-induced parkinsonism (NIP). L-Deprenyl was administered to 20 psychiatric patients who developed parkinsonism following haloperidol treatment, in an open design, for six weeks. Daily dosage was $10 \mathrm{mg}$. Evaluations before treatment and weekly thereafter included the Brief Psychiatric Rating Scale, Clinical Global Impression, Webster Rating Scale (WRS) and Hoehn and Yahr Rating Scale. The latter two scales evaluated severity of parkinsonism. The results demonstrate significant improvement in parkinsonism following the administration of L-deprenyl in 7 patients with mild extrapyramidal symptomatology (WRS $<10$ ). In 12 patients with moderate symptomatology (WRS 10-20), there was no improvement with deprenyl alone. Significant change did occur, however, when adding an anticholinergic agent (biperiden, $2-4 \mathrm{mg}$ daily). One patient with severe parkinsonism (WRS $>22$ ) was totally non-responsive and was excluded from the study. No adverse effects, including psychosisexacerbation, occurred with L-deprenyl. Conclusion: The study suggests that L-deprenyl could be an alternative treatment in mild cases of NIP.

REID WGJ, HELY MA, MORRIS JGL, BROE GA, MARGRIE S, O'SULLIVAN DJ AND WILLIAMSON PM Department of Neurology, Westmead Hospital, NSW 2145, Australia

\section{CLINICAL CORRELATES OF DEMENTIA IN PARKINSON'S} DISEASE

Neuropsychological assessments were performed in 107 de novo patients participating in the Sydney Multicentre Study of Parkinson's Disease. Assessments were made at baseline and after 3 and 5 years. Performance at baseline and after 5 years was compared with controls. At baseline, $37 \%$ of patients whose symptoms of Parkinson's disease began after the age of 70 years were demented. This compared with a prevalence of dementia of $8.8 \%$ in patients whose symptoms began before the age of 70 years. By 5 years, the prevalence of dementia in the two groups had risen to $62.3 \%$ and $16.3 \%$, respectively. The death rate was higher over the 5 year period in the demented patients. Demented patients had more symmetrical signs, and higher scores for disability, gait and balance impairment and bradykinesia at baseline than non-demented patients. The presence of dementia at baseline predicted a poor response to treatment. The dementia at baseline had features of a subcortical dementia. Subsequently, demented patients developed features such as aphasia, apraxia and agnosia, which made the dementia indistinguishable from that of Alzheimer's disease. Patients with well preserved cognitive function at baseline had a good response to levodopa and were more likely to develop levodopa-induced dyskinesia. These results show that the clinical features of Parkinson's disease and response to treatment are influenced by the age of onset of symptoms and by the presence of dementia.

RIEDERER P, FRÖLICH L, BLUM-DEGEN D, SOFIC E, GSELL W, GÖTZ M AND GERLACH M

Department of Psychiatry, University of Würzburg, Germany

NEUROCHEMICAL SIMILARITIES AND DISSIMILARITIES BETWEEN DAT AND PARKINSON'S DISEASE 


\section{Abstracts of the International Symposium on Dementia in Parkinson's Disease}

Progressed stages of Parkinson's disease (PD) and dementia of Alzheimer type (DAT) are characterized by multi-neurotransmitter changes. PD: DA > NA $>$ 5-HT > ACh; DAT: ACh > 5-HT $>>$ NA > DA. Therefore, similarities in the primary and secondary pathophysiological processes may be assumed. For example, it can be shown that in PD as well as in DAT, radicals play a decisive role. Furthermore, evidence exists for a disturbed energy metabolism in DAT with concomitant deficit in PDHcand CAT activity; and for changes in respiratory chain enzyme activities in PD. All these changes are mainly detectable in the regions of interest involved in both disorders. However, qualitative and quantitative differences are notable.

\section{RIEKKINEN P, HELKALA E-L, HARTIKAINEN P AND SOININEN H \\ A.I. Virtanen Institute, University of Kuopio, Department of Neurology, Kuopio University Hospital, Kuopio, Finland}

\section{COGNITIVE AND MEMORY DEFICITS IN PATIENTS WITH UNTREATED PARKINSON'S DISEASE AND AMYOTROPIC LATERAL SCLEROSIS: COMPARISON WITH ALZHEIMER'S DISEASE}

We investigated the profile of cognitive and memory deficits of 22 Parkinson's disease (PD) patients, 24 amyotropic lateral sclerosis (ALS) patients, 24 Alzheimer's disease patients (AD), and 26 age-matched controls. The patients were at the early phase of the disease and untreated. The ALS and AD patients exhibited deficits in simple visuoperceptual functions and in complex visuoperceptual reasoning, whereas the PD patients showed deficits only in simple visuoperceptual functions. Moreover, all patient groups had impairment in tasks requiring set shifting from one reaction to another that may suggest frontal dysfunction. The ALS and PD patients also showed impairment in the task of learning a word list demanding organization of the material to be remembered. The $\mathrm{AD}$ group had more impaired recognition of the learned words than other groups. Preserved delayed recall of logical passages suggests that memory per se is not impaired in ALS or in PD. The patterns of errors in a test of recognition of learned words imply, at least partially, different underlying deficits. An inability to inhibit irrelevant information may contribute to memory impairment in ALS and AD patients, whereas the memory deficit in PD may derive from lowered initiating behavior.

\section{RINGENDAHL H AND JÖRG J.}

\section{Klinik für Neurologie, Wuppertal, Germany \\ PROBABILITIES OF ERROR FOR TEST-RETEST DIFFERENCES IN MOTOR PERFORMANCE}

Apparative testing of fine motor functions may contribute to an objective multidimensional assessment. Kraus and Przuntek (1989) applied an adapted form of the 'Motorische Leistungsserie' (MLS). In the present study we expanded this test regarding important variables such as finger dexterity and rotary pursuit. Parkinson's disease (PD) patients show strong fluctuations in their motor function. Therefore a retest reliability was stated for the first time. Should the level prove to be sufficiently set, drug induced fluctuations of single patients could be statistically ensured. The study included 70 right-handed PD patients, mean age $66.8 \pm 9.8$, mean duration of illness $5.8 \pm 4.8$ years. Patients with dementia and tremor type were excluded. All patients were tested with the MLS, with a consecutive testing 24 hours later. The patients with a well adjusted medication received different drug combinations; an alteration of the medication in the last 24 hours did not occur. Seven factors were extracted: manual and finger dexterity, wrist-finger speed, complex movements left and right, arm-hand steadiness, psychomotor coordination. Memory correlated with line tracing (right) and reasoning with line and pursuit rotor tracing (left). The data were independent of age and duration of illness. The right hand $\left(r_{\mathrm{tt}}=0.89\right)$ and left hand $\left(r_{\mathrm{tt}}=0.91\right)$ test and nearly all subtests showed a sufficient retest reliability. The MLS has a sufficient retest reliability. All probabilities of error for test-retest differences were given. From this it is possible to assess stastistically the effect of pharmacological treatment in single patients. Single subtests may be applied for demented patients.

RIVAUD S, VERMERSCH AI, VIDAILHET M, AGID Y AND PIERROT-DESEILLIGNY C

INSERM U289, Bâtiment Nouvelle Pharmacie, Hôpital de Salpétrière, 47 bd. de l'Hôpital, 75013 Paris, France

\section{SINGLE AND SEQUENTIAL MEMORY-GUIDED OCULAR SACCADES IN PARKINSON'S DISEASE}

Single and sequential memory-guided ocular saccades were recorded in 8 Parkinson's disease patients with ('on condition') and without ('off condition') levodopa. In the single memory-guided saccade paradigm, involving a 6 second delay, accuracy of the first saccade (motor component) and of the final eye position (spatial component) was significantly impaired compared to the control group, and was not improved by treatment. Motor impairment (first saccade) related to basal ganglia dysfunction, and spatial impairment (final eye position) related to a spatial working memory deficit in the dorsolateral prefrontal cortex. During sequences of four memory-guided saccades, the chronology of saccades was impaired in patients in the off condition, but significantly improved in the on condition. These results suggest the existence of a temporal working memory deficit, probably resulting from decreased activation of the supplementary motor area, which can be reversed by levodopa.

ROMERO S, CHOUZA C, FLORES M, LÓPEZ C, ALJANATI R, DE MEDINA O, CAAMAÑO J AND SCARAMELLI A

Instituto de Neurología, Hospital de Clinicas, Montevideo, Uruguay

\section{NEUROPSYCHOLOGICAL STUDY OF SENESCENCE, SENILITY AND PARKINSON'S DISEASE}

Twenty-three senescent, 64 senile and 60 parkinsonian patients, not previously treated with L-dopa, were studied from a neuropsychological point of view in order to analyze the profile of cognitive disintegration. We investigated the following items in each patient: (1) intelligence, through Piaget's Genetic Test in the Dominion of Physical Amounts and Weschler Bellevue Test; (2) memories, verbal, visual, visual with verbal support and visuospatial; (3) intelligence instruments, language, gnosias and praxias using the constructional praxia forms created and standardized by Mendilaharsu et al. We found a 'non-homogeneous deterioration' profile in the three groups, with mnesic and constructional praxia impairment, while intelligence and other instruments (language, gnosias and other praxias) were relatively preserved. Senescents were less affected, while parkinsonians and seniles showed a more severe impairment. In these patients the mnesic retrogenesis presented an early involvement of the visual and visuo-spatial memories; the verbal ones were more preserved. Praxia retrogenesis starts with a unilateral hemispheric dysfunction, evolving to a bilateral profile including 'closing in' in some cases. Senescents and parkinsonian patients show a higher percentage of normal constructional praxia; on the other hand, senile patients have higher incidence of bilateral profile of apraxia. The parkinsonians, the youngest group $(p<0.001)$, were situated between the senescents and seniles according to degree of impairment. Our neuropsy- 
chological results suggest that Parkinson's disease could be a particular form of premature aging, in accordance with other findings in different fields of research on Parkinson's disease and aging.

\author{
ROMERO S, DO CAMPO O, ALCÁNTARA J, CHOUZA C, \\ SILBERBERG G, DE LOS A, MASEDA M, LASAROV G AND \\ DELFINO I \\ Neurology Institute, Department of Psychiatry, Clinical Hospital, \\ Montevideo, Uruguay
}

\section{NEUROPSYCHOLOGICAL AND PSYCHOPATHOLOGICAL STUDY OF PARKINSON'S DISEASE}

Twenty-one patients with Parkinson's disease who had not received any previous treatment with L-dopa were studied using a multidisciplinary neuropsychological, psychiatric and psychological approach. From the neuropsychological point of view, Parkinson's disease may involve several areas: mnesic, constructive apraxia and performance in the Wisconsin Card Sorting Test (WCST). The intellectual level does not show signs of damage. Considering that the patients were studied with a Frontal Scale, results were compared with those obtained with the WCST and also with perseverations in the Bender Test. From the psychopathological point of view, these patients relate, in their own words, the beginning of the disease with a traumatic episode; an intense depressiveanxious disease. No major depressive condition was observed. Experiences referred to organic aspects interspersed with those corresponding to the traumatic event coexist in the evolution of Parkinson's disease. We wonder about the interaction of these psychic mechanisms in the initiation and development of the disease.

\section{RUNDEK T AND DEMARIN V}

Department of Neurology, University Clinic Sestre Milosrdnice, Zagreb, Croatia

\section{CEREBRAL VASOREACTIVE RESPONSE IN PATIENTS WITH MULTI-INFARCT DEMENTIA, DEMENTIA OF ALZHEIMER'S TYPE, AND DEMENTIA IN PARKINSON'S DISEASE}

Cerebral vasoreactivity (CVR) is a physiological protective mechanism that prevents brain damage by keeping stable blood flow supply. Impairment of CVR occurs in many pathophysiologic cerebral conditions, and therefore has diagnostic and prognostic value. In order to analyze CVR impairment, 30 patients with multi-infarct dementia (MID), 45 with dementia of Alzheimer's type (DAT), and 20 with dementia in Parkinson's disease (DPD) were analyzed. The basic diagnosis of dementia was performed according to DSM-III-R and NINCDS-ADRDA criteria. Additionally, the Folstein Mini Mental Scale (FMMS < 25) was used as a measure of cognitive impairment and Hachinski ischemic score to distinguish vascular dementia. For all patients we performed CT scans, Color Doppler Flow Imaging of carotid and vertebral arteries, psychological rating scales (FMMS, GBS, SCAG), and Transcranial Doppler (TCD) with acetazolamide (AZT) test. The results showed impaired TCD in all MID patients before AZT stimulation, in $47 \%$ with DAT, and $10 \%$ with DPD. After AZT stimulation reduced CVR was observed in MID patients with moderate and severe mental deterioration, and in those DAT and DPD patients who had impaired TCD before the AZT test $(p<0.01)$. In conclusion, AZT test with TCD is helpful in clarifying the hemodynamic origin of dementia, indicating the basic different pathogenicity between various types of dementia.
RUZICKA E, ELMASSIOUI F, PILLON B, DUBOIS B, MALAPANI C, RENAULT B AND AGID Y Clinic of Neurology, Charles University, Prague, Czech Republic; and CNRS UA 654, LENA and INSERM U-289, Paris, France

CONTRASTING EFFECTS OF APOMORPHINE ON MOTOR AND COGNITIVE PROCESSING IN PARKINSON'S DISEASE

To evaluate the influence of central dopaminergic transmission on cognitive processing in Parkinson's disease, we studied 9 patients suffering from severe motor status fluctuations, in the 'off state' (more than 12 hours after the last dose of medication) and in the 'on state' (half an hour after injection of an appropriate dose of apomorphine, $0.05 \mathrm{mg}$ per $\mathrm{kg}$ of weight), using a short neuropsychological battery and auditory eventrelated potentials (ERP). Two ERP tasks were used: an auditory 'oddball' tone discrimination paradigm and modified Posner's task of reorientation of attention. Apomorphine injection provoked: (1) significant improvement of the patients' motor status (mean decrease of UPDRS score from 47.2 to 20.1, $p<0.01$ ); (2) significant increase of P2 and P3 latencies in the odd-ball paradigm ( $p<0.01$ and 0.05 , respectively); (3) decrease of N2 amplitude in the Posner's task $(p<0.05)$; (4) decrease in category fluency $(p<0.05)$; performance on Stroop and literal fluency tests remained unchanged. The present data show contrasting effects of apomorphine, improving overall motor performance but impairing some aspects of cognitive processing. This impairment could be due to a nonspecific effect of apomorphine on arousal. Such an interpretation seems unlikely, given that Stroop test performance was unchanged. Therefore the results suggest the intervention of different basal ganglia-prefrontal cortex loops in motor and cognitive behavior, or complex interactions within pre- and postsynaptic brain dopamine receptors.

\section{SCHRÖDER H, GIACOBINI E, GHOBRIAL M AND MAELICKE A \\ Department of Anatomy, University of Köln, Germany; Departments of Pharmacology and Pathology, SIU School of Medicine, Springfield, IL, USA; and Department of Physiological Chemistry, University of Mainz, Germany \\ DEMENTIA IN PARKINSON'S DISEASE — CELLULAR EXPRESSION OF NICOTINIC CHOLINOCEPTORS AS COMPARED TO ALZHEIMER'S DISEASE}

Deficits in nicotinic cholinoceptor function have been shown to be hallmarks of Alzheimer's disease as well as of dementia in Parkinson's disease by means of binding studies assessing macroscopically defined cortical regions. We here report on the investigation of nicotinic receptor expression at the cellular level using immunocytochemistry in the frontal cortex of Alzheimer and Parkinson dementia patients and controls. Vibratome sections of age-matched controls (mean age 74 years), Alzheimer (mean age 74 years) and Parkinson dementia patients (mean age 77 years) were incubated with the monoclonal antibody WF6, picking up the receptor $\alpha$-subunit, followed by a peroxidase detection system. Immunoreactive neurons were assessed quantitatively as total neuron numbers. In both diseases, patients showed markedly decreased densities of immuno-reactive neurons (Alzheimer, $900 \pm 160$; Parkinson dementia, 2700 \pm 853 ) as compared to controls (Alzheimer study, $8020 \pm 980$; Parkinson study, $5605 \pm 1357$ ), with statistical significance for the Alzheimer patients $(p<0.0001)$. Total neuron numbers were not significantly different between controls and diseased brains. Thus, in Alzheimer's disease as well as in Parkinson's dementia, a subpopulation of neurons - probably mostly pyramidal cells — may lose their ability to express nicotinic cholinoceptors. The problem is currently being studied using in situ hybridization.

Supported by the Deutsche Forschungsgemeinschaft Schr. 283/8-1, 8-2. 
SEPIASHVILI R, MALASHKHIA Y, GELADZE M, LUKAVA R, NADAREISHVILI $Z$ AND YACOBASHVILI S

Institute of Clinical Immunology and Allergology, Georgia

\section{NEUROPEPTIDE DEFICITS IN PARKINSON'S DISEASE DEMENTIA}

Fourteen patients with Parkinson's disease dementia (PDD) and 10 patients with Parkinson's disease (PD) without dementia were studied. All PDD patients had rigidity and no tremor. PD patients had resting tremor. Vasopressin (VP) and $\beta$-endorphine (BE) content in the blood and in the cerebrospinal fluid (CSF) were investigated using radioimmune assay.

\begin{tabular}{lccccc}
\hline & \multicolumn{2}{c}{$\begin{array}{c}\text { Vasopressin } \\
(\mathrm{pg} / \mathrm{ml})\end{array}$} & \multicolumn{2}{c}{$\begin{array}{c}\text { } \text {-Endorphine } \\
(\mathrm{pg} / \mathrm{ml})\end{array}$} \\
\cline { 2 - 6 } & Blood & CSF & & Blood & CSF \\
\hline PDD & $2.8 \pm 0.7$ & $2.4 \pm 0.5$ & & $1.2 \pm 0.2$ & $2.1 \pm 0.3$ \\
PD & $3.1 \pm 0.8$ & $6.7 \pm 1.1$ & & $5.1 \pm 0.1$ & $12.3 \pm 1.2$ \\
$p$ & $>0.5$ & $<0.01$ & & $<0.01$ & $<0.001$ \\
\hline
\end{tabular}

In PD in the blood and CSF compared with PD, VP and BE were decreased. The defect of synthesis of neuropeptides may play an important role in the development of cognitive disturbances in PDD. In our study dementia developed only in patients with rigidity and without tremor; no patients with tremor form of PD were demented.

\section{SHEK YUEN LAU S}

Department of Computer Science, University of Regina, Regina, Saskatchewan, Canada

\section{CONTRAST ENHANCEMENT OF MEDICAL IMAGES USING ROUGH SETS}

Enhancement of poorly taken medical images is essential for diagnosis. The contrast enhancement approach presented is decomposed into two stages. First, given low contrast or noisy image, a thresholding technique based on a two dimensional histogram is applied to segment the objects of interest. Second, by defining an indiscernibility relation in Rough Sets theory, the segmented objects are identified. Then the mean gray level of each object is calculated and used to build a histogram. A new gray level mapping function is defined by employing the histogram equalization procedure. An enhanced image with better visual contrast and noise reduction is obtained. In conclusion, the contrast enhancement technique discussed here is fast and thus is very practical in surgical uses.

\section{SHEK YUEN LAU S}

Department of Computer Science, University of Regina, Regina, Saskatchewan, Canada

\section{MEDICAL IMAGE COMPRESSION BY DIFFERENCE PYRAMID AND FUZZY SETS}

A difference pyramid, a multi-dimensional structure, is designed to remove data redundancies. First, the mean pyramid is built, based on $2 \times 2$ blocks. The original image is the bottom level of such a pyramid. Higher level nodes are obtained by the mean gray level inside the corresponding $2 \times 2$ block of the predecessors. Then the difference pyramid is constructed by subtracting the current nodes to the $2 \times 2$ block of the former level of the mean pyramid. The decoded image can be formed from the highly decorrelated difference pyramid by the expand and sum procedure. The difference pyramid will undergo fuzzification, contrast condensation and intensification and defuzzification process, followed by quantization to yield a lower rate of bits per pixel (bpp). Experimental results show that only 0.8 bpp is required to encode an $8 \mathrm{bpp}$ image. In addition, the difference pyramid is well suited to progressive transmission, which makes the analysis and diagnosis of patients' images more convenient in different places.

\section{SHULMAN LM, SINGER C, LEVIN B AND WEINER WJ}

\section{AN ANALYSIS OF OUTCOME OF DIAGNOSTIC TESTING FOR DEMENTIA IN PATIENTS WITH PARKINSON'S DISEASE}

Dementia occurs in approximately one third of all patients with Parkinson's disease (PD). We studied the usefulness of common diagnostic tests performed in the evaluation of dementia in this population. A retrospective review of the results of laboratory, neuroimaging and electroencephalographic studies was conducted in a group of idiopathic PD patients with subsequent onset of dementia. We evaluated thyroid function tests, RPR or FTA, vitamin B-12, and folate levels. Neuroimaging included either CT or MRI brain scanning. The patient sample was composed of 37 patients with idiopathic PD $(65 \% \mathrm{M}, 35 \% \mathrm{~F}$; mean age 70.4 years; mean duration of disease 5.9 years; mean Hoehn and Yahr stage 2.6) who were diagnosed with dementia by neuropsychological testing. Neuroimaging results were as follows: normal in $59 \%$ by CT, $40 \%$ by MRI; atrophy in $36 \%$ by CT, $40 \%$ by MRI; and multiinfarcts in $4.5 \%$ by CT, $20 \%$ by MRI. EEG recording demonstrated diffuse slowing in $60 \%$, and was normal in $40 \%$. No abnormalities were identified by laboratory testing. Commonly performed diagnostic testing for dementia in PD patients did not identify novel etiologies for dementia, with the exception of multiinfarcts, as demonstrated by MRI. We conclude that the 'dementia work-up' in PD patients rarely provides new information beyond supportive evidence of an underlying neurodegenerative process. Further studies are suggested to address the questions of both the relative merits of this testing, and whether the yield is lower in PD patients with dementia as compared to patients with new onset dementia alone.

SLOVIN H, ABELES M, HAALMAN I, PRUT Y, VAADIA E, ZELENSKAIA V AND BERGMAN H

Department of Physiology, Hadassah Medical School, Jerusalem, Israel

\section{COGNITIVE IMPAIRMENTS AND CORTICAL NEURONAL ACTIVITY IN LOW-DOSE MPTP TREATED MONKEYS}

Frontal cognitive impairments have been reported frequently in Parkinson's disease. The main output of the basal ganglia is directed to the frontal cortex. Physiological studies of the basal ganglia of MPTP treated monkeys have shown distinct alternations in neuronal activity. Hence it is predicted that neuronal activity in the frontal cortex will be affected in the parkinsonian state. Two monkeys were trained to perform a spatial delayed (1-32 s) response task with alternations between two behavioral modes (go and no-go mode). The activity of up to 16 units was recorded simultaneously in the frontal cortex, by an array of six electrodes. After 40 penetrations, the monkeys were treated with successive low dose MPTP injections ( 4 sessions of $4 \times \mathrm{IM} 0.1 \mathrm{mg} / \mathrm{kg} / \mathrm{day}$ ). Another 40 penetrations were done in this state. After MPTP treatment the monkeys were significantly impaired in their ability to switch between the behavioral modes. The total number of errors (mainly location errors) increased and was dependent on the duration of the delay. Reaction time was prolonged 
following MPTP treatment; however the movement time did not change. Mean firing rate and the strength of responses to behavioral events of single units decreased in the MPTP state. Preliminary results show changes in the firing pattern of single units after MPTP treatment (e.g. increase in $2 \mathrm{~Hz}$ oscillatory activity). Cross-correlation analysis suggests that the level of synchronization between neurons was lower in the parkinsonian state. Histological analysis of the substantia nigra showed $20-40 \%$ reduction in the number of neurons. These results indicate that low dose MPTP treatment can produce cognitive impairments with no significant motor effect, and demonstrate change in neuronal activity in the frontal cortex which may be related to the behavioral deficits.

\section{SPEISER Z, LEVY R AND COHEN S}

Department of Physiology and Pharmacology, Tel Aviv University, and Teva Pharmaceutical Industries, Israel

\section{PRECLINICAL STUDIES WITH \\ $N$-PROPARGYL-1[R]-AMINOINDAN AS A POTENTIAL DRUG FOR THE TREATMENT OF PARKINSONISM}

The potential of $N$-propargyl-1[R]-aminoindan ([R]-PAI), a selective $\mathrm{MAO}_{\mathrm{B}}$ inhibitor, to restore or increase central dopaminergic function was assessed in various drug-induced models of dopaminergic hypofunction or dysfunction: haloperidol-induced catalepsy which is due to postsynaptic blockade of dopamine receptors, $\alpha$-methyl-p-tyrosine $(\alpha-\mathrm{MpT})$ hypokinesia due to blockade of catecholamine synthesis, amphetamineinduced stereotypy due to blockade of catecholamine synthesis, amphetamine-induced stereotypy due to blockade of dopamine reuptake, and anoxia- or hypoxia-induced motor and memory dysfunction. In haloperidol-induced catalepsy in mice $(4 \mathrm{mg} / \mathrm{kg}$ s.c.), pretreatment with [R]-PAI $2.4 \mathrm{mg} / \mathrm{kg}$ i.p. restored normal motor behavior. At $0.4-2.4 \mathrm{mg} /$ kg i.p., [R]-PAI significantly improved the recovery of motor activity in haloperidol-induced catalepsy in rats $(1.5 \mathrm{mg} / \mathrm{kg}$ s.c.). In $\alpha-\mathrm{MpT}$ induced hypokinesia in rats $(100-120 \mathrm{mg} / \mathrm{kg}$ i.p.), pretreatment with [R]-PAI at $2.5 \mathrm{mg} / \mathrm{kg}$ i.p. restored motor activity almost to control level. [R]-PAI $(0.32 \mathrm{mg} / \mathrm{kg} /$ day per os, or acutely $1 \mathrm{mg} / \mathrm{kg}$ i.p. $)$ potentiated D-amphetamine-induced stereotypy in rats $(0.5 \mathrm{mg} / \mathrm{kg} \mathrm{s.c.})$. Racemic PAI, which is an equimolar mixture of the two isomers, was less than half as active as the pure [R]-isomer, suggesting interference from [S]-PAI. In post-natally anoxia-induced impairment of memory and learning in rats and in hypoxia-induced deficits in adult and senescent rats, chronic daily medication with [R]-PAI $(0.24 \mathrm{mg} / \mathrm{kg}$ i.p. or $0.32 \mathrm{mg} / \mathrm{kg}$ per os $)$ improved normal locomotor behavior in $\alpha-\mathrm{MpT}$ treated rats and memory and learning capacity in the passive and active avoidance tests. [R]-PAI was either equipotent or superior to selegiline in the acute tests and superior to MDL 72,974 in the mice catalepsy and $\alpha-\mathrm{MpT}$ tests.

\section{SPRINZELES LL}

Parkinson's Disease Foundation, Columbia-Presbyterian Medical Center, New York, NY, USA

\section{IMPACT OF DEMENTIA IN PARKINSON'S DISEASE ON FAMILIES}

Holistic treatment of cognitively impaired patients with Parkinson's disease (PD) must expand to address the needs of the family. The purpose is to help the family maintain some psychosocial stability; to learn effective coping mechanisms; to reduce disruptive dynamics within the family constellation; and to keep demented patients in their own homes. Otherwise a household with one patient will soon have two. Preliminary investigation of 35 interviewees among professionals and spouses in support groups yielded the following information: 23 people claimed to have benefited from counselling or self-help group programs, evidenced in improved communication and intact familial support system. Moreover, most patients did not need to be institutionalized.

\section{STRITTMATTER M, HAMANN G, STRUBEL D, REUNER C} AND CRAMER H

Dept. Neurology, University of Saarland, 66424 Hamburg, Germany; Dept. Neurology, University of Freiburg, 7800 Freiburg, Germany; and Dept. Geriatrics, University of Strasbourg, France

\section{NEUROCHEMICAL PARAMETERS OF DEMENTIA IN PARKINSON'S DISEASE}

Various neurotransmitter deficits have been established in post mortem brain tissue in neurodegenerative disease with dementia like senile dementia of Alzheimer type (SDAT) and Parkinson's disease (PD). In cases of severe dementia in PD a coincidence with SDAT is postulated. CSF values of neurotransmitter and their metabolites appear to be a useful and valid additional ante mortem instrument of diagnosis. In a clinicalneurochemical study with 42 old-aged parkinsonian patients $(79.4 \pm 6.8$ years) and 10 age-matched controls $(80.3 \pm 5.4$ years) we found the following results. (1) Longer duration of PD and age were significantly correlated with the severity of dementia in PD $(r=0.80, r=0.75)$, indicating the possibility of functional interaction between age-dependent SDAT-deficiency and PD. Motor disease progression was significantly correlated with dementia scores $(r=0.78)$. (2) Significantly reduced levels of homovanillic acid (HVA) were not related to the severity of single motor symptoms in PD, and moreover not significantly correlated to the stage of dementia $(r=0.45)$, but L-dopa treatment temporarily improved memory impairment. (3) Only in cases of severe dementia (GDS 7) hydroxyindoleacetic acid (5-HIAA) $(p<0.05)$ and choline acetyltransferase (CAT) $(p<0.01)$ were significantly reduced. (4) Somatostatin-like immunoreactivity (SLI) was significantly decreased $(p<0.05)$ in PD in comparison to the controls. Moreover, alterations of the molecular forms (somatostatin-14, somatostatin-28, des-ala-somatostatin) in less severe stages of dementia could be compatible with an early degeneration of cortical intrinsic neurons. Dementia in PD has remarkable similarities to that in SDAT according to a degneration of multiple neuronal networks, especially of dopaminergic, cholinergic and peptidergic pathways. The exact frequencies and severities of cognitive symptomatology remain to be eludicated in prospective longitudinal clinicopathological studies with quantification of various cognitive functions and quantification of neuropathological-neurochemical changes.

TAGARIS G, THOMAIDIS T, RAKOPOULOU I AND

KARAGEORGIOU C

Neurological Department of Athens General Hospital, Athens, Greece

\section{QUANTITATIVE EEG ANALYSIS IN PATIENTS WITH PARKINSON'S DISEASE AND MODERATE MENTAL DETERIORATION BEFORE AND AFTER THE ADMINISTRATION OF NIMODIPINE}

The aim of this study was quantitative EEG analysis (QEEG) of patients with Parkinson's disease and moderate degree of mental deterioration before and after the administration of nimodipine. Fifteen patients were studied. Higher cerebral functions were evaluated using the Mini Mental State Examination. All of them had received nimodipine per os in a dose of $90 \mathrm{mg} / \mathrm{day}$. QEEG analysis was performed before treatment and was repeated two months later. The initial QEEG revealed a diffuse increase in theta activity in all patients. Theta activity was significantly decreased in 9 patients after treatment with nimodipine. 
TÁRCZY M, DABASI G, SZOMBATHELYI É, BODROGI A, KÁRPÁTI R, TAKÁTS A AND SIMÓ M

Department of Neurology, Semmelweis Medical University and International Medical Centre, Budapest, Hungary

\section{THE EFFECT OF SELEGILINE ON COGNITIVE FUNCTIONS OF PARKINSONIAN PATIENTS WITH DEMENTIA}

According to literature data, dementia in parkinsonian patients may result from coexistent Alzheimer's disease/defective function of dopaminergic pathways, including cognitive loop and mesolimbicocortical system/ vascular alterations. Using HMPAO SPECT we distinguished three main types of hypoperfusion in Parkinson patients with dementia: (i) 'posterior' type; (ii) predominantly frontal lobe type; (iii) multiple small defects. Analysis of these groups with the aid of MMSE, Hachinski score, investigation of cortical symptoms, memory tests (digit span, word pair test, short story), word fluency, Lurija's methods and CURS revealed the following. (1) Patients of posterior type showed a marked dementia with impairment of some cortical functions (agnosia, apraxia). (2) Patients with predominant frontal lobe hypoperfusion could be characterised with milder dementia, memory impairment, disturbance of sequential motor activities and freezing phenomenon. (3) Patients with multiple small defects of primary vascular origin showed severe dementia and focal neurological signs, Hachinski score values being $>7$ points. Selegiline (Jumex) was introduced in all groups to the continuing levodopa therapy. The effect was measured after 60 days of treatment. Selegiline proved to be effective, improving memory functions and alertness, especially in patients with frontal lobe hypoperfusion. Our findings support the view that selegiline may improve mild dementia and reduces symptoms similar to frontal lobe dysfunction.

\section{TREVES TA, KLIMOVITZKI S, VERCHOWSKI R, RABEY JM AND KORCZYN AD}

\section{PARKINSON'S AND ALZHEIMER'S DISEASES: COMBINED RISK FACTOR ANALYSIS}

Parkinson's disease (PD) and Alzheimer's disease (AD) share clinical, biochemical and pathological signs. They also have similar distribution. Risk factors for PD and AD have been studied separately, but if these two diseases result from a common process, common risk factors should also be identified. Such an analysis can be done by comparing the factors that seem to affect each of the diseases when cases are compared to controls. Also, if a factor affects both diseases, comparison of PD cases with $\mathrm{AD}$ cases should not show a preferential distribution for one or the other. Such an analysis was performed in $75 \mathrm{PD}$ and $75 \mathrm{AD}$ cases. Their spouses served as their respective controls for ' within groups analysis'. It appeared that history of dementia and Parkinsonism were more frequent in families of $\mathrm{AD}$ and $\mathrm{PD}$ patients, with predilection for their respective disease. In each disease, previous depression was a risk factor for the disease, although more so in AD than in PD. Previous severe flu was a risk factor for PD but not for AD. These results suggest that both age-related diseases may proceed from common processes and genetic susceptibility, the expression of which will depend upon environmental factors.

\author{
VAN SPAENDONCK KPM, BERGER HJC, HORSTINK MWIM \\ AND COOLS AR \\ University of Nijmegen, Nijmegen, The Netherlands
}

\section{CARD-SORTING IN PARKINSON'S DISEASE: A COMPARISON BETWEEN ACQUISITION AND SHIFTING PERFORMANCE}

Impaired performance of PD patients on card-sorting tests, especially on the Wisconsin Card Sorting Test (WCST), is a frequently recurring finding of neuropsychological studies in PD. However, there is no consensus as far as the underlying deficit of poor performance is concerned. This lack of consensus reflects the fact that card-sorting tests are complex and performance of these tests cannot be related to one single mental function. The WCST is essentially a test to be performed in subsequent phases. In all phases the task is concept formation. In the acquisition phase, the feedback of the experimenter indicates which cues of the test materials are relevant to making correct assignments, and which are not. In the shifting phases, the subject has to find out that a cue which was relevant hitherto is now irrelevant, and vice versa. In this study we compared differences between the subsequent phases of card-sorting performance of PD patients and CS. We presented three different cardsorting tests: the WCST, and a verbal and spatial variation. Only subjects who accomplished the acquistion on all card-sorting tests participated in this study. In the acquisition phase, PD patients performed slightly better than control subjects. In the shifting phase, CS performed better than PD patients. After correcting shifting performance for basic concept formation (i.e. acquisition performance), the difference between PD patients and CS turned out to be significant. The results of the present study are in line with other findings indicating that PD patients are impaired in problem solving which is not guided by external cues but by processing of internal information. In contrast, $\mathrm{PD}$ patients are not impaired in problem solving, which is guided by external cues.

\section{VIEREGGE P, VERLEGER R, STÜVEN F AND KÖMPF D Department of Neurology, Medical University of Lübeck, Germany \\ IMPAIRED AUDITORY SELECTIVE ATTENTION IN PARKINSON'S DISEASE - A STUDY OF EVENT-RELATED POTENTIALS}

Patients with Parkinson's disease (PD) are impaired in the use of internally driven strategies for linking meaningful information. We hypothesized that impairments of selective attention contribute to these difficulties and are detectable by its event-related correlate, 'processing negativity' (Nd). Fourteen PD patients (mean age $61 \mathrm{yrs;} \mathrm{Hoehn-Yahr}$ I-III) were compared with 16 age-matched healthy controls. Patients were investigated in balanced order, once with usual morning dosage of anti-parkinsonian drugs and once without these. Both groups performed an auditory two-channel task: subjects had to attend to tones presented to one ear (i.e. press a button to occasionally presented longer tones) and to ignore tones presented to the other ear. Tones were presented at a rate of $1 \mathrm{~Hz}$ (slow) or $2 \mathrm{~Hz}$ (fast). $\mathrm{Nd}$ was measured as the difference of the potentials evoked by standard tones in the attended minus the unattended ear. ERPs were recorded and averaged conventionally. Patients had lower amplitudes for $\mathrm{Nd}$ at slow presentation rates $(p<0.05)$, but not at fast presentation rates. The difference found at all three leads was largest at $\mathrm{Cz}(p<0.01)$. No effect of anti-parkinsonian drugs on $\mathrm{Nd}$ was established. Auditory selective attention seems to be impaired in PD patients. The disturbance may be due to non-dopaminergic brain changes.

VIEREGGE P, VERLEGER R, STÜVEN F AND KÖMPF D Department of Neurology, Medical University of Lübeck, Germany

\section{EVENT-RELATED POTENTIALS IN NON-DEMENTED} PATIENTS WITH PARKINSON'S DISEASE

Increases of $\mathrm{P} 3$ latency in nondemented patients with Parkinson's disease (PD) are linked to incipient cognitive decline. Practice effects possibly relevant for different results on dopaminergic influences of event-related 
potentials (ERP) have been largely overlooked. We compared 14 nondemented PD patients (mean age $61 \pm 7$ yrs; HYS I-III) with 16 agematched healthy controls. Patients were investigated in balanced order, once under their usual morning dosage of anti-parkinsonian drugs and once without this. All individuals had to perform the oddball task: 250 tones were presented to both earphones at the same time, at a fixed interval of $1.5 \mathrm{~s} ; 86 \%$ were 'nontargets' $(1000 \mathrm{~Hz}), 14 \%$ were 'targets' $(2000 \mathrm{~Hz})$. Subjects had to press a button in response to targets. ERPs were recorded and averaged conventionally. Cognitive testing was by Rey's Auditory Verbal Learning Test (AVLT). Latencies and amplitudes of N1, N2b, and P3 did not differ between patients and controls, nor among patients, when results under full anti-parkinsonian drug supply were compared to those without the morning dose. Order-of-session effects emerged for $\mathrm{N} 1$ and $\mathrm{N} 2 \mathrm{~b}$ but not for $\mathrm{P} 3$ amplitudes. There were no correlations between ERP latencies, AVLT and UPDRS-III results. Correlation between disease measures and P3 latency in nondemented PD patients remains weak; non-dopaminergic mechanisms should be considered for changes of P3 latency.

\section{WENDER M, PRUCHNIK D AND KOWAL P \\ Department of Neurology, University of Medical Sciences, Poznan, Poland}

\section{DESCRIPTIVE AND ANALYTICAL EPIDEMIOLOGY OF PARKINSON'S DISEASE IN POLAND}

The epidemiology of Parkinson's disease was evaluated in the Poznan region of Western Poland. The incidence of Parkinson's disease in the region under investigation amounts to 12.6 per 100000 of population, which is the middle value in the world-scale. The prevalence of the disease-65.9 per 100000-is in the lower range of values found in many countries of the world. Among various age groups the highest incidence and prevalence of Parkinson's disease was found in the age groups 7079 and $80-89$, with slightly higher prevalence among males. The existence of disease foci in some villages and small towns seems to depend upon unfavourable genetic factors, connected with very limited migration movements in those places. In further studies personal histories of 300 patients with Parkinson's disease were compared with cases of sciatica to identify possible risk factors. Hair colour described on a 4 point scale and skin colour evaluated on a 5 point scale demonstrated significant differences between both groups analysed. However it is not possible to determine a definitive association between quantity of pigment, indicated by hair and skin colour, and Parkinson's disease. A significantly lower percentage of smokers was noticed in the group of Parkinson's patients, which seems to be connected with the influence of nicotine on the catecholamine metabolism, leading to increase of dopa production.

\section{WHITEHOUSE PJ, GELDMACHER DS AND VOCI JM Department of Neurology, University Hospital, Cleveland OH44106, USA}

\section{THE DEMENTIAS IN PARKINSON'S DISEASE: TREATMENT STRATEGIES}

Strategies to develop treatments for the dementias in Parkinson's disease must encompass short, intermediate and long term approaches, ideally based on an understanding of the pathophysiology of the dementias found in this condition. Short term approaches can be based on the understanding of neurotransmitter system changes, for example, loss of cholinergic basal forebrain neurons or alterations in bioaminergic brainstem nuclei. Intermediate strategies will depend on an understanding of which cell populations die and the basic mechanisms that support their viability. Particularly fruitful approaches may involve the use of intraventricular growth factors and eventually new delivery systems and drugs that can enhance these growth factor systems. Long term strategies will involve understanding the pathogenesis of cell loss, which of course will depend on understanding the different dementias that occur in Parkinson's disease, including plaque and tangle dementia, Lewy body dementia, and so-called simple atrophy. Throughout this entire process of developing treatment for the dementias of Parkinson's disease one must be aware of the potential negative or positive effects on the motor abnormalities that are the characteristic features of the disease.

\section{YAKHNO NN}

Clinic of Nervous Diseases, Neurogeriatric Research Laboratory, Moscow Medical Academy, Rossolimo St. 11, 119021 Moscow, Russia

\section{COMPARATIVE ASSESSMENT OF DEMENTED AND} NON-DEMENTED PATIENTS WITH PARKINSON'S DISEASE

The pattern of cognitive disorders, neuroimaging data and brain electrical activity changes in Parkinson's disease (PD) with and without dementia is not yet well defined. 78 patients with idiopathic $\mathrm{PD}$ from 33 to 77 years old were studied using standardized clinical scales for neurological assessment, neuropsychological tests, CT and MRI with quantitative and qualitative assessment of data, brain mapping in different functional states and computerized stabilography. Dementia was diagnosed in 25\% of patients. The most severe neurologic disorders, especially hypokinesia, postural instability, pseudobulbar signs, were observed in patients with dementia. There was a correlation between aging and severity of dyspraxia, ventricular enlargement on $\mathrm{CT}$ and MRI. The characteristic feature of the neuropsychological disorders in dementia was the prevalence of frontal lobe dysfunction signs. Memory disturbances were different in demented and non-demented patients. There was significant slowing of EEG in demented patients. Postural impairment was more severe in demented patients with PD. Frontal lobe and parietal lobe dysfunction correlate with this disorder. Our results support the assumption that there are qualitative differences between PD patients with and without dementia.

YOUDIM MBH, REICK A AND LAVIE L

Faculty of Medicine, Technion, Haifa, Israel

\section{IRON DELOCALIZATION AND THE RELEVANCE OF SUPEROXIDE PRODUCTION BY NITRIC OXIDE TO NIGRAL CELL DEATH}

The etiology of progressive nigral dopamine neuron death in Parkinson's disease (PD) remains elusive. Our previous observations on the chemical pathology of Parkinsonian substantia nigra (SN) support the concept of oxidant stress. These include increases of iron and ferritin and hydrogen peroxide producing monoamine oxidase $\mathrm{B}$ activity, decrease of reduced glutathione (GSH) and inhibition of mitochondrial respiratory chain enzyme, Complex 1 . The dopaminergic neurotoxin 6-hydroxydopamine can bring about similar changes in the animal model of PD. If oxidant stress is an initial trigger for neurodegeneration, an endogenous or exogenous produced neurotoxin may initiate it. We have shown that nitric oxide may fulfil this role, since it is able to delocalize ferritin bound iron, inhibit Complex 1 activity, act as a signal transducer of superoxide oxygen production in activated microglia-macrophages and induce membrane lipid peroxidation. The dramatic proliferation of reactive macrophage-microglia in SN of PD and innervation of SN by corticostriatal glutaminergic neurons suggests close attention needs to be paid to NO produced by these cells in PD. 


\author{
ZAKHAROV VV, AKHUTINA TV, DAMULIN IV AND \\ YAKHNO NN \\ Clinic of Nervous Diseases, Neurogeriatric Research Lab., Moscow \\ Medical Academy, Rossolimo St. 11, 119021, Moscow, Russia
}

\section{MNESTIC IMPAIRMENT IN PARKINSON'S DISEASE}

Mnestic functions of 26 patients with Parkinson disease (PD) were studied. 10 of them were younger and 16 older than 60 years. 8 of the 26 had dementia. Besides using the MMSE and OMCT we studied free recall and recognition in verbal and non-verbal memory, effects of semantic encoding during acquisition and semantic memory. Our data show the qualitative and quantitative heterogeneity of mnestic impairment in PD. Most patients of any age have decreased free recall, lessened acquisition and retrieval activity, little reduction of category fluency. We found a correlation between quantitative memory scores and severity of PD symptoms. In patients with dementia mnestic impairment has several qualitatively new features: recognition decrease, incapacity to benefit from semantic encoding, severe impairment of semantic memory. Memory scores of patients who were older than 60 were lower than those of patients who were younger than 60 . Specific therapy improves memory scores in younger patients with mild and moderate cognitive impairment. Thus, according to our data, most PD patients have memory impairment. In the cases without dementia acquisition is spared (we conclude because recognition is spared), so memory impairment is due to faulty retrieval. In PD with dementia we disclose acquisition insufficiency that is a qualitatively new sign in memory impairment pattern in comparison to PD without dementia.

\section{ZENKOV LR, YOLKIN MN AND YAKHNO NN \\ Clinic of Nervous Diseases, Neurogeriatric Research Lab., Moscow Medical Academy, Rossolimo St. 11, 119021, Moscow, Russia}

\section{BRAIN MAPPING IN PARKINSON'S DISEASE}

There have been several reports concerning EEG in Parkinson's disease (PD), but brain electrical activity changes in PD remain poorly understood. We studied 19 patients with idiopathic $\mathrm{PD}$ (mean age 65.7 years). The patients were divided into two groups on the basis of intellectual decline (6 patients with dementia and 13 without). Two different age groups ( 9 patients under 60 years and 10 patients over 60 years) were compared. Mapping of EEG obtained in four functional states (relaxed alertness with opened and closed eyes, performance of verbal and nonverbal tests) was made. The main results are: (1) a strong correlation between peak frequency slowing and motor disability worsening was observed; (2) there was significant slowing of EEG in demented patients compared to non-demented; (3) verbal and non-verbal test performance showed significant decrease in alpha, theta, delta power in demented patients, and decrease of alpha and theta power and increase of delta power in non-demented group; (4) brain electrical activity changes registered during tests were most prominent in the central and the left parieto-occipital regions; (5) we did not observe statistically significant difference between the two age groups.
ZHUCHENKO TD, PODOROISSY VA AND YAKHNO NN

Clinic of Nervous Diseases, I.M. Sechenov Moscow Medical Academy, Rossolimo St. 11,119021 Moscow, Russia

\section{COGNITIVE DISORDERS AND POSTURAL IMPAIRMENT IN PARKINSON'S DESEASE}

The goal of our research was to study postural disturbances in demented and non-demented patients with Parkinson's disease and to estimate the effectiveness of postural biofeedback training. 20 patients were examined, 8 of them demented. Average age was 58.2 years old. Scaled neurological examination, ataxia tests (Porcher, Barbeau, 1980), neuropsychological investigation, computerized stabilography (CS) were performed. CS measurements included: velocities to and out of the center of balance, acceleration, amplitude, curving and total length of the path of sway. Postural disorders were more severe in demented patients with dyspraxia in akinetic-rigid form of PD and did not correlate with age. They had prominent disequilibrium with absent or ineffective postural responses, and severe impairment of spatial and motor praxis. Postural biofeedback training was successful and improved stance. Demented patients with frontal lobe dysfunction failed to regulate posture, using biofeedback. We conclude that disturbances of posture and gait in PD are more severe in patients with dementia. There are two types of postural impairment, connected with frontal lobe and parietal lobe dysfunction.

ZIJLMANS JCM, NOTERMANS SLH, PASMAN JW, HORSTINK MWIM AND THIJSSEN HOM

Departments of Neurology, Clinical Neurophysiology and

Diagnostic Radiology, University Hospital, Nijmegen,

The Netherlands

\section{QEEG AND NEUROMETRICS IN PATIENTS WITH SUBCORTICAL MRI LESIONS:} ARGUMENTS FOR VASCULAR PARKINSONISM

The diagnosis of vascular parkinsonism has been challenged for decades. The goal of the present study is to investigate whether quantitative EEG (qEEG) and neurometric data evaluation can provide arguments for the existence of vascular parkinsonism. Therefore the qEEGs of 15 patients with parkinsonism and extended subcortical lesions on MRI scans and of 15 patients with parkinsonism without extended subcortical lesions were compared for previously established ischemic parameters. Furthermore, occipital slowing, assessed as an increase of relative delta and/or theta bandpower in the parieto-occipital leads by neurometric evaluation, was taken into account as a potentially discriminating parameter for Parkinson's disease. It appeared that patients with parkinsonism and extended subcortical lesions have to be distinguished from patients who have Parkinson's disease. Although these patients did not have significantly more signs that can be associated with ischemia, they had significantly less occipital slowing than patients who had Parkinson's disease. This means that lesions in other than the subcortical structures known to be impaired in Parkinson's disease may cause parkinsonism in patients with cerebrovascular insufficiency. Metabolic studies should demonstrate the ischemic etiology in this type of parkinsonism. 


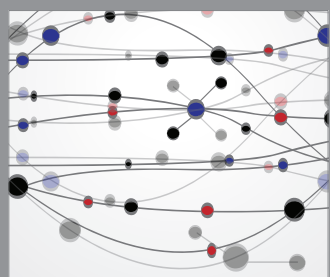

The Scientific World Journal
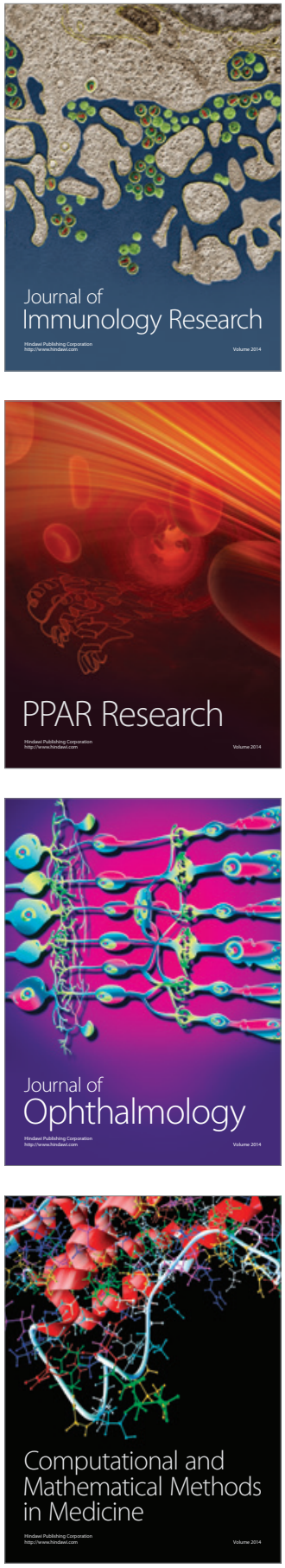

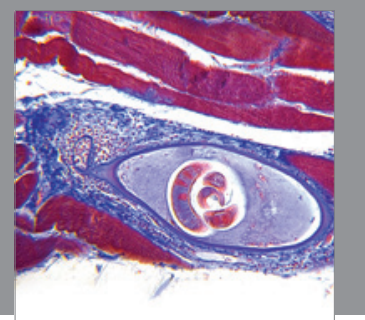

Gastroenterology

Research and Practice
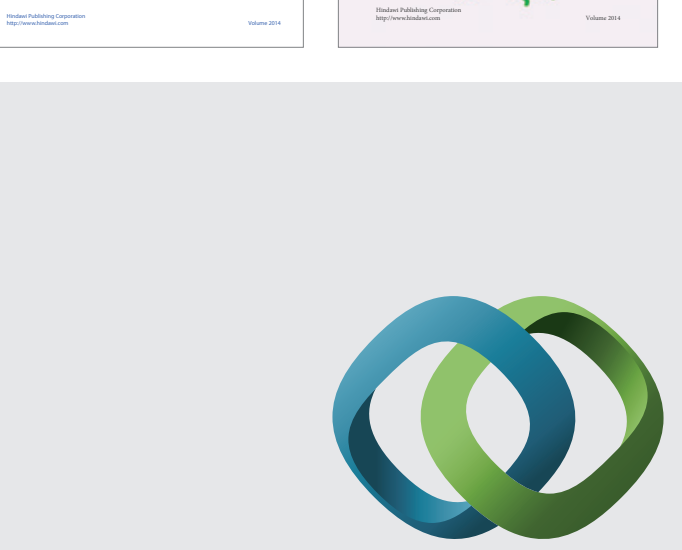

\section{Hindawi}

Submit your manuscripts at

http://www.hindawi.com
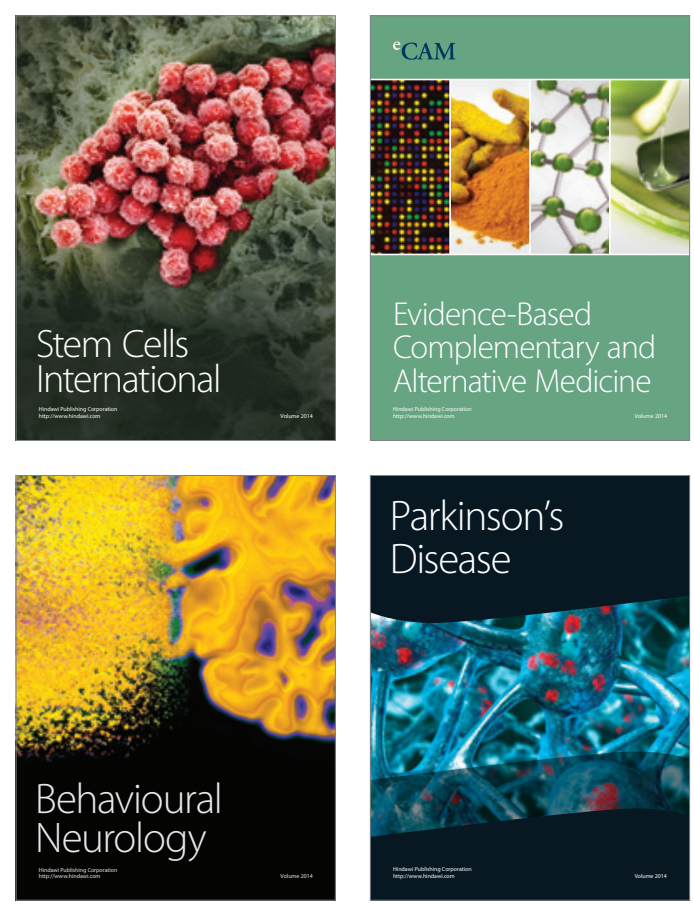

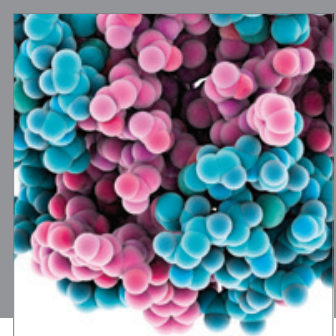

Journal of
Diabetes Research

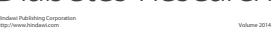

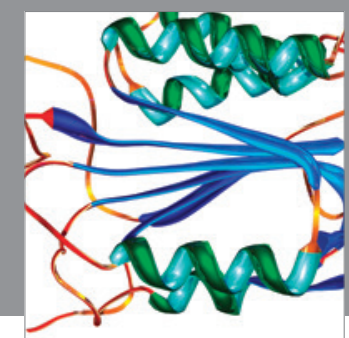

Disease Markers
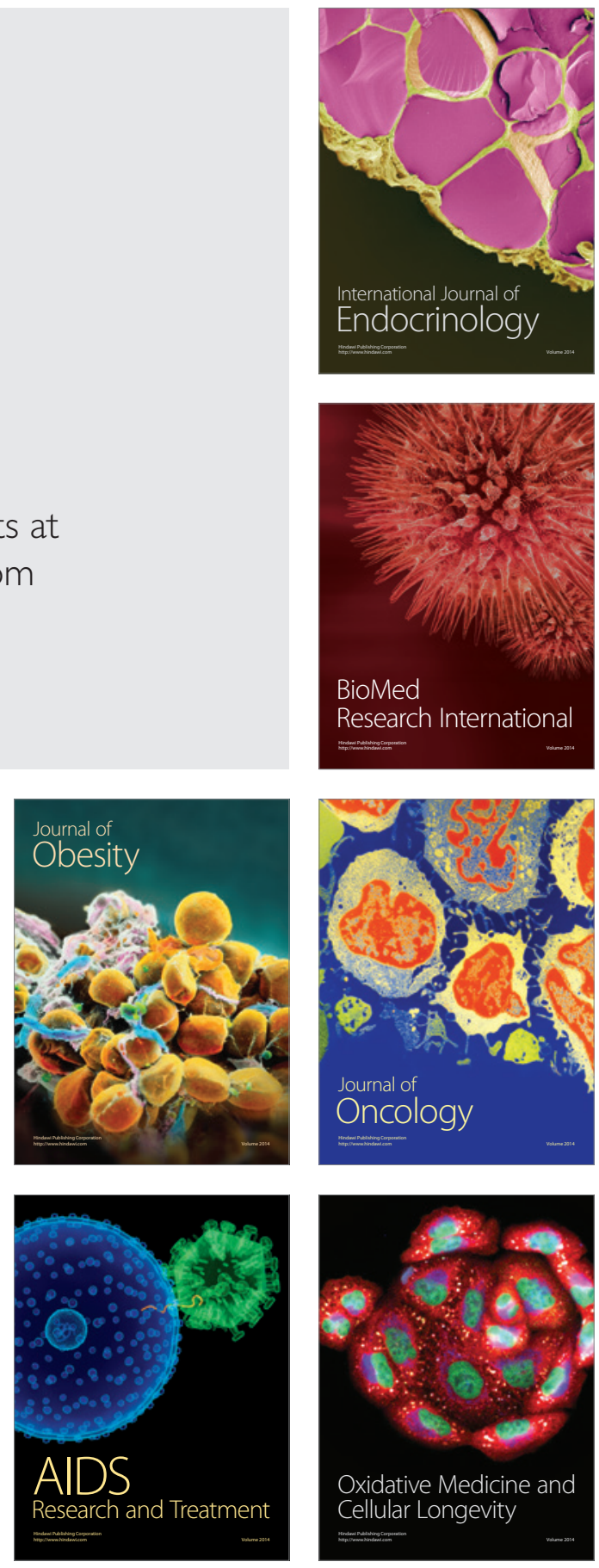